\title{
Supplier Involvement in New Product Development under Technological Uncertainty
}

\section{Lisa Melander}

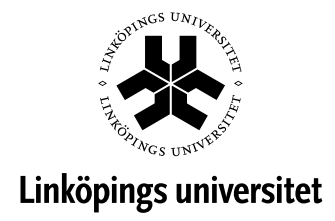

2014

Department of Management and Engineering Linköping University, SE-581 83 Linköping, Sweden 
Cover art by Robin Govik, 2014

(C) Lisa Melander, 2014

Supplier Involvement in New Product Development under Technological Uncertainty

Linköping Studies in Science and Technology, Dissertations, No. 1568

ISBN: 978-91-7519-416-5

ISSN: 0345-7524

Printed by: LiU-Tryck, Linköping

Distributed by:

Linköping University

Department of Management and Engineering

SE-581 83 Linköping, Sweden

Tel: +4613281000 


\begin{abstract}
This thesis addresses the challenges that firms are faced with when collaborating with suppliers in new product development (NPD) projects under technological uncertainty. A critical observation that is made in this context is that technologies are evolving faster, making products more complex. At the same time, firms become more specialized. Due to increased complexity and specialization, firms do not possess all the necessary technologies in-house and therefore need to collaborate with external organisations to incorporate new technology into their products. Common collaborators are suppliers who become integrated into the buying firm's NPD project. Scholars and practitioners alike have stressed the importance of involving suppliers in NPD (Takeishi, 2001; Petersen, Handfield, \& Ragatz, 2005; Silverstone, Wallis, \& Mindrum, 2012; Tevelson, Alsén, Rosenfeld, Benett, Farrell, \& Zygelman, 2013). However, finding suppliers and collaborating with suppliers in NPD can be problematic. In addition, external collaborations also impact the buying firm internally, since it often needs to coordinate its departments. Supplier involvement in NPD has been studied for decades (for an overview of the field see Johnsen, 2009), however, little is known about the impact of technological uncertainty in these settings. Consequently, the purpose of this thesis is to explore supplier involvement in NPD under technological uncertainty.
\end{abstract}

The research in this thesis is based on six case studies that were conducted at two large system integrator firms: $\mathrm{ABB}$ and Ericsson. In total, 53 interviews and two workshops were conducted to collect relevant data. The thesis consists of a compiled summary and five appended papers. The framework that is developed in the thesis highlights that challenges in supplier involvement in NPD projects under technological uncertainty can be divided into challenges that are related to supplier selection, buyer-supplier collaboration, and internal coordination between $\mathrm{R} \& \mathrm{D}$ and purchasing. The main findings of these studies revolve around the identified challenges.

Challenges in supplier selection are concerned with the issues of involving new suppliers or relying on old acquaintances, managing uncertainties, the dilemma of whether to commit to long-term relationships or to maintain flexibility, and deciding on which department that is responsible for evaluating and selecting the supplier. The present study of buyers and suppliers in NPD, shows the challenges that are involved in balancing control, reaching goal alignment, and managing transactional and relational governance. Internal challenges investigate the coordination between the R\&D department and purchasing in NPD projects where suppliers are involved. The results of the study indicate that, in projects with high technological uncertainty, there is limited coordination between the R\&D department and purchasing since purchasing had but little involvement in these projects. There is organisational separation however, where purchasing is mainly responsible for transactional governance, and the $\mathrm{R} \& \mathrm{D}$ department is responsible for relational governance. The present findings may be of value for firms who engage in collaborative NPD, or for firms who aim to involve suppliers in their development of new products.

Key words: new product development, supplier involvement, collaborative R\&D, technological uncertainty, supplier selection, buyer-supplier collaboration, coordination, $R \& D$, purchasing, project 


\section{POPUlÄRVETENSKAPLIG SAMMANFATTTNING}

Tekniken utvecklas allt snabbare och företag kan inte vara experter inom varje teknikområde, därför behöver de samarbeta med andra företag, ofta leverantörer. Att ha en leverantör med i ett produktutvecklingsprojekt kan vara problematiskt, då det kräver samarbete och en grad av öppenhet. Det finns flera utmaningar med att involvera leverantörer i produktutvecklingsprojekt, först att utvärdera och välja en lämplig leverantör, att kunna sätta upp ett samarbete med leverantörer och att kunna koordinera internt mellan olika funktioner i det köpande företaget, speciellt mellan utvecklingsingenjörer och strategiskt inköp.

Resultatet från djupstudier av sex strategiska utvecklingsprojekt, hos $\mathrm{ABB}$ respektive Ericsson, visar att produkter blir mer innovativa om de utvecklas i nära samarbeta med leverantörer. Företag samarbetar ofta med andra företag, i de flesta fall med sina leverantörer, för att bli mer konkurrenskraftiga på markanden. Men det gäller att noga välja sin samarbetspartner. Företag bör välja en kompetent leverantör som har tillräckligt med teknisk kunskap för att utvecklingsprojekten ska vara genomförbara, och de måste kunna samarbeta.

Inget företag kan ha expertis inom samtliga teknikområden, därför behöver företag samarbeta. Det viktigt att företag gör medvetna val i hur nära de väljer att samarbeta med leverantörer. Man bör överväga flera aspekter i projektet innan man väljer vilken samarbetsform som är lämplig. Dessa aspekter inkluderar vilket teknikområde, vilken leverantör och vilken framtida strategi man vill ha. Resultatet av den här forskningen är riktad till teknikföretag och leverantörer som bedriver eller vill bedriva samarbete i utvecklingsprojekt.

Generellt kan företag välja att ha ett nära samarbete med leverantören eller att hålla leverantören på avstånd. I ett nära samarbete behövs förtroende för att våga släppa in leverantören och dela med sig av kunskap. Då delas information och problem löses gemensamt, vilket ofta gör att produktutvecklingen går snabbare. Nackdelen med ett nära samarbete är att det kan vara att företaget kan hamna i en situation där företaget blir låst till en leverantör och dess teknik. I ett samarbete där man håller leverantören på avstånd delar man inte med sig av information och man löser problem på var sitt håll. Fördelen med den här samarbetsformen är att företaget behåller flexibilitet om det skulle visa sig att det kommer en bättre teknik eller billigare leverantör.

För att klargöra ansvarsområden och vilken information som kan spridas mellan företaget kan de upprätta ett kontrakt. Svårigheten ligger i att när man gemensamt försöker utveckla något nytt så vet man inte i förväg vilka problem som kan uppstå eller vilken typ av information man behöver utbyta. Kontrakt fungera bra som riktlinje, men för att få ett fungerande nära samarbete så behövs förtroende mellan företagen. Det är också viktigt att man stämmer av så att man har liknande mål för samarbetet och att man har den tekniska kunskap som behövs.

Tidigare forskning har pekat ut inköp som en strategiskt viktig spelar i samarbeten, då de tidigare har haft kontakt med och känner till potentiella leverantörer. Inköp har också pekats ut som medlare mellan företaget och leverantören, där inköp har haft en ledande roll. Studien hos ABB och Ericsson pekar på att inköps roll varierar i utvecklingsprojekt med hög teknisk osäkerhet. 


\section{ACKNOWLEDGEMENTS}

"What are your most interesting findings?"

I've heard these words many times and I am now at the point where I smile contentedly when I hear that question. Just the other day, I answered it by saying:

"You know what? I have many interesting findings."

Particularly, with respect to practise, this research can help firms become more innovative. It has been a challenge for me to not be too practical, whilst managing to be 'academic'. In some ways, my $\mathrm{PhD}$ journey has been very enjoyable. I got to do research on a very interesting topic, I got to study innovative firms, I got to meet a lot of bright people, I got to challenge myself, and I got the opportunity to write and express myself. All of these things I enjoy doing. There were a few bumps in the road of course, and sometimes the road itself disappeared. But I managed to find my way again, with help from the wonderful people around me.

My supervisors have skilfully and thoughtfully guided me through the $\mathrm{PhD}$ journey, by both challenging and encouraging me. Many thanks to Professor Fredrik Tell for believing in me, trusting me to explore new venues in the research, and always being positive. Your support and energy has been very valuable! Thank you Nicolette Lakemond, for your expertise in the topic, your concerned involvement, and your professional ability to provide critique and praise when needed. Thank you for always being straightforward and handling the rejection of our papers (not too often!) with new determination. Thank you Professor Lars Bengtsson, for comments on an early draft of this thesis. Your inspiring words have improved the thesis tremendously. I also want to thank my colleagues at FEK and PIE, especially my fellow doctoral students, with whom I have had a great time on our $\mathrm{PhD}$ courses, and coffee breaks.

My gratitude also goes out to the collaborating firms, who agreed to participate in the study. $\mathrm{ABB}$, Ericsson $\mathrm{AB}$, and their suppliers, who welcomed my probing questions. The projects that I have studied and the people who were involved in them have been a source of valuable inspiration. Thank you VINNOVA for financial support! I could not have conducted this research project all by my own; I must acknowledge help from co-authors and friends. Thank you David Rosell, for being my research partner in the Ericsson cases and managing to get us a 'Best Paper' award at the CINet Conference. During my time at Linköping University, I got to know Henry Lopez-Vega, who, over the years, has become one of my closest friends.

During my time at Linköping University, I managed to convince my twin sister, dear Anna, to move here to be closer to me. It was great having you in the same city for those few years. However, I realized that we talk on the phone several times every day; so even if we are no longer in the same place, you are still close to my heart. Some of my achievements during my $\mathrm{PhD}$ study were not academic. I managed to find Alexander, got him to move in with me, and convinced him that we should get a dog, Tjarlie. You understand what a struggle it is to become a $\mathrm{PhD}$, and you always reminded me that doing a PhD is just that: doing a PhD.

An explanation may be needed, to help readers understand why I have chosen to quote Sherlock Holmes in my thesis. More than hundred years ago, Arthur Conan Doyle began his 
stories on Sherlock Holmes, describing mysteries that still today fascinate readers. In his books, there exists an awkward collaboration between Holmes and Watson, two very different individuals who join forces, solve problems, and benefit from each other. They develop a somewhat unexpected friendship, which, if compared to my research may not be too different from the collaboration between a buying firm and a supplier, or the coordination of the R\&D department and purchasing department as internal functions at a buying firm. These collaborative entities (buyer-supplier and R\&D-purchasing) start out as being different and distinct, but, having to solve problems together, they benefit from each other's competence and may end up as trusted friends. So we may come to see that the relationship between Sherlock and Watson is not so very different from the relationships that are described in my research.

Consider this first quote from Sherlock, which is one of my favourites.

You see, but you do not observe. The distinction is clear.

(Sherlock Holmes in The Adventures of Sherlock Holmes: a Scandal in Bohemia)

\author{
Lisa Melander \\ Linköping, 2014
}




\section{APPENDED PAPERS}

\section{Paper 1}

Melander, L. \& Tell, F., 2014. Uncertainty and supplier selection in collaborative NPD projects: a case study. Published in the Journal of Engineering and Technology Management, Vol. 31, No. 1, 2014, 103-119.

\section{Paper 2}

Melander, L. \& Lakemond, N., 2014. Variation of purchasing's involvement: case studies of supplier collaborations in new product development. Published in the International Journal of Procurement Management, Vol. 7, No. 1, 2014, 103-118.

\section{Paper 3}

Melander, L. \& Lakemond, N., 2014. Organizational separation of technologically uncertain NPD projects involving suppliers. Earlier version of the paper presented at the EURAM conference 26-29 June 2013, Istanbul. Resubmitted for peer review to a scientific journal after major revisions (second round).

\section{Paper 4}

Melander, L., Rosell, D. \& Lakemond, N., 2014. In pursuit of control: involving suppliers of critical technologies in new product development. Earlier version of the paper presented at the Academy of Management Conference 9-13 August 2013, Orlando. Submitted for peer review to a scientific journal.

\section{Paper 5}

Melander, L., 2013. To evaluate or to use past experience? Collecting information for supplier selection under technological uncertainty in new product development projects. Earlier version of the paper presented at the Nordic Academy of Management Conference 21-23 August 2013, Reykjavik. Under peer review in a scientific journal. 


\section{RELATED PUBLICATIONS}

Melander, L., 2011. Supplier involvement in new product development: a model of the supplier assessment-selection-integration process, in Proceedings of the 23rd Annual NOFOMA Conference on Logistics and Supply Chain Management in a High North Perspective, Harstad, Norway, 9-10 June 2011, 875-890.

Melander, L. and Lopez-Vega, H. 2013. Impact of technological uncertainty in supplier selection for NPD collaborations: literature review and a case study. Under peer review in a scientific journal.

Melander, L. and Tell, F., 2013. Cooperation with Suppliers in New Product Development: Conflicts of Interest and the Moderating Role of Buying Firms' Internal Organization. Earlier version of the paper presented at the 22nd Nordic Academy of Management Conference, Reykjavík, Iceland, 21-23 August, 2013.

Rosell, D., Melander, L., and Lakemond, N., 2013. Strategies for Managing Supplier Knowledge in Collaborative Innovation. Earlier version of the paper presented at the EURAM 2013 Democratising Management Conference, Istanbul, Turkey, 26-29 June 2013. 


\section{Table of contents}

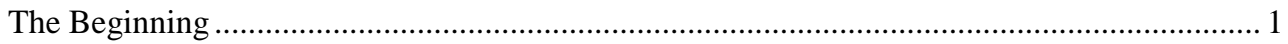

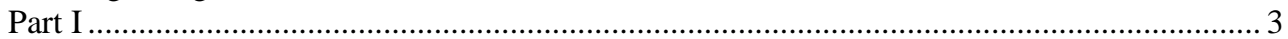

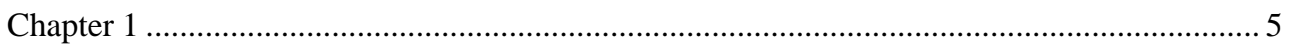

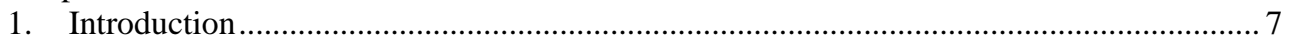

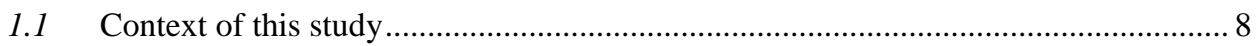

1.2 Challenges that firms face in collaborative NPD ................................................ 9

1.2.1 Supplier selection for NPD projects............................................................ 9

1.2.2 Buyer-supplier collaboration in NPD projects ................................................ 10

1.2.3 Internal coordination of $\mathrm{R} \& \mathrm{D}$ and purchasing in NPD projects ....................... 10

1.3 Purpose and research questions ......................................................................... 11

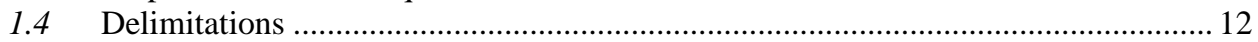

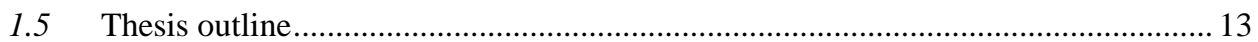

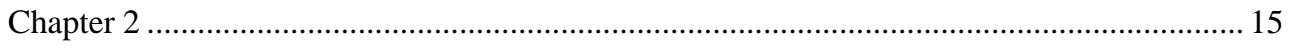

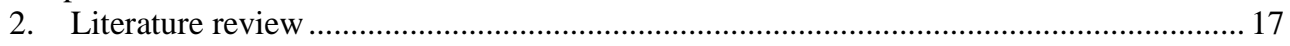

2.1 Setting the stage: uncertainty and collaboration in large organizations ................... 17

2.2 Technological uncertainty ................................................................................. 19

2.2.1 Uncertainty related to development of a technology ........................................ 20

2.2.2 Uncertainty related to a lack of information .................................................... 21

2.3 Supplier selection for NPD projects .................................................................... 21

2.3.1 Information asymmetry and adverse selection ............................................... 21

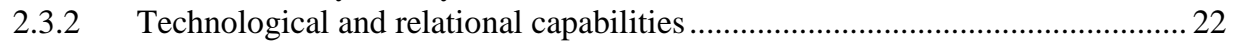

2.3.3 Should firms select new or familiar suppliers? ................................................ 24

2.3.4 Post selection.............................................................................................. 24

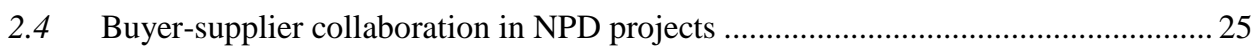

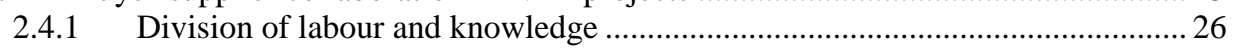

2.4.2 Controlling suppliers ………………………………………………….... 26

2.4.3 Contracts and trust.................................................................................. 27

2.4.4 Goal alignment .................................................................................... 29

2.5 Organisational coordination: R\&D and purchasing in NPD projects........................ 30

2.5.1 Cross-functional teams in NPD projects ........................................................ 30

2.5.2 The R\&D department in NPD projects ............................................................ 32

2.5.3 The purchasing department in NPD projects .................................................... 32

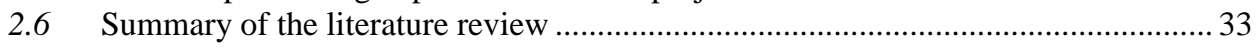

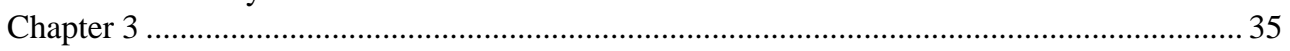

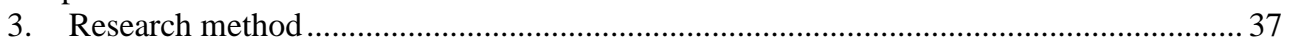

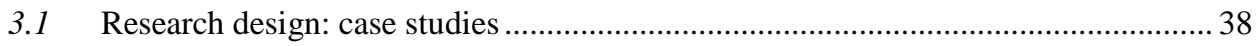

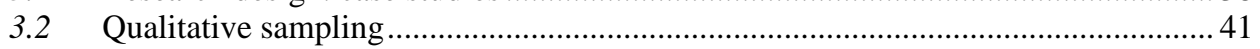

3.2.1 Firm sampling ……………………………………………………... 42

3.2.2 Case sampling …………………………………………………….... 43

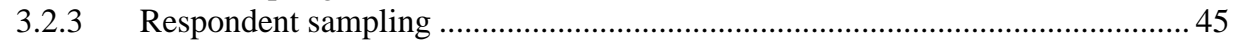

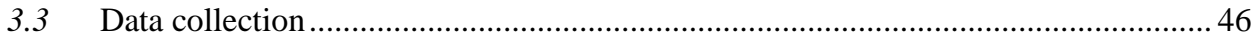

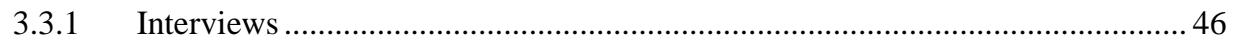

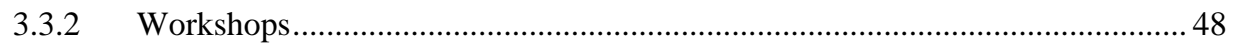

3.3.3 Secondary data ..................................................................................... 49

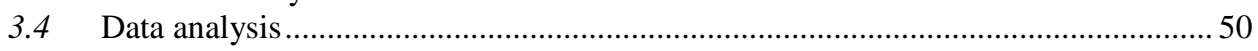

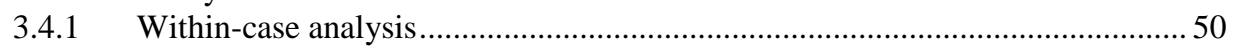




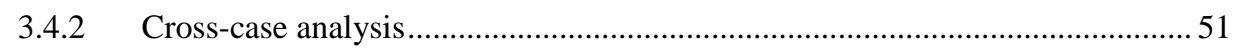

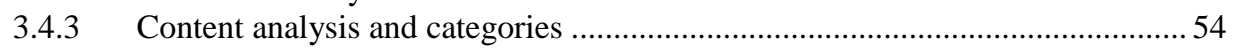

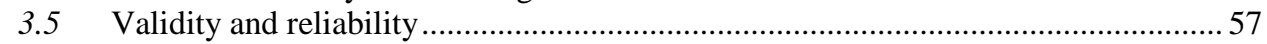

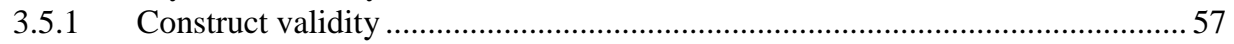

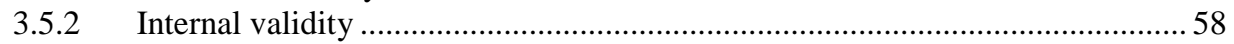

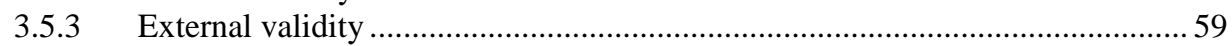

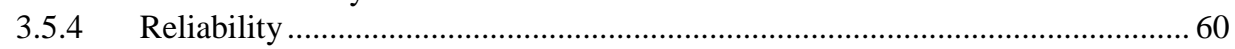

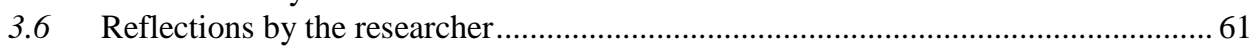

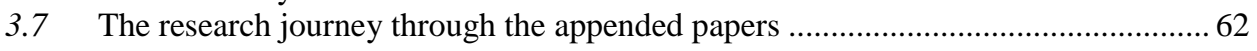

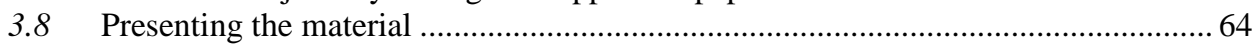

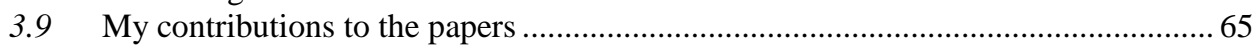

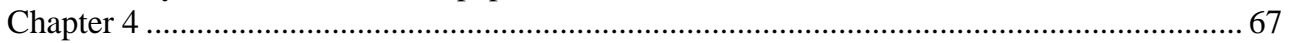

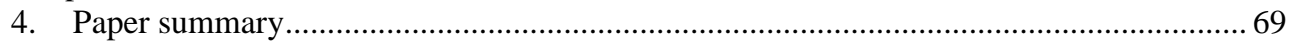

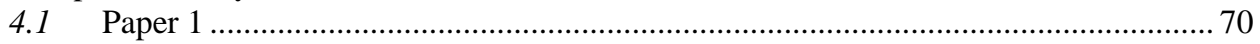

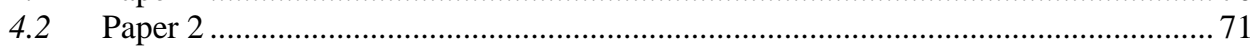

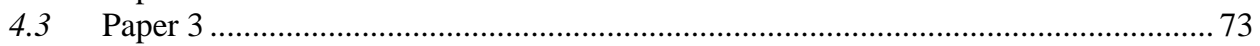

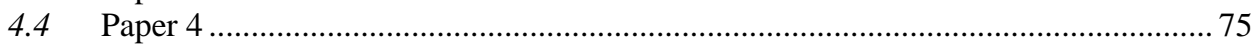

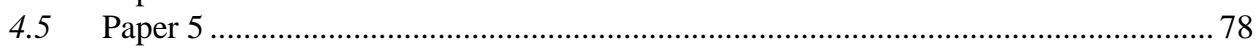

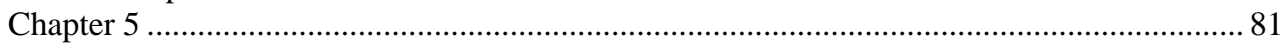

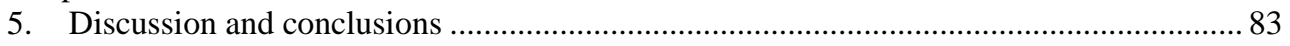

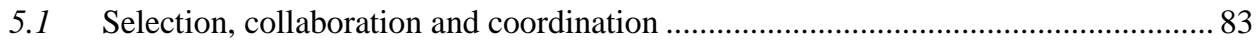

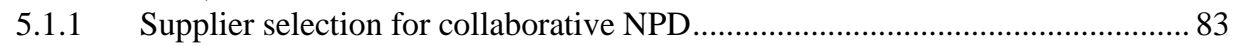

5.1.2 Collaboration between buyer and supplier in NPD projects ............................ 85

5.1.3 Coordinating R\&D and purchasing in NPD projects involving suppliers ......... 86

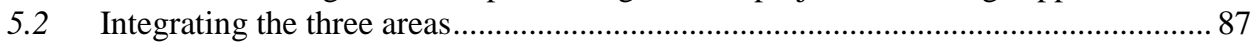

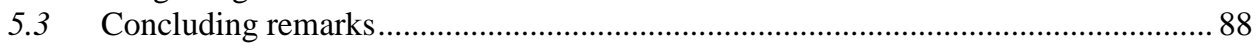

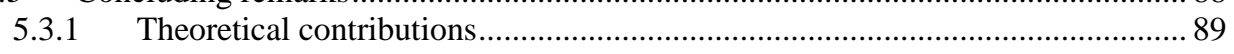

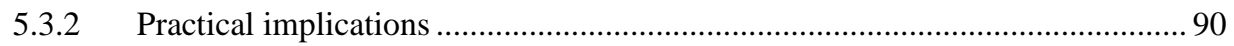

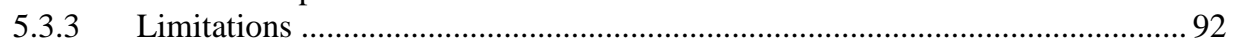

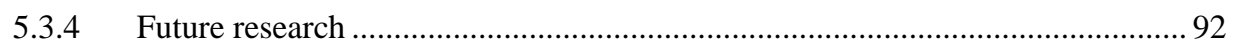

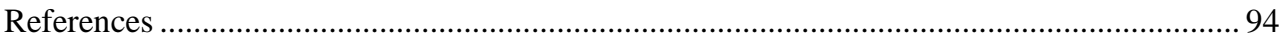

Part II......

Paper 1

Paper 2

Paper 3

Paper 4

Paper 5

Part III

Appendix A - Interview guide

Appendix B - Interviews at ABB and Ericsson

Appendix C - Example of analysis: goal alignment

Appendix D - Example of analysis: control

Appendix E - Example of purchasing constructs

Appendix F - Key definitions and research scope

The End 


\section{List of figures}

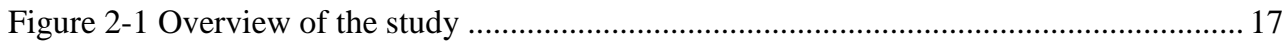

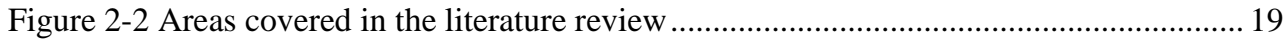

Figure 2-3 The focus of this study: coordination of $R \& D$ and purchasing ........................... 31

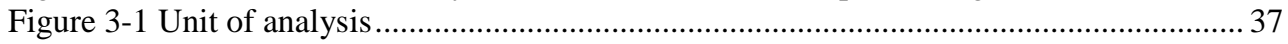

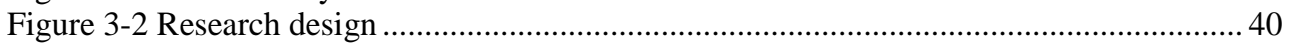

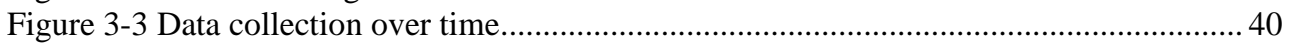

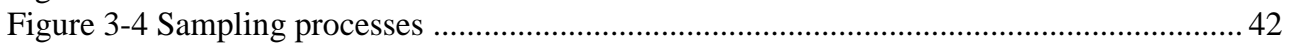

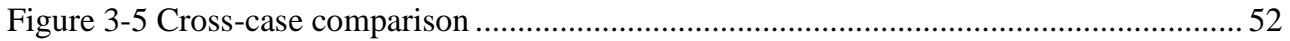

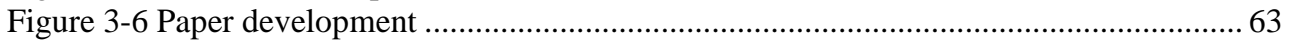

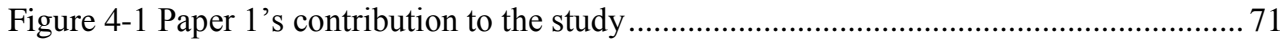

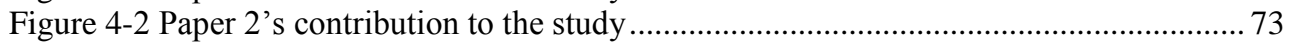

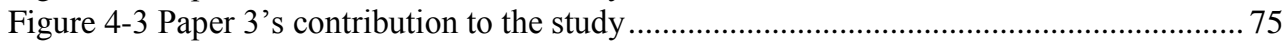

Figure 4-4 Control on a project and strategic level ................................................................. 76

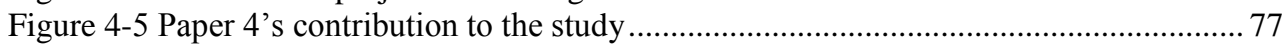

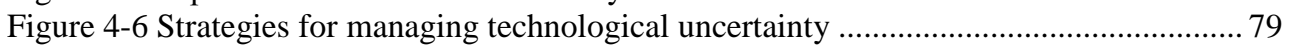

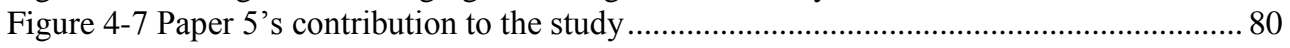

Figure $5-1$ The three areas that were studied respectively ................................................. 83

\section{List of tables}

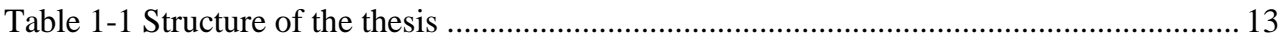

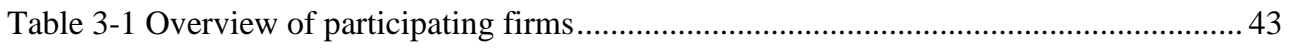

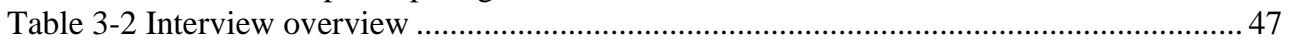

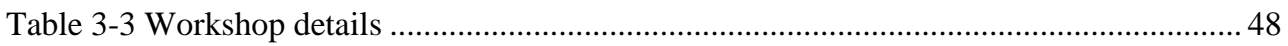

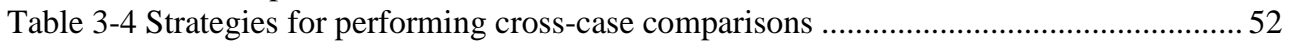

Table 3-5 Case comparison, constructs from agency theory …...........................................5 54

Table 3-6 Examples of the categories used in early versions of Paper 3 and Paper 4 ............56

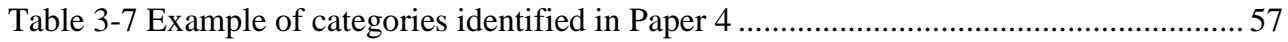

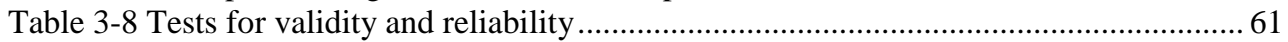

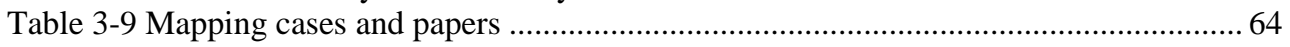

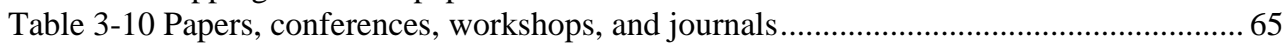

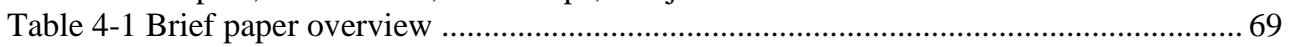

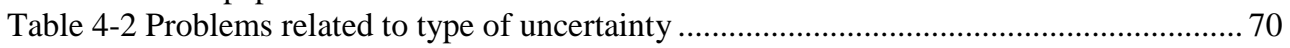

Table 4-3 Variation in purchasing's role in the NPD projects .............................................. 72

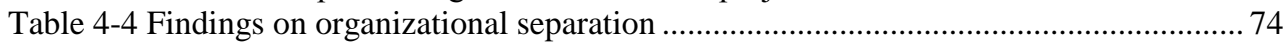




\section{THE BEgINNING}

Nothing clears up a case so much as stating it to another person.

(Sherlock Holmes in The Memoirs of Sherlock Holmes: Silver Blaze) 


\section{PART I}

\section{COMPILED SUMMARY}

You know my methods, Watson. There was not one of them which I did not apply to the inquiry. And it ended by my discovering traces, but very different ones from those which I had expected.

(Sherlock Holmes in The Memoirs of Sherlock Holmes: The Crooked Man) 


\section{ChAPTER 1}

There is nothing more deceptive than an obvious fact, he answered, laughing.

(Sherlock Holmes in The Adventures of Sherlock Holmes: the Boscombe Valley Mystery) 


\section{INTRODUCTION}

The following situation is a description of a problem that one of the R\&D managers that I interviewed was faced with when the firm decided to involve suppliers in developing a new product. The progress of the project had been previously reported to the corporate headquarters and therefore the $R \& D$ manager was under a lot of pressure to report on the progress of the project while not exceeding the budget or time plan.

Manager A is responsible for managing the project that will develop one of the firm's new products. The new product is complex; it includes new technology and the firm's management wants it to reach the market quickly. The firm does not possess one of the vital technologies that is to be incorporated into the product. Without this technology, the product cannot be developed. The firm has no plans to invest in the technology, as it is in a technological area where the firm is not specialized in. Therefore, the firm will need to involve a supplier that can contribute with the technology. There are many uncertainties present, since the technology is new and the buying firm needs to rely on the supplier for its development. Also, because the technology is new, the firm is not certain that the selected technology will be the one that is most suitable in the future, as there are competing technologies available. The firm must find a supplier that has the required technology and is interested in joining the project. Here the firm faces information asymmetry, since the supplier is specialized and has more information about the technology than the buying firm. The two firms need to agree on how to collaborate in the project. In addition, Manager A may have to face internal coordination issues between the $R \& D$ department and the purchasing department, because purchasing may be responsible for the firm's supplier relationships, while the $R \& D$ department is responsible for developing the firm's new products. Consequently, Manager A faces a considerable task where a number of factors can affect the new product development (NPD) project.

The situation described above is becoming more and more common as technologies are evolving at a rapid pace and products become increasingly complex. Hence, many firms need to specialize in order to stay competitive. In order to keep up with the fast development of technologies, firms can involve suppliers that contribute with new technology. Research has shown that firms can accelerate their speed in developing products by collaborating with suppliers (Langerak \& Hultink, 2005; López-Vega, 2012). Researchers have shown that increasingly complex systems and higher technical complexity is challenging for firms (Mikkola, 2003; Tell, 2003). Similar indications are shown in practice, where the increasing complexity of products, as identified by Accenture for example, is a challenge for firms to innovate, which, they claim, can be solved by collaborating with suppliers (Silverstone et al., 2012).

Due to increasing complexity, it is difficult for each firm to have knowledge of all of the technologies that are implemented into their products (Grant \& Baden Fuller, 2004). By collaborating and using supplier involvement in NPD, it is possible for firms to tap into suppliers' knowledge. Consequently, firms become dependent on suppliers and their technologies. Thus, firms need to integrate suppliers into their organisations. For decades, researchers have recognized that suppliers' involvement in NPD is important (for an overview of the field see Johnsen, 2009). Many academic scholars have stressed the importance of integrating suppliers into NPD projects (cf. Takeishi, 2001; Petersen et al., 2005; Johansson, Axelson, Enberg, \& Tell, 2011). The practical implications of supplier involvement in NPD 
have been discussed in several recent consultant reports (Andrew, Manget, Michael, Taylor, \& Zablit, 2010; Capozzi, Gregg, \& Howe, 2010; Silverstone et al., 2012; Tevelson et al., 2013), demonstrating that supplier involvement is highly relevant, not only 'academically', but also in practice.

Collaboration with suppliers is common; a survey made by the Boston Consulting Group (BCG) shows that most firms collaborate with their suppliers. However, it seems that these firms mainly focus on operational efficiency and thus miss opportunities for collaborative product development (Tevelson et al., 2013). Similarly, academic studies have shown that firms can gain more from collaborating with competent suppliers (Wasti \& Liker, 1999; van Echtelt, Wynstra, van Weele, \& Duysters, 2008; Lau, Tang, \& Yam, 2010). Research shows that when firms decide to collaborate with suppliers, it has consequences not only between the buying firm and the supplier, but also within the buying firm (cf. Handfield, Ragatz, Peterson, \& Monczka, 1999; Lakemond, Berggren, \& Weele, 2006; Tell, 2011; Yan, 2011).

Previous research has focused on comparing how Japanese firms and Western firms collaborate with suppliers (Womack, Jones, \& Roos, 1991; Liker, Kamath, Nazli Wasti, \& Nagamachi, 1996) and lean supply (Lamming, 1993). Other areas that have been studied are success factors for supplier involvement (Ragatz, Handfield, \& Scannell, 1997; Monczka, Petersen, Handfield, \& Ragatz, 1998), early supplier involvement (Bozdogan, Deyst, Hoult, \& Lucas, 1998; McIvor \& Humphreys, 2004), black-box integration (Koufteros, Edwin Cheng, \& Lai, 2007) and co-location (Lakemond \& Berggren, 2006). A review of the field shows varying results from supplier involvement under technological uncertainty (Johnsen, 2009). When firms collaborate with suppliers in NPD, they face technological uncertainties, which is problematic and challenging. However, it is not clear how firms deal with these challenges. Therefore, to get a better understanding of this situation, this thesis is based on in-depth case studies of collaborative NPD projects involving suppliers under technological uncertainty.

\subsection{Context of this study}

Today, as technology evolves quickly and new products are introduced to the market at a remarkable speed, it is more important than ever to succeed in NPD. A report by BCG shows that innovation is a top strategic priority for a majority of firms (Andrew et al., 2010). Also supporting the importance of innovation is the McKinsey Global Survey (MGS) from 2010, where $84 \%$ of firms say that innovation is 'extremely' or 'very important' for their firms' strategy (Capozzi et al., 2010). In a survey made by Accenture, a majority of the firms that were surveyed claimed that their business strategy was largely or totally dependent on innovation (Alon \& Chow, 2008). With a large number of firms having innovation as a top priority, it is not surprising that we see so many new products being introduced to the market. Innovation is important, since, ideally, a new product can set a new industry standard or open up new markets (Wheelwright, 1992). The focus of this study is on technical innovations where new products are developed by incorporating new technology.

Technological development is vital for firms, but can be problematic as there are uncertainties involved in technological progress (Burns \& Stalker, 1961). It has long been established that firms specialize in order to be more efficient and effective (Lawrence \& Lorsch, 1967) but they also need to collaborate with other firms in order to be competitive. Firms that have collaborated with suppliers for a long time are called 'system integrators', and they have a high level of complexity in their products (cf. Tell, 2003). Although firms have collaborated 
with external suppliers for a long time, collaboration seems to be more important than ever. However, today's firms face rapid technological changes, leading to technological uncertainty. Collaborations with suppliers in NPD involves uncertainties and information asymmetry (Akerlof, 1970; Holmström, 1979), resulting in challenges for the buying firm. These challenges have, so far, not been sufficiently recognized.

\subsection{Challenges that firms face in collaborative NPD}

The thesis focuses on three areas that are particularly problematic for firms when collaborating with suppliers in NPD, namely (i) supplier selection, (ii) collaboration with the supplier during the project, and (iii) the buying firm's internal coordination within the project.

\subsubsection{Supplier selection for NPD projects}

Supplier selection is associated with technology selection, since a particular technology may be provided by only a few suppliers. Potential suppliers need to be assessed in order for the firm to ensure that the supplier has suitable technology and a compatible organisation (McCutcheon \& Stuart, 2000; Tyler, 2001; Petersen et al., 2005). However, due to technological uncertainty, it may be difficult to properly assess potential technologies as it may not be known which particular technology will be the most suitable technology for the development task at hand. In addition, the assessment can be challenging due to information asymmetry, where the suppliers have information that the buying firm does not have. This could, in turn, lead to an incorrect selection, where the supplier claims to have capabilities that it does not possess (Eisenhardt, 1989b). By not having access to required information, it is difficult to properly assess the supplier. Consequences of selecting a non-suitable supplier could result in higher costs and a longer time before the product/service is brought to the market, and also in lost position in relation to the firm's competitors. It is thus important to make a careful selection of the supplier which is to be involved in the NPD project. In the selection process, firms can evaluate suppliers according to a number of criteria (cf. Handfield et al., 1999; Wagner \& Hoegl, 2006). These criteria range from technological-, relational-, cultural-, and operational issues, as well as the cost of the technology under consideration.

Current research is inconclusive with respect to the issue of whether it is more beneficial to involve a supplier from prior collaborations or whether it is more beneficial to involve a new supplier. One survey study of manufacturing firms has indicated that prior contacts with a supplier reduces the risk of selecting a supplier whose organisation and culture are incompatible with the buying firm (Håkanson, 1993). It is easier to collaborate with known suppliers, because the firms know of each other's organisations and structures. Schiele (2006) suggests that firms should develop their relationship with suppliers in NPD over a long time in order to reap the benefits from the collaboration. However, he also points out that there is a possibility that a firm may miss out on establishing new relationships with innovative suppliers if it only selects suppliers with whom it has existing relationships. It is beneficial to select new suppliers because they broaden the firm's network (Beckman, Haunschild, \& Phillips, 2004; Raassens, Wuyts, \& Geyskens, 2012) and bring in new ideas (Yan, 2011). Thus, there is no obvious answer to whether firms should involve known suppliers or new suppliers. 


\subsubsection{Buyer-supplier collaboration in NPD projects}

Recently, Accenture identified management of relationships across organisational boundaries as a major challenge for firms in the coming era of collaboration between companies (Silverstone et al., 2012). During the last decade, research has given much attention to how firms can benefit from external ideas by opening up their NPD process (Chesbrough, 2003). However, technological uncertainty and information asymmetry may make supplier collaborations in NPD difficult to manage. Technological uncertainty may lead to technical problems and doubt as to whether the incorporated technology is suitable. Information asymmetry can increase these doubts as the buying firm may have less information than the supplier and, therefore, needs to trust that the supplier has sufficient expertise and capability to incorporate the technology into the product.

When collaborating with external firms, the increase in specialization demands close interaction and organisational considerations between the firms, (Brusoni \& Prencipe, 2001). However, organising with external suppliers is an on-going task since the way to best organise in NPD may vary during the project's progress (Lakemond et al., 2006). In addition, the possibility of dividing work between the firm and the supplier is limited, depending on the type of problem that is to be solved and how the problem is to be solved (Brusoni, 2005). In order to create a common ground for mutual understanding and commitment in collaborative NPD projects, firms can use contracts where the firms agree on and specify responsibilities. However, collaboration and contracting in NPD is not possible without some level of trust (Gulati, 1995; Poppo \& Zenger, 2002; Blomqvist, Hurmelinna, \& Seppanen, 2005; Arranz \& Arroyabe, 2011). In fact, it is suggested that firms need to build long-term relationships with key suppliers and ensure that each firms' capabilities are aligned in order to gain long-term collaborative benefits (van Echtelt et al., 2008). However, such long-term and trusting relationships take time and effort to develop. Once such a relationship has been established, a potential danger could arise. Giving its suppliers more design and development responsibility, may result in a negative effect on the buying firm's ability to offer new products. Research indicates that it is possible that buying firms deteriorate in innovative capabilities when they assign more responsibility to their suppliers (Koufteros, Vonderembse, \& Jayaram, 2005).

\subsubsection{Internal coordination of $R \& D$ and purchasing in NPD projects}

The literature shows that, in order for inter-firm collaboration to work, internal coordination needs to work first (Takeishi, 2001). More specifically, internal integration is an important enabler of external integration (Koufteros et al., 2005). Therefore, internal coordination is a pre-requisite for supplier involvement in NPD (Lau, 2011). Moreover, internal relationships are needed if the firm is to learn and gain knowledge from external sources (Praest Knudsen $\&$ B $\varnothing$ tker Mortensen, 2011). In NPD, an important intra-firm relationship across functions is the collaboration between R\&D and purchasing. Traditionally, since R\&D has technological capabilities, it has been responsible for NPD projects, including projects where suppliers are involved, whereas purchasing's involvement was limited to negotiations and the contracting of the finished product. In this traditional view of the purchasing function, purchasing is not involved in NPD, but, instead, purchasing manages inputs, ensures that these are delivered on time, in sufficient quality, and are at an acceptable price (Burt \& Soukup, 1985). Purchasing also searches for new suppliers, assesses and selects these new suppliers, and is responsible for the contact with existing suppliers (Lamming, 1993). During the past few decades however, purchasing has expanded to include an innovation-orientation role (Schiele, 2010). 
Innovation-orientation is concerned with aligning internal development activities with development activities at suppliers, including ensuring that the supplier's technical competencies are properly exploited, and committing the suppliers' activities to the NPD project (Wynstra, Weggeman, \& van Weele, 2003). Hence, purchasing has evolved to become a part of NPD's activities. However, purchasing are not experts in technology and therefore purchasing's contribution to the NPD project can aggravate technological uncertainty. In addition, there may be information asymmetry between the R\&D department and purchasing, making coordination difficult.

At the buying firm, the suppliers' initial contact is often the purchaser, who is a link between the firm and the supplier. Thus, the purchasing function has a critical impact on suppliers that contribute to NPD. A report from McKinsey argues that a difficult problem with the purchasing function in companies is that purchasing is too focused on cost and not involved enough in the firm's strategy (Hardt, Reinecke, \& Spiller, 2007). The report indicates that collaboration with suppliers in NPD was problematic since the purchaser focused on cost which made innovative collaboration difficult. In contrast, research has highlighted the importance of purchasing in NPD (Birou \& Fawcett, 1994; Cousins, Lawson, \& Squire, 2006; Schiele, 2006; Luzzini \& Ronchi, 2011), where purchasing facilitates NPD and, it is claimed, manages the relationship with the suppliers (Walter, 2003). Many other studies point to the importance of involving purchasing in NPD (McGinnis \& Vallopra, 1999; Faes, Knight, \& Matthyssens, 2001; Carr \& Pearson, 2002; Perrone, Zaheer, \& McEvily, 2003; Schiele, 2010), but few discuss how purchasing's role is influenced by technological uncertainty. However, it has been argued that purchasing's influence is suppressed under technological uncertainty (Oh \& Rhee, 2010). Consequently, internal coordination poses a potential challenge for technology suppliers.

\subsection{Purpose and research questions}

The purpose of this thesis is to explore supplier involvement in NPD under technological uncertainty. This thesis focuses on three research questions:

1) How do firms select which supplier to include in NPD projects under technological uncertainty?

2) How do firms collaborate with suppliers in NPD projects under technological uncertainty?

3) How are R\&D and purchasing coordinated in collaborative NPD projects involving suppliers under technological uncertainty?

To answer these research questions, the thesis is based on case studies at two system integrator firms. The firms are innovative and market leaders in their industry. In their respective NPD projects, they face technological uncertainty and information asymmetry. In total, six supplier collaborations in NPD were studied. The context of Sweden is interesting as, according to the Organisation for Economic Co-operation and Development (OECD) (2013), Sweden is the fourth largest spender on R\&D as a percentage of its GDP (3.4\%). Only Israel, Finland and South Korea spend (proportionately) more. In addition, BCG's innovation index places Sweden as the $10^{\text {th }}$ most innovative country in manufacturing (Andrew, Stover DeRocco, \& Taylor, 2009). 
It is possible for firms to improve their collaboration with suppliers in NPD, as surveys show that suppliers mainly contribute with improving existing products (Belderbos, Carree, \& Lokshin, 2004; Faems, Van Looy, \& Debackere, 2005). Thus, there is hidden potential to be found in collaborating with suppliers in NPD. Studies show that suppliers provide easy access of knowledge (Un, Cuervo-Cazurra, \& Asakawa, 2010) and can be key sources of innovation in the early stages of product innovation (Laursen \& Salter, 2006). Consequently, firms can get more out of collaborating with suppliers in NPD by involving them in more innovative projects. In this thesis, supplier involvement in NPD is defined as the buying firm sharing responsibility for a design of a new product (subsystem or component) with a supplier (Takeishi, 2001).

In the research field of 'supplier involvement in NPD', several areas are covered, including supplier selection (Vonderembse \& Tracey, 1999), early supplier involvement (Dowlatshahi, 1998), supply risks (Zsidisin \& Smith, 2005) and purchasing (Carr \& Pearson, 2002). In this field, a variety of terms are used, such as supplier collaboration, supplier cooperation, supplier coordination, and supplier integration. However, in this thesis, I have chosen to use two main terms; collaboration and coordination. These two terms are used in order to make a clear distinction between external and internal aspects. Collaboration is used for the external relationship, between the buying firm and the supplier. Collaboration is described by Wagner \& Hoegl (2006 p 940) as:

[W] hen a supplier is involved in the buying firm's NPD process, members from two different organizations have to collaborate for the achievement of common goals.

Coordination, on the other hand, is used to describe the relationship within the buying firm, more specifically between $R \& D$ and purchasing. A review of the literature on coordination reveals that scholars use a variety of definitions (Okhuysen \& Bechky, 2009). However, among these definitions there are three commonalities (Okhuysen \& Bechky, 2009 p 469):

(1) people work collectively; (2) the work is interdependent; and (3) a goal, task, or piece of work is achieved.

It should be noted that I have chosen to define collaboration and coordination as per above, although there are alternative definitions. Similarly, I have chosen to define other terms that are used in this thesis, for details see appendix F.

\subsection{Delimitations}

The focus of the thesis is on the challenges that firms face when involving suppliers in collaborative NPD projects under technological uncertainty. It should be noted that there exist a number of other uncertainties that firms face in collaborative NPD (such as market uncertainties, organisational uncertainties, and commercial uncertainties), but the focus in this thesis is on technological uncertainty. It should be acknowledged that these other uncertainties also create challenges for firms. The context of the study is on product innovation, where strategic components are supplied by advanced technology suppliers (Kraljic, 1983). Consequently, only product development is studied, not process development or service development, where suppliers also can contribute. The study involves the phases of technology selection, supplier selection, and collaboration during the development of the 
product. The study does not include front-end innovative scanning, where firms search for new ideas (Börjesson, Dahlsten, \& Williander, 2006). This study does not include the industrialization phase either, as it has limited technological uncertainty, although it can contain uncertainties in form of how the product is to be produced, for example.

Firms can collaborate with a number of external organisations, such as universities or competitors. However, this thesis is limited to supplier involvement. Similarly, firms can collaborate in a number of different settings, but this thesis only concerns collaborations for NPD. Other settings, such as outsourcing (Bengtsson, von Haartman, \& Dabhilkar, 2013b) or new service development (Kindström \& Kowalkowski, 2009) are not explored. Coordination is limited to the $R \& D$ and purchasing departments within the firms. However, there are other departments that could be involved in the NPD project, such as the sales-, finance-, and quality departments, for example. The firms involved in the study are large system integrators who develop complex products. This thesis does not study other forms of firm, such as startups or smaller businesses.

\subsection{Thesis outline}

This thesis comprises of three parts: the complied summary, the papers, and the appendices (see table 1-1 below).

Table 1-1 Structure of the thesis

\begin{tabular}{|c|c|c|}
\hline Part & Chapter/Paper & Content/Paper title \\
\hline \multirow[t]{5}{*}{ Part I } & Introduction & Introducing the phenomenon of supplier collaboration in NPD \\
\hline & Literature review & Theoretical starting point \\
\hline & Methodology & Description of methodological choices \\
\hline & Paper overview & Brief summary of the appended papers \\
\hline & Conclusions & Conclusions, limitations, and future research \\
\hline \multirow[t]{5}{*}{ Part II } & Paper 1 & $\begin{array}{l}\text { Uncertainty and supplier selection in collaborative NPD projects: a case } \\
\text { study }\end{array}$ \\
\hline & Paper 2 & $\begin{array}{l}\text { Variation of purchasing's involvement: case studies of supplier } \\
\text { collaborations in new product development }\end{array}$ \\
\hline & Paper 3 & $\begin{array}{l}\text { Organizational separation of technologically uncertain NPD projects } \\
\text { involving suppliers }\end{array}$ \\
\hline & Paper 4 & $\begin{array}{l}\text { In pursuit of control: involving suppliers of critical technologies in new } \\
\text { product development }\end{array}$ \\
\hline & Paper 5 & $\begin{array}{l}\text { To evaluate or use past experience? Collecting information for supplier } \\
\text { selection under technological uncertainty in new product development } \\
\text { projects }\end{array}$ \\
\hline Part III & Appendices & $\begin{array}{l}\text { Interview guide, information about respondents in each case study, analysis } \\
\text { tables, and key definitions }\end{array}$ \\
\hline
\end{tabular}

Part I, the compiled summary, starts with Chapter 1, the introduction, where the topic of the thesis is introduced. Following this is Chapter 2, the literature review, which presents the main areas of the thesis: uncertainty, supplier selection, and external and internal collaboration. The framework of the thesis is presented in this chapter. Chapter 3 describes the methodology and the choices I made during the development of the thesis. In Chapter 4, an overview of the papers is presented. Finally, in Chapter 5, the results of the study are presented, its limitations, and future research are discussed. 
Part II, where my papers are presented, include five papers. Paper 1 focuses on supplier selection. Paper 2 discusses purchasing's role. Paper 3 studies how firms govern NPD projects. Paper 4 is concerned with how firms control suppliers. Paper 5 focuses on supplier selection.

Part III contains the appendices to this thesis. 


\section{CHAPTER 2}

What one man can invent, another can discover.

(Sherlock Holmes in The Return of Sherlock Holmes: the Adventure of the Dancing Man) 


\section{LITERATURE REVIEW}

\subsection{Setting the stage: uncertainty and collaboration in large organizations}

It is challenging for firms to involve suppliers in collaborative NPD under technological uncertainty. This setting deserves study due to three changes that influence firms. First, technological development entails more uncertainties, which, in turn, requires firms to make more careful supplier selections. Second, there is a trend for more involvement with suppliers in NPD, which requires collaboration efforts. Finally, as organisations grow, they become more complex and require further coordination efforts. Following the above discussion, this thesis presents the challenges that firms face when collaborating with suppliers. Figure 2-1 provides a schematic overview of this study.

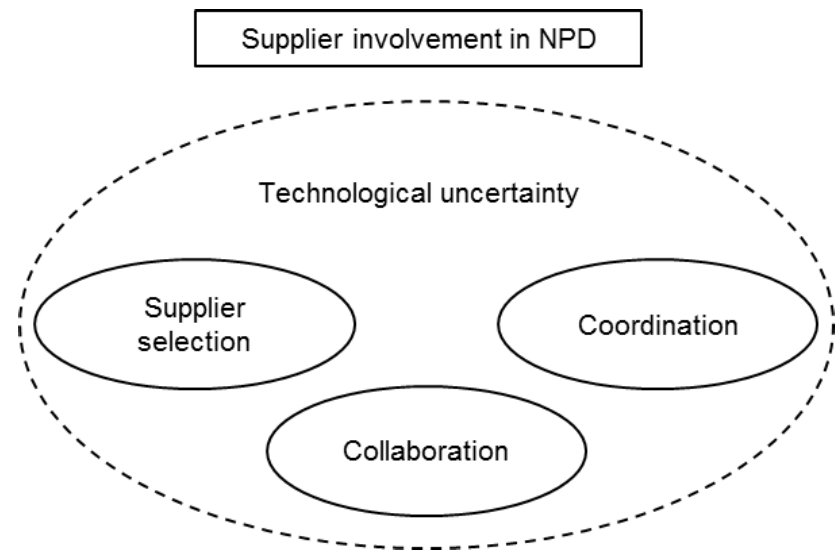

Figure 2-1 Overview of the study

Managing uncertainties has always been a complicated business, as influential researchers have shown (Burns \& Stalker, 1961; Lawrence \& Lorsch, 1967). Two major changes have influenced the management of innovation (Burns \& Stalker, 1961). First, organisations have become larger and thus control has moved from owners to managers. Second, technological development has expanded from being related to individuals to being explored by organisations (cf. Tell, 2003).

Technologies constantly evolve and imply uncertainties that firms need to manage. Technological uncertainty is challenging for firms, particularly in collaborative NPD, where the firm is dependent on the supplier to contribute with new technology. In a situation of technological uncertainty, selecting the most suitable supplier for an NPD project is problematic. 'Uncertainty' is a central concept in this study, which is also a key concept in transaction cost economics (TCE) theory and agency theory. In TCE theory, uncertainty refers to unanticipated changes that concern a transaction. In agency theory, uncertainty exists between two parties and is based on information asymmetry, where one party has information that the other party does not have (Akerlof, 1970). This classical problem in agency theory deals with principal-agent relationships within or between organisations where the principal delegates work for the agent. Specialization is a key contributor to TCE theory, leading to two 
parties in a transaction, and in agency theory, where specialization leads to work being divided between an agent and a principal.

Suppliers have been involved in NPD for several decades, as shown in a review by Johnsen (2009). Research points to the benefits that can be accrued from involving suppliers in product development (Lamming, 1993; Knudsen, 2007; Lau et al., 2010). These benefits include a source for innovation, technical skills, access to a broader network, and lower costs. However, more complex organisations pose coordination challenges. Galbraith (1995) suggests that coordination activities should be spread out across different organisational units. The author points out that, in order to succeed, firms need to define roles and responsibilities within the firm (Galbraith, 1995).

Burns \& Stalker (1961) show that, as firms evolve, changes occur in their relationships with external organisations. These changes complicate how organisations might be controlled. Lawrence \& Lorsch (1967) discuss how firms deal with technological change and point out that firms need to achieve both differentiation and integration. It is important for firms to specialize while also managing to collaborate in order to survive in a dynamic environment:

A high degree of differentiation implies that managers will view problems differently and that conflicts will inevitably arise about how best to proceed. Effective integration, however, means that these conflicts must be resolved to the approximate satisfaction of all parties and to the general good of the enterprise. (Lawrence \& Lorsch, 1967 p 53)

However, the authors also show that the more specialised a firm is, the more difficult it is for it to achieve integration (Lawrence \& Lorsch, 1967). As continuous change has become the natural state in most industries, firms need to establish an effective organisation. Most firms collaborate with their suppliers, as shown in a recent BCG report (Tevelson et al., 2013). Due to this state of affairs, firms face collaboration challenges.

The broad challenges presented are of particular interest when firms involve external organisations to participate in their activities. Activities performed by external organisations not only affect the relationship between the focal firm and the partner, but also the internal organisation of the focal firm. In this thesis, I focus on one such situation, namely supplier involvement in NPD under technological uncertainty.

In this chapter, the litterature review covers four areas: technological uncertainty, supplier selection, inter-firm collaboration, and intra-firm coordination. Within these areas, there are a number of aspects that have been studied. What I actually focus on is highlighted in figure 22. With respect to uncertainty, I focus on technological uncertainty, although there are a number of additional uncertainties that can affect NPD. In the next area of study, I focus on supplier selection for collaborative NPD projects. Continuing on to inter-firm collaboration, firms can collaborate with a number of actors, but I limit this study to collaboration with suppliers. Finally, intra-firm coordination can take place between a number of actors that belong to a firm. In this study, I limit our attention to coordination between the R\&D department and the purchasing organisation. The research scope and key definitions are presented in appendix F. 


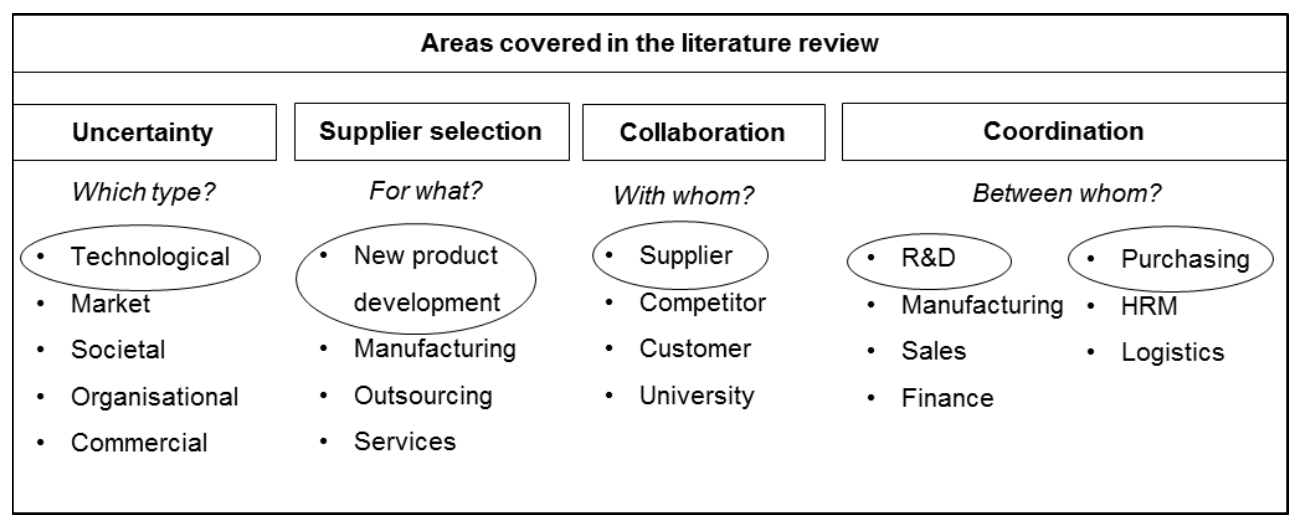

Figure 2-2 Areas covered in the literature review

Supplier involvement has been studied by using a number of theories, such as a resourcebased view, a knowledge-based view, and network theory. A central variable in my study is uncertainty, which is an important variable in both TCE theory and agency theory. Therefore, the theories that are used in this thesis are TCE theory and agency theory. From the TCE theory, the aspects of uncertainty, opportunism, and use of contracts in collaborations have been useful. Important variables from agency theory include the principal-agent relationship and information asymmetry.

However, there are additional perspectives that could have been included in my study. A recent and popular perspective is 'open innovation' (Chesbrough, Vanhaverbeke, \& West, 2008) which focuses on collaboration. One part of open innovation considers collaboration with external suppliers in NPD. However, as open innovation mainly concerns strategic considerations and this study is on a project level, where I study individual projects, I decided not to use open innovation as a main theory. Notwithstanding this, many of the scholarly works referred to in this thesis use open innovation. Furthermore, a great deal has been written about supplier involvement in NPD and it can thus almost be seen as a field of its own. Although the study concerns projects instead of the innovation strategies that are employed by the corporation, strategic decisions were made at the project level, such as the selection of technology and the selection of supplier.

\subsection{Technological uncertainty}

Uncertainty refers to situations where outcomes are not known (Knight, 1921) and to where it is not even possible to predict future outcomes (Shenhar \& Dvir, 1996). In TCE theory, uncertainty refers to unanticipated changes that concern the transaction (Williamson, 1991) and it is not an uncommon situation when firms face a number of technological options. In a review of articles using TCE theory, David and Han (2004) found that there was considerable diversity in terms of how uncertainty was measured. They found that despite the fact that the operationalization of the construct varied, the most commonly used variable was the volatility of the technology.

A number of different uncertainties exist, such as technological uncertainty, societal uncertainty, organisational uncertainty, commercial uncertainty, and market uncertainty (Hall 
\& Martin, 2005; Lee, Yeung, \& Edwin Cheng, 2009). All NPD activities involve uncertainties (Wheelwright, 1992) as firms are venturing into the unknown to develop new products. In these situations, managers in NPD strive to obtain information so as to reduce uncertainty (Davila, 2000). However, more information may not always reduce uncertainty. This is because of knowledge complexity (Ditillo, 2004). There are a number of concerns in NPD due to technological uncertainty: (i) the new technology's compatibility with existing components, (ii) the firm's ability to make incremental development, (iii) the firm's efforts in ensuring of quality and reliability of the new technology, (iv) the time needed to develop or acquire the new technology (Gupta \& Wilemon, 1990). This thesis is limited to investigating technological uncertainties.

In this thesis, technological uncertainty is discussed in terms of paradigms and absence of information. Uncertainty in the sense of paradigm relates to the development of a broad technology. For example, in this study, battery technologies are divided into three technological paradigms: nickel-cadmium battery technology, salt water battery technology, and lithium-ion battery technology. In contrast, uncertainty related to a lack of information is based on one particular technology; for example, a lack of information about the lithium-ion battery technology. This could also be related to a lack of information about a particular supplier's development of the lithium-ion battery technology, for instance.

\subsubsection{Uncertainty related to development of a technology}

The rate of technological change, a source for technological uncertainty, differs across technologies and industries (Malerba \& Orsenigo, 1996). Technological developments can vary in the type, source, and capabilities needed for the development process. The development of a number of technologies that are applicable to a product may cause a situation of uncertainty, because a firm might not know which technology to implement into its product. Moreover, technological evolution is characterised by experimentation, another state of uncertainty, before acceptance (Henderson \& Clark, 1990). This has been described as advancement along specific technological trajectories and paradigms (Dosi, 1982). Technological trajectories denote the way knowledge enfolds with regard to a specific technology, including the problem-solving strategies and the technological advancements that take place. Technological evolution may occur by means of continuous change or as a result of discontinuous paradigm shifts. The existence of several, partially competing trajectories leads to uncertainty. During periods of uncertainty, firms compete by developing products based on a number of different technologies before a preferred technology emerges (Henderson \& Clark, 1990). In addition, in situations with uncertain technology, firms tend to avoid uncertainty by waiting for the technology to stabilize before reaching a decision on whether to insource or outsource the technology (McDermott \& Handfield, 2000). Pioneering technology may require significant time on testing which consumes time and resources, in comparison to a proven technology (Clark \& Fujimoto, 1991).

A firm's options of whether to invest in a new technology or to invest in a technology that has been accepted in the industry entail a difficult balancing act, which has been described by as follows:

Investing in a technology that has not been widely adopted by other companies is a risky decision. This is because features, reliability, costs and performance of the technology have not been well understood, creating 
difficulties in properly using the technology for developing the new product. In the same time, however, new technology often offers products unique advantages, such as superior quality, user friendliness, lower costs, etc., compared to what existing technology could. (Yan, (2011 p 137-138)

\subsubsection{Uncertainty related to a lack of information}

Under technological uncertainty, the actual technology that will be most suitable for the firm's needs may not be known (Tegarden, Hatfield, \& Echols, 1999), or it may be the case that the firm does not have enough information to evaluate whether a particular technology is suitable or not. Thus, for firms, it can be problematic to select the most appropriate technology for NPD. They have three options: (i) use a proven technology, (ii) use a prospective technology (Krishnan \& Bhattacharya, 2002), or (iii) wait for the prospect technology to be proven (Wernerfelt \& Karnani, 2006).Technological uncertainty and a lack of information to properly assess potential alternatives make it difficult for firms to select the technology that they need to implement into their products.

Following the argument in TCE theory, research suggests that when faced with increased technological uncertainty, firms tend to internalize the work rather than relying on suppliers (Hoetker, 2005; Oh \& Rhee, 2008). However, in the context of this study, firms may need a different approach as they are specialized and do not possess all the necessary technology inhouse. Therefore, they need to collaborate with external actors. Studies show that in situations of high technological uncertainty firms can choose between either developing the products inhouse or in collaboration with competent suppliers with sufficient capabilities (Oh \& Rhee, 2010). In supplier collaborations, the relationship that the firms can have depends on the nature and maturity of the technology that is being developed (Johnsen, Phillips, Caldwell, \& Lewis, 2006). Under technological uncertainty, the technology greatly influences the potential relationship between a buying firm and a supplier. However, selecting a supplier is a matter of finding the right supplier.

\subsection{Supplier selection for NPD projects}

Traditionally, research on supplier selection has focused on suppliers that supply components for manufacturing (Choi \& Hartley, 1996). The current trend shows us that supplier selection has expanded into outsourcing (Dabhilkar, Bengtsson, von Haartman, \& Åhlström, 2009), services (Day \& Barksdale, 2003), and NPD collaborations (Emden, Calantone, \& Droge, 2006). In this thesis, I limit supplier selection to the context of NPD collaborations.

\subsubsection{Information asymmetry and adverse selection}

In agency theory, the assumption is that there exists a state of information asymmetry between the principal and the agent. Similarly, firms face information asymmetry in collaborative NPD. Information asymmetry is discussed by Akerlof (1970), where an asymmetrical situation is one where the buyer has to deal with uncertainty since he has less information than the seller. In Akerlof's example, the buyer does not have information on whether the product in question has good or bad quality, while the seller knows the product's quality. To limit uncertainty, the buyer can collect information, or trust the seller and his reputation. Similarly, when a firm searches for a supplier to involve in NPD, the firm needs to collect information about potential suppliers. Collecting information about suppliers' technologies and capabilities may 
be difficult since some of that information may be sensitive, and suppliers could be reluctant to share it. From this example, it follows that businesses who are willing to share information are more attractive as a potential supplier (Dyer, 1997). When sharing such information, suppliers may provide information about their technology, organisation, and development skills.

However, relying solely on information that is provided by the supplier could be problematic since it is possible for the supplier to misrepresent its abilities by claiming to have certain skills or abilities that it does not have. This problem is referred to as adverse selection in agency theory (Eisenhardt, 1989b). In adverse selection, undesired results may occur when the buying firm and the supplier have access to different information or one party has been misinformed about the other party's abilities. An additional problem is the fact that it may be difficult to verify whether the supplier actually has the ability that it claims to have. However, if the buying firm has access to accurate information about the supplier, then misrepresentation can be easily discovered. For this reason, it is advised that buying firms should gather additional information about a potential supplier for the purpose of learning more about the supplier's nature and actions (Holmström, 1979).

\subsubsection{Technological and relational capabilities}

A recent survey shows that identifying and selecting suppliers for NPD collaborations is particularly important when aiming to improve the firm's innovation performance (Bengtsson, Lakemond, \& Dabhilkar, 2013a). Firms may evaluate a supplier's capabilities, making sure that the supplier has the required competence and that it is able to jointly collaborate in an NPD project. Research shows that suppliers are evaluated according to two categories; (i) technological capabilities and (ii) relational capabilities (Handfield et al., 1999; Wagner \& Hoegl, 2006; Feng, Fan, \& Ma, 2010). In addition to these two broad classifications, cost is another criteria (Hoegl \& Wagner, 2005). However, cost is not as important in situations of high technological uncertainty (such as in NPD) in comparison with supplier selection in situations where there is little or no technological uncertainty (for example basic manufacturing). In basic manufacturing, cost is one of the most important selection criteria (Ho, Xu, \& Dey, 2010). Previous research has argued that suppliers are diverse with respect to their capabilities, and that collaborative partnerships should be reserved for suppliers with outstanding technology and sophisticated management (Kamath \& Liker, 1994). Supplier capabilities in relation to collaborative NPD have been thoroughly investigated in the literature, both technological capabilities and relational capabilities.

Research on technological capabilities shows that technological capabilities includes knowledge about the new technology as well as future technologies (Wasti \& Liker, 1999; Caputo \& Zirpoli, 2002; Wagner \& Hoegl, 2006; Wynstra, von Corswant, \& Wetzels, 2010). This includes the supplier's innovation and technological capabilities (Handfield et al., 1999; Petersen, Handfield, \& Ragatz, 2003). The supplier needs to master the new technology, and the supplier should strategically focus on potential future technologies. Firms also need to consider whether technical alignment between the firm and the supplier is possible (Emden et al., 2006). Such technical alignment includes technical capability, resource complementarity, and overlapping knowledge bases. The importance of technological capabilities is stressed in the literature (Bailey, Masson, \& Raeside, 1998; Le Dain, Calvi, \& Cheriti, 2011). For example, one survey shows that technology is the most important criteria for firms when 
selecting a collaboration partner in NPD (Rundquist \& Halila, 2010). However, these capabilities are difficult to assess before the supplier is selected (Håkanson, 1993).

In product development, firms rely upon specialized suppliers for components and subsystems. The specialization of such suppliers is often related to the specific technology they use for producing a specific component/sub-system. Therefore, firms need to be technically competent in order to properly assess a suppliers' technology (von Corswant \& Tunälv, 2002). For some technologies, there are many competing suppliers, while for others, there are only a few. Additionally, some technologies or specific components may be proprietary to only one supplier. Whether the technology is critical for the product or not also affects the selection process. If the technology is critical to the product and the number of available suppliers is limited, then a detailed technological assessment of the potential supplier should take place (Handfield et al., 1999).

Relational capabilities include a supplier's willingness to collaborate with the firm, and to establish trust between the firms. Also of relevance is the existence of a compatible culture between the firms (Chung \& Kim, 2003; Wagner \& Hoegl, 2006; Feng et al., 2010; Lockström, Schadel, Moser, \& Harrison, 2010). A supplier's relational capabilities are connected to the supplier's interaction with the buying firm. Therefore, through repeated collaboration between the buying firm and the supplier, the relational capabilities improve. Firms also need to consider potential strategic alignment and relational alignment (Emden et al., 2006), where strategic alignment concerns motivation and goal correspondence, and relational alignment includes compatible cultures, the propensity to adapt, and long-term orientation. Besides alignment, a case study of five manufacturing firms shows that firms search for suppliers who can provide an outsider's point of view (Wagner \& Hoegl, 2006). Because of this, firms can find more innovative solutions and new ideas on how to develop their products.

Despite the importance of technological capabilities, a survey study on assembly industries (McCutcheon, Grant, \& Hartley, 1997) stresses the importance of relational capabilities, arguing that, for future NPD projects, the supplier's cooperativeness can be more important than its technological capabilities. Particularly in situations with uncertainty, studies indicate that cooperative competencies complement technological competencies (Tyler, 2001). It is important for firms to be able to collaborate easily within an NPD project. One aspect of this is demonstrated in a case study of a company in the electronic industry by McIvor et al. (2006), who stress the importance of having a culture that facilitates and encourages collaboration between the firm and its supplier.

In the context of technological uncertainty, firms are advised to select knowledgeable and competent suppliers (Koufteros et al., 2007). In his conceptual paper, Tyler (2001) argues that technological and relational capabilities complement each other. An empirical study of computer manufacturers showed that, in situations of high technological uncertainty, relational capabilities became more important, while in situations with low technological uncertainty the supplier's technological capabilities became more important (Hoetker, 2005). The argument that is put forward here is that, in the case of low technological uncertainty, the supplier could be trusted to have sufficient technological capabilities to develop the product on its own. Therefore, there was little need for close interaction between the firms, and thus relational capabilities were less important. In contrast, under high technological uncertainty, the project may require both the buying firm and the supplier's capabilities to develop a 
product. In this situation, not only are technological capabilities important, but also relational capabilities because the firms need to interact and work together to solve problems.

\subsubsection{Should firms select new or familiar suppliers?}

Searching for suppliers, collecting information on them, and assessing suppliers can be costly and time-consuming. Therefore, firms may be inclined to collaborate with suppliers who have participated in the firms' previous NPD projects. In the process of selecting a supplier, survey studies of R\&D collaborations highlight the importance of having prior collaborations with the supplier (Håkanson, 1993; Li, Eden, Hitt, \& Ireland, 2008). A study of over one thousand $\mathrm{R} \& \mathrm{D}$ alliances suggests that firms prefer to select suppliers who are well-known (Li et al., 2008).

However, other studies claim that firms should search for new suppliers to involve in NPD and thereby broaden their network (Beckman et al., 2004; Johnsen, 2011; Raassens et al., 2012). These findings are supported by studies that indicate that firms who solely select suppliers with whom they have had prior ties reduce their access to valuable external technologies (Raassens et al., 2012). In addition, in technological uncertain NPD projects, it could be beneficial to select suppliers who are new to the buying firm, because these suppliers might bring in different or conflicting ideas, which could help create more innovative solutions (Yan, 2011). In support of this argument, we turn to the claim that collaborating with a supplier from a previous NPD project may hamper creativity and innovation because the project teams may be stuck with working models from previous projects, thereby stifling innovation (Skilton \& Dooley, 2010).

It should be emphasised that firms need to make careful selections with respect to suppliers, because the partner that seems most capable may not be the most suitable for the firm's needs (Diestre \& Rajagopalan, 2012). Firms need to consider the long-term orientation of the suppliers, because long-term orientation facilities collaboration under technological uncertainty (Emden et al., 2006). In addition, firms need to establish a careful balance between long-term relationships with some suppliers, while inviting new suppliers to participate NPD (Clark \& Fujimoto, 1991).

\subsubsection{Post selection}

After a firm has completed its supplier selection, there may be uncertainty or doubt as to whether the supplier that was selected is the most suitable. Such uncertainties can reduce supplier involvement in NPD projects or even result in the firm changing suppliers (van Echtelt et al., 2008). To change supplier once investments in co-design activities already have been made can be costly, as shown in a study of Fiat Auto (Zirpoli \& Caputo, 2002). Changing supplier could also result in late market entry. It has been suggested that uncertainties about selecting the most appropriate supplier could be handled by involving several suppliers in the NPD project (Zsidisin \& Smith, 2005; Langner \& Seidel, 2009). However, such a strategy may also be costly and dilute the focus of all parties involved.

A potential problem with early supplier involvement is that firms may become locked into a technology before it is sufficiently stable (Wheelwright, 1992). Such a technological lock-in can occur when a firm selects a technology that is not easily interchangeable with another technology. Thus, it is possible that the firm becomes locked into a technology (Handfield et 
al., 1999) when the firm decides to develop their product with this technology. Finally, in collaborations, ownership of proprietary technologies can create power asymmetries where one party is dependent on the other, also resulting in a lock-in situation, as demonstrated in a case study of a manufacturing firm (Narasimhan, Nair, Griffith, Arlbjørn, \& Bendoly, 2009).

By collaborating with a supplier, it is possible that a firm becomes locked-into the supplier. For example, there may be one supplier that is more advanced in the required technology and there are no alternative suppliers. Consequently, the firm may become dependent upon this supplier. Changing a supplier is viewed as being difficult and is described in a study of Australian firms as a big challenge, a nightmare, and extremely costly (Bhattacharya, Singh, \& Bhakoo, 2013). However, this situation is from the buying firm's perspective, which I adopt in this thesis. In contrast, suppliers can also find it challenging to collaborate with buying firms. As shown in a study of small suppliers who collaborate with larger buying firms, the suppliers struggled with unequal relations and found it difficult to influence the buying firm (Stjernström \& Bengtsson, 2004).

Studies indicate that firms find it difficult to achieve early involvement (Eisenhardt \& Tabrizi, 1995). Collaborations can also be problematic, because partnerships in projects with a higher level of uncertainty are more difficult to sustain, as demonstrated by using data from the French Community Innovation Survey (CIS) (Lhuillery \& Pfister, 2009). In the following sections, I will discuss buyer-supplier collaboration in NPD.

\subsection{Buyer-supplier collaboration in NPD projects}

Collaboration between external organisations is called inter-firm collaboration. In this thesis, collaboration is limited to collaborative product development, where organisations jointly develop a new product. Collaboration is described by Wagner \& Hoegl (2006 p 940) as:

[W] hen a supplier is involved in the buying firm's NPD process, members from two different organizations have to collaborate for the achievement of common goals.

Collaboration is important, as shown by several studies that point to an increased need for firms to involve external actors in NPD (Gupta \& Wilemon, 1990; Chesbrough, 2003). There exists a number of different inter-firm collaborations; for instance, between a firm and a supplier, a firm and a university, a firm and a customer, or a firm and a competitor. I have limited the present study to collaboration between a buying firm and a supplier. Of course, taking a supplier's perspective would result in a study of a firm and its customer in an NPD collaboration. Suppliers have long been important contributors to buying firms' NPD. In the past, suppliers were identified as sources for innovation (von Hippel, 1988) and they are still considered to be important sources of innovation (Cuervo-Cazurra \& Un, 2010; Bengtsson et al., 2013a). The suppliers that were studied for this thesis provide technology to a larger extent than normal, and are referred to as technology suppliers. In these buyer-supplier relationships, the buying firm is dependent on the supplier's knowledge of a technology that is new to the buying firm.

Previous studies in NPD show ambiguous results with respect to the benefits (or lack thereof) from collaborating with suppliers. Some studies point to the benefits of accelerating the speed of innovation projects by involving suppliers (Langerak \& Hultink, 2005; López-Vega, 2012), 
others show mixed results on speed (Eisenhardt \& Tabrizi, 1995), while other studies indicate that firms actually become slower at introducing products to the market (Praest Knudsen \& Bøtker Mortensen, 2011). Suppliers have been identified as sources of innovation (von Hippel, 1988; Knudsen, 2007) who improve product innovation (Lau et al., 2010; Un et al., 2010). However, other studies have claimed that collaborating with suppliers in NPD has no effect on innovativeness (Su, Tsang, \& Peng, 2009). Notwithstanding the different conclusions that are drawn by these different studies, it seems that it is a challenge for firms to get the most out of involving suppliers in NPD projects.

\subsubsection{Division of labour and knowledge}

Specialisation results in a division of labour and knowledge, making firms dependent on suppliers for providing new technology. Studies show that the main objective for involving suppliers in NPD is to gain access to technology and technological expertise, and to enjoy the supplier's insights during the design process (Birou \& Fawcett, 1994). Through collaboration with external organisations, the firm can also change perspective on certain issues and knowledge development can be facilitated (Börjesson \& Elmquist, 2011). It is suggested that firms should collaborate with firms who differ from the buying firm, in order to increase the benefits from the collaboration. In fact, collaboration with partners that are similar to the firm gives fewer benefits than partners that are diverse (Baum, Calabrese, \& Silverman, 2000) since similar firms provide less diverse pools of information and know-how. However, it may be more difficult to collaborate with firms that are different than with firms that are similar, since similar firms share knowledge bases and pre-understandings (Johansson et al., 2011).

In collaborations, it is possible for firms to tap into the other party's knowledge and technology. Even though a partner can be trusted to develop a part of a product, it is important to have knowledge about all the different technologies that are involved in a product. It is also crucial to have knowledge of different technologies and technology trajectories (Caputo \& Zirpoli, 2002) that could be relevant for the firm in the future. In order to be efficient in collaborative product development, the work can be divided between the parties. The buying firm needs to decide who will undertake the design and engineering work (development), and what responsibility the supplier should have (Clark \& Fujimoto, 1991). However, the possibility of dividing work is limited depending on the type of problem that is to be solved, and how the problem is to be solved (Brusoni, 2005). Managing the project entails (i) division of work and assigning work tasks inside and outside the firm, and (ii) organization of activities inside and outside the firm (Clark \& Fujimoto, 1991). With respect to how the firms will manage the relationship between each other, the buying firm's own competence and ability to control the relationship are primarily considered (Zirpoli \& Camuffo, 2009).

\subsubsection{Controlling suppliers}

In projects with technological uncertainty, firms seek to control the NPD projects and the suppliers involved in these projects. However, there are a number of challenges that are related to control in NPD. These are presented by McDermott (1999) as a lack of control of suppliers, a fear of losing control of the NPD, poor communication with suppliers, and internal coordination. Time is another important aspect of NPD, where it is critical to be first to the market with the product. In time-critical projects, particularly in high-tech product development projects, deadlines and milestones are used to control the progress of the project (Lindkvist, Söderlund, \& Tell, 1998). Control also involves having control of the firm's 
technology. In collaborations, it is possible for the supplier to gain knowledge about the firm's technology. Such an information leak could have severe implications, since the firm can lose their advantage towards competitors or the supplier may become a future competitor. Thus, the form of governance in R\&D collaborations is influenced by the possibility of the firm losing control of technological assets (Oxley \& Sampson, 2004).

Three forms of control combinations in NPD are discussed by Rijsdijk and van den Ende (2011): (i) output control, (ii) process control, and (iii) clan control. By using output control, desired outputs are monitored and evaluated. Process control, on the other hand, involves monitoring the agent's behaviour and mechanisms for appropriate behaviour, while clan control is a socialization process among individuals. Similarly, Aulakh and Gencturk (2000) have investigated output control, process control, and social control in inter- and intraorganisational relationships. In their study, social control refers to monitoring and orienting agents towards organisational goals. Social control within the firm created shared values and improved adaptability (Aulakh \& Gencturk, 2000), something which was also suggested to have similar effects in intra-organisational relationships. Combining these different controls has a varied effect on project performance (Rijsdijk \& van den Ende, 2011).

Monitoring involves observing the agent's efforts and outcomes, which enables the principal to be up-to-date on the agent's progress. Output monitoring refers to measuring something, for example product delivery time, product quality, and product accuracy. Behaviour monitoring, on the other hand, involves evaluating the agent's processes. By monitoring, principals can decrease the frequency by which their agent's fail to fulfil promises or obligations (Rokkan \& Buvik, 2003). However, to monitor an agent involves a cost and when this cost is high, an outcome-based contract is to be preferred. But when the costs of monitoring are acceptable, a behaviour-based contract may be more efficient (Eisenhardt, 1989b). However, more monitoring is not always better (Jacobides \& Croson, 2001) and does not necessarily increase the agent's alignment towards the principal's goals (Tosi, Katz, \& Gomez-Mejia, 1997). Moreover, close monitoring may have negative effects on an agent as the agent may perceive a loss of independence and the presence of distrust on the part of the principal. One way to avoid the negative effect of monitoring is to establish social contracts (van der Valk \& van Iwaarden, 2011).

Monitoring suppliers in a buyer-supplier relationship can have different effects depending on whether the relationship is output-based or behaviour-based (Heide, Wathne, \& Rokkan, 2007). Moreover, a powerful buyer has more ability to force the supplier to accept monitoring. If, on the other hand, the supplier is powerful, the monitoring activities of the buying firm can be more easily mitigated. Additionally, the effects of monitoring depend on the relationship that exists between the firms. Closer relationships with informal arrangements which allow for behavioural monitoring can supress opportunistic behaviour (Heide et al., 2007). There are several aspects that firms have to consider before they decide upon how to monitor their suppliers. In addition to monitoring, firms can control their suppliers through a combination of contracts and trust.

\subsubsection{Contracts and trust}

A contract defines responsibilities, measures compliance, and establishes compensation (Baldwin, 2008). In addition, contracts are important since they align expectations, gain detail insights, divide responsibilities, and limit conflicts in the collaboration (Mayer \& Teece, 
2008). In collaborative NPD, there are a number of contractual mechanisms that partners can agree upon. Examples of such contractual mechanisms include confidentiality contracts, nondisclosure agreements (NDA), exclusivity contracts, and purchasing agreements. These contractual mechanisms are used to reach higher levels of technology information sharing and safeguard each party involved (Ragatz et al., 1997). Research shows that the contractual form that firms select is based on the type of R\&D project and the firm's prior history with the partner (Gulati, 1995).

In line with TCE theory, Cox (1996) suggests that firms should form a single source contract with the supplier where ownership and IP rights are clearly specified. However, in NPD, particularly in projects with technological uncertainty, it is difficult to design a contract that covers every potential future situation. Therefore, there needs to be a measure of flexibility in the contract. In addition, contracts that are too rigid may cause the supplier to lose incentive to innovate. Rosetti and Choi (2008) describe the need for flexibility (p 532) by claiming that:

[S] upply management that incorporates flexible and incomplete contracting would appear to be more effective than coercive techniques often practiced in the automotive, aerospace, and electronics industries.

In the literature, a number of authors have pointed to the importance of combining contracts (transactional mechanisms) and trust (relational mechanisms) in collaborative NPD (Gulati, 1995; Poppo \& Zenger, 2002; Blomqvist et al., 2005; Liu, Luo, \& Liu, 2009; Arranz \& Arroyabe, 2011). In fact, contracts and trust are complementary modes of governance that supplement each other. Contracts and trust are also more efficient when used together. It has been shown that contracts are more efficient in restraining opportunism, while trust and norms improve relationship performance more than contracts do (Liu et al., 2009). Contracts can create a ground for mutual understanding and commitments in collaborative NPD projects. However, collaboration and contracting in $R \& D$ is not possible without some level of trust (Blomqvist et al., 2005).

The literature on the subject claims that it is important to foster and nurture a sense of trust in supplier collaborations (Monczka et al., 1998), and that firms need to encourage and enable suppliers to participate in NPD, and develop the supplier's trust and commitment (Walter, 2003). But how can a firm create a sense of trust between itself and its partner? Studies indicate that it takes years of collaboration and years of personal relationship to develop trust and norms (Poppo \& Zenger, 2002). Hence, longer relationships are required to create trust. Longer relationships also allow the buying firm to access complementary capabilities and specialized knowledge from the supplier (Lorenzoni \& Lipparini, 1999). However, in order to gain more from collaborating with suppliers, the buying firms' capabilities are also important. Studies show that buying firms with higher manufacturing capability gain more from collaborations with suppliers than buying firms with less capability (von Haartman \& Bengtsson, 2009). The importance of trust varies, depending on which firms are involved, how they collaborate, and what is being developed. One study has shown that trust is more important in situations of geographical dispersion, computer-mediated communication, and national diversity (Muethel, Siebdrat, \& Hoegl, 2012).

An absence of trust can have negative effects on an NPD project. As shown in a case study of two NPD projects, inter-organisational collaboration with suppliers where there is a lack of trust, will lead to additional innovation costs (Bunduchi \& Smart, 2010). However, as shown 
in a study of three firms in the packaging industry, by establishing trust-based relationships, cost for coordination and production can be lowered (Lorenzoni \& Lipparini, 1999). Additional benefits from trust was shown in a large sample of buyer-supplier relationships, where is was demonstrated that trust enabled openness and understanding in the collaborations (Ritter \& Walter, 2003). Moreover, research based on firms in the computer industry indicates that relationships with trust creates a good environment for product innovation (Tangpong, Michalisin, \& Melcher, 2008). In order to capture potential benefits from trust, it is suggested that firms promote trust, share information, and align their goals (McDermott \& Handfield, 2000).

\subsubsection{Goal alignment}

When collaborating with a partner in NPD projects, firms strive to reach goal alignment, that is, the parties are in accordance with what the goal of the project is. A lack of goal alignment comes from the assumption that the agent has interests that are not in accordance with the principal's interest. By developing goal alignment in buyer-supplier relationships, the firms can achieve compatible objectives even though the buying firm may have preferences that are not aligned with the supplier's original preferences. Goal alignment between the buyer and supplier within the project is important, regardless of the level of technological challenges that emerge in the project or how cooperative the supplier is (Yan, 2011).

The benefits of goal alignment is that it can work as an assurance against opportunism in a buyer-supplier relationship (Jap, 1999), and that firms in a relationship with goal alignment see a longer time-horizon for their collaboration than with other firms (Jap \& Anderson, 2003). Goal alignment is not only important in inter-firm relationships, within the firm there also needs to be goal alignment. That is to say, goals at the operating level, that guide the individual project, must also contribute to the firm's long-term objective (Wheelwright, 1992). By agreeing from the outset on what the objective of a collaborative project is, firms can strive towards a shared goal. During the progress of the project, the objective needs to be revisited in order to ensure that the firms still have goal alignment. Firms that enjoy good relationships and an open environment can actually benefit from not agreeing on a common goal at certain times. By entering into conflicts over the projects' goals, which had to be resolved, the firms enabled broader considerations from different perspectives, as well as indepth considerations of possible paths for their projects (Yan, 2011).

When agreeing on the goal of the NPD project, firms can use various tools, such as technology roadmaps where information can be displayed. A technology roadmap is a tool for communicating technology, and product and market perspectives. This provides a long-term vision to help the firm with making strategic decisions (Phaal, Farrukh, \& Probert, 2004). In addition, technology roadmaps can be used to connect innovation strategies with sourcing strategies (Schiele, 2010). In practice, it is not uncommon for several types of technological roadmap to be used (Lee \& Park, 2005). It is shown that the utilization of technology roadmaps is influenced by the maps' alignment with the firms' objectives (Lee, Phaal, \& Lee, 2011). In collaborative NPD, technology roadmaps can be shared between participating firms to reveal their long-term planning. Aligning the firms' technological roadmaps helps the firm to obtain strategic benefits (Handfield et al., 1999). Moreover, a powerful buyer's technology roadmap can influence its supplier's technology roadmap (McIvor et al., 2006). However, sharing knowledge through technology roadmaps could have negative effects, as indicated by Petrick \& Echols (2004 p 96): 
Sharing knowledge may encourage opportunistic behaviour when knowledge asymmetries occur, as well as behaviourally conditioning firms to trust less if they experience negative effects from sharing early on, or incur more negative than positive experiences from sharing. Also, leakage may accidentally or strategically occur causing some firms who are highly skilled at something to lose out to less competent counterparts.

\subsection{Organisational coordination: $R \& D$ and purchasing in NPD projects}

In collaborative NPD, the buying firm needs to coordinate their work in the project. In this thesis, it is the R\&D department and purchasing department's coordination in the NPD project that is studied. Coordination in this context is important as research indicates that, in collaborative NPD, it is important that the firms' internal coordination works (Takeishi, 2001; Koufteros et al., 2005; Praest Knudsen \& Bøtker Mortensen, 2011). A review of the literature on coordination reveals that scholars use a variety of definitions (Okhuysen \& Bechky, 2009). However, among these definitions three commonalities can be identified (Okhuysen \& Bechky, 2009 p 469):

(1) people work collectively; (2) the work is interdependent; and (3) a goal, task, or piece of work is achieved.

Organisational coordination involves different departments and functions, which leads to cross-functional issues.

\subsubsection{Cross-functional teams in NPD projects}

As departments within the firm specialize, they need to interact in order to achieve the firm's overall goal (Carlile \& Rebentisch, 2003). The departments are interdependent and need to deal with several different communication interfaces. As firms specialize and have specialized departments, they need to coordinate their internal systems of organisation, as described by Grant (1996 p 113):

Given the efficiency gains of specialization, the fundamental task of organization is to coordinate the efforts of many specialists.

In cross-functional coordination, different departments are dependent on each other and reduce uncertainty by transferring information between the parties (Song, Montoya-Weiss, \& Schmidt, 1997; Fliess \& Becker, 2006). A multiple case study of collaborative NPD suggests that activities are coordinated according to goals, cost, quality, and time (Fliess \& Becker, 2006). Coordination can be thus achieved with respect to a number of different variables. Coordination in cross-functional teams in NPD projects is particularly challenging for large firms with well-developed functional departments that consists of specialists (Wheelwright \& Clark, 1992). The authors argue that a promising team structure are "heavyweight" project teams, where the project leader is a senior manager who has primary influence over the project team and can allocate these individuals to be solely dedicated to the NPD project. Consequently, the functional department has less influence on the individuals in the NPD project team. Heavyweight teams can thus reach integration in the NPD project, but still face the problem of possible conflicts with the functional departments. 
Coordinating within NPD can be particularly problematic because individuals from different departments view NPD differently (Dougherty, 1992) and structure knowledge differently (Carlile, 2002). Problems with coordination are discussed by Johansson et al. (2011), who point out that knowledge differentiation, interdependence, and uncertainties need to be considered when coordinating. However, even though cross-functional coordination can be problematic, a survey of cross-functional coordination in NPD demonstrates that it is beneficial to include multiple functional perspectives in these projects (Song et al., 1997). Similarly, another survey study based on individuals involved in NPD indicates that by increasing the use of cross-functional teams in NPD, projects can be more successful (McDonough, 2000). A more recent survey shows that the effects of cross-functionality in collaborative NPD are limited, but joint decision-making can facilitate exploration of suppliers' innovation capabilities (Bengtsson et al., 2013a). However, firms need to consider when it is beneficial to involve the different departments. At least one survey has indicated that not all functions should be involved during all stages of the NPD project, as some only contribute to the project during certain phases (Song, Thieme, \& Xie, 1998).

This thesis is limited to studying coordination of the R\&D and purchasing departments within the NPD organisation (see figure 2-3) although there are a number of additional departments that could be involved in NPD projects. Individuals from the R\&D department, in this thesis called 'R\&D', often consist of engineers and technical experts who are responsible for the buying firm's product development. In contrast to this, individuals from purchasing (in this thesis, 'the purchasing function') consist of purchasers who are either operational purchasers or strategic purchasers. At the buying firm, purchasing is often responsible for communication and contracting with suppliers for delivery of components.

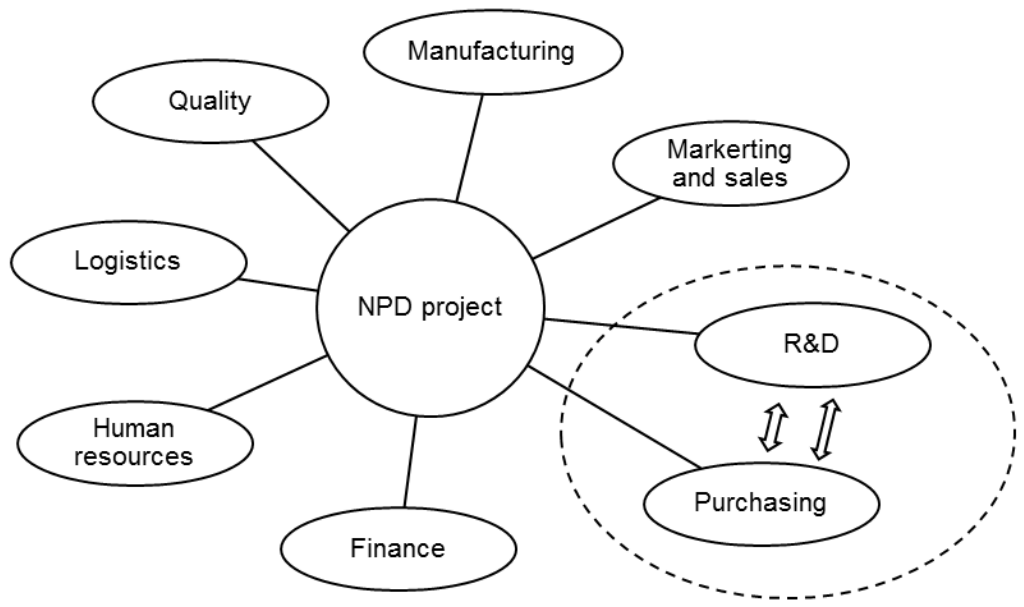

Figure 2-3 The focus of this study: coordination of $R \& D$ and purchasing 


\subsubsection{The R\&D department in NPD projects}

Traditionally, the R\&D department has developed products for the firm without much coordination with other departments within the firm. The department consists of technical experts who design and develop new products for the firm. However, since the beginning of the 1990s, there has been focus on the coordination of the R\&D department with a number of other departments in the effort to develop innovative products (cf. Wheelwright \& Clark, 1992; Song et al., 1997; Reger, 1999; Brusoni, Prencipe, \& Pavitt, 2001; Olson, Walker, Ruekerf, \& Bonnerd, 2001). Cross-functional coordination in NPD was identified as beneficial, as described by Henke, Krachenberg, \& Lyons (1993 p 218):

Rather than letting each functional area in isolation do its "own thing" and then pass the activity to the next department in a serial decision-making process, a cross-functional team brings together a carefully selected array of specialists who jointly and simultaneously make design and manufacturing decisions. This has the effect of speeding up the development process.

Although cross-functional coordination has been shown to be beneficial for the firm, a recent survey study reveals that when the R\&D department coordinates with other departments it can result in a loss of the department's sovereignty, and a dispersion of responsibilities, thus resulting in the department losing influence within the firm (Engelen \& Brettel, 2012). For this reason, additional cross-functional coordination may not be in the interest of the R\&D department, although it is in the interest of the firm as a whole.

\subsubsection{The purchasing department in NPD projects}

In a traditional view of the purchasing function, purchasing acquire inputs, ensure that these inputs are delivered on time, in sufficient quality, and are at an acceptable price. In addition, purchasing searches for new suppliers, assesses and selects these new suppliers, and is responsible for the contact with existing suppliers and negotiates prices. These activities can be translated into (i) a rationalization role, i.e. contributing to the firm's competitiveness by focusing on production costs, logistics, and prices of sourced products, and (ii) a structure role which refers to managing the supplier network and making sure that suitable suppliers are available (Axelsson \& Håkansson, 1984; Wynstra et al., 2003). For these reasons, purchasing is specialized in managing suppliers.

An overwhelming amount of previous research has indicated that purchasing has a very important role in collaborative NPD projects that involve suppliers (Birou \& Fawcett, 1994; Dowlatshahi, 1997; McGinnis \& Vallopra, 1999; Nijssen, Biemans, \& De Kort, 2002; Walter, 2003; Schiele, 2006; van Echtelt, Wynstra. F, \& van Weele, 2007; Luzzini \& Ronchi, 2011). This is due to the fact that purchasing has become a more strategic function of firms that are involved in NPD and who work with specialists from other functions in the firm (Gadde \& Håkansson, 1994). This is demonstrated by how purchasing can address certain issues, both on an operational level and a strategic level, in the firm (Das \& Narasimhan, 2000). In order to contribute to NPD, purchasing needs to expand their capabilities to deal with crossfunctional collaboration (von Corswant \& Tunälv, 2002). For this reason, purchasing should develop relationships with the major players in NPD, such as R\&D (Birou \& Fawcett, 1994). How the purchasing organisation is internally organised has a strong influence on purchasing's involvement in NPD (Schiele, 2010). For purchasing to take a more prominent 
role in NPD, it needs to have sufficient competencies and have a purchasing organisation that facilitates purchasers' involvement in NPD projects (Lakemond, Echtelt, \& Wynstra, 2001). In fact, a recent study shows that firms with higher integration of purchasing and higher involvement of purchasing in NPD, use purchasing as a unique interface with the supplier (Luzzini \& Ronchi, 2011).

However, a point of criticism of the many studies mentioned above that claim that (i) purchasing has become more strategic, that (ii) purchasing should be involved in NPD, and that (iii) purchasing should be responsible for the contact with the supplier who collaborates in NPD is that many of these studies are based on data collected from purchasing and from the purchasers' point of view (for example see Carr \& Smeltzer, 1999; McGinnis \& Vallopra, 1999; Wynstra, van Weele, \& Axelsson, 1999; Faes et al., 2001; Stanley \& Wisner, 2001; Carr \& Pearson, 2002; Perrone et al., 2003; Wynstra et al., 2003; Luzzini \& Ronchi, 2011). Interestingly, one study that combined the purchasers' view as well as the firms' view of strategic purchasers showed that the purchasers view themselves as having a strategic role, while the organisation does not acknowledge this internally (Tassabehji \& Moorhouse, 2008). Moreover, this study showed that the firm did not recognize the strategic value of the purchasers, and purchasing was not involved in firms' strategic management decisions.

In order for the departments at the firm to be specialized and effective, purchasing should also be specialized. However, studies have described purchasing as being both supplier specialists (Walter, 2003), integrators, and having a cross-functional leadership role (McGinnis \& Vallopra, 1999; Oh \& Rhee, 2010). As a result of these observations, the issue of specialization of purchasing in collaborative NPD involving suppliers is ambiguous. In this thesis, the coordination of R\&D and purchasing in NPD projects will be investigated.

\subsection{Summary of the literature review}

Buyer-supplier collaboration in NPD under technological uncertainty has been studied from the innovation perspective and the supplier management field (Clark \& Fujimoto, 1991; Lamming, 1993; van Echtelt et al., 2008; Johnsen, 2009). Suppliers are important contributors to innovation for firms (von Hippel, 1988; Cuervo-Cazurra \& Un, 2010). Although buyersupplier collaborations have been well studied, there are a number of issues that remains to be resolved in the field. It is still not clear how firms should select suppliers for NPD collaborations (Clark \& Fujimoto, 1991; Diestre \& Rajagopalan, 2012) or how firms can control their suppliers (McDermott, 1999; Rijsdijk \& van den Ende, 2011) or how to coordinate R\&D and purchasing in an NPD project (Wheelwright \& Clark, 1992; Song et al., 1998).

With regards to supplier selection, information asymmetry is problematic because the buying firm has less information than the supplier. It may be difficult for the buying firm to verify whether the supplier has the capabilities that it claims to have. Research points to a number of capabilities that firms should evaluate in a supplier (Handfield et al., 1999; Wagner \& Hoegl, 2006; Feng et al., 2010), these can be divided into two categories; (i) technological capabilities and (ii) relational capabilities. Some studies highlight the importance of having prior collaboration with the supplier (Håkanson, 1993; Schiele, 2006; Li et al., 2008), while some studies indicate that firms benefit from searching for new suppliers to involve in NPD (Beckman et al., 2004; Johnsen, 2011; Raassens et al., 2012). 
In collaborative NPD involving suppliers, an important aspect that demands consideration is the need for the buying firm to control the supplier. However, it is not immediately clear how this should be achieved. One suggestion is that, in order to control suppliers, firms should specify contracts that align each party's expectations and assign specific responsibilities. Although contracts can specify work division, it may be difficult to do so because it is not known which problems may occur in technological uncertain NPD projects. Despite the vast literature on buyer-supplier collaborations in NPD, it is not obvious how firms are to control suppliers in technological uncertain projects.

This thesis focuses on coordination between $R \& D$ and purchasing. As firms get more specialized departments, they need to coordinate their experts, which is something that has been recognized as challenging (Dougherty, 1992; Wheelwright \& Clark, 1992). However, studies have argued that benefits can be enjoyed from having cross-functional teams in NPD projects (Wheelwright \& Clark, 1992; McDonough, 2000; Bengtsson et al., 2013a). Notwithstanding this, only a few studies have investigated purchasing's involvement in NPD under technological uncertainty, including previous research which has provided indications that the role of purchasing is suppressed with increasing technological uncertainty $(\mathrm{Oh} \&$ Rhee, 2010). In contrast to this, another study shows that, when there is high technological risk, the purchasing department is entrusted with the whole supply management process (Luzzini \& Ronchi, 2011). My observation is that the literature is not unanimous on how firms coordinate internally when involving suppliers in NPD projects under technological uncertainty. 


\section{CHAPTER 3}

I could not help laughing at the ease with which he explained his process of deduction. When I hear you give your reasons, I remarked, the things always appears to me to be so ridiculously simple that I could easily have done it myself, though at each successive instance of your reasoning I am baffled until you explain your process. And yet I believe that my eyes are as good as yours.

(Dr Watson to Sherlock Holmes in The Adventures of Sherlock Holmes: a Scandal in Bohemia) 


\section{RESEARCH METHOD}

This study takes the buying firms' perspective of the NPD collaboration. However, of the six projects studied, five of the suppliers were included in the study. Thus, the supplying firms' views have also been included in the study. The buying firms are large system integrators with large R\&D and large purchasing departments, making them interesting to study. The unit of analysis is the collaborative NPD project between the buying and the supplying firm. The projects under study varied in length and level of responsibility of the involved firms. In each project, the supplying firm contributed with technology that was new to the buying firm. In some cases, the technology was also new to the industry and market. It should also be noted that, in the individual projects, the buying firms and the suppliers had different types and levels of design responsibilities.

I investigated collaborative NPD by studying projects where firms involve suppliers to develop new products. This study is of a qualitative nature, where individual projects were studied to gain an in-depth understanding of the challenges that firms face when involving suppliers in NPD. By conducting case studies, I gained an analytical advantage by scrutinizing the projects closely. The cases studies were instrumental to a successful illustration and explanation of the phenomenon of collaboration. The study was delimited by the individual projects that were investigated, thus the studies could be focused on the buying firms and the suppliers in each of these projects. This is in line with Yin (2009), who argues that such studies should be clearly defined and delimited. To be more specific, the unit of analysis was the project (Figure 3-1). By limiting the study to the projects, I did not, for instance, study the firms as a whole, although I did collect information about the firms' organizations so as to get a better understanding of how they organized their projects.

The main perspective that was adopted in the study was the buying firm's perspective, although a majority of the suppliers were included in the study. At the buying firm, two relationships were examined: (i) internal relationships and (ii) external relationships. The actors that were studied in the internal relationship were mainly the purchasing function and the $R \& D$ function. These relationships subsume both personal and organisational relations. With regards to the external relationship, the actors that were studied were the buying firms and the suppliers.

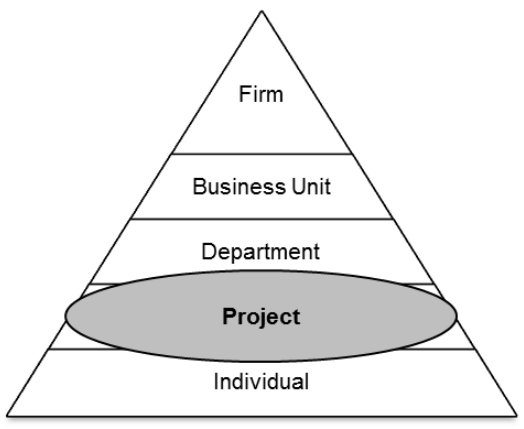

Figure 3-1 Unit of analysis 


\subsection{Research design: case studies}

The present research project was designed to investigate and provide an understanding of the phenomenon of collaborative NPD limited to collaborations with suppliers. To explore this phenomenon, qualitative case studies of NPD projects at two firms that collaborate with suppliers were conducted. Performing a case study is a method to systematically study a phenomenon, and is recommended for the study of a complex unit which has multiple variables (Merriam, 1994). When trying to understand a complex phenomenon, performing a case study is a recommended method (Strauss \& Corbin, 1998; Yin, 2009). However, as discussed by Stuart et al. (2002 p 421-422), case studies have additional uses in research:

Case studies should not be seen as a methodology appropriate only for understanding and the preliminary stages of theory development. Because of their observational richness, they also provide a means of refutation of, or extensions to, existing concepts.

Case studies are useful to the further development of existing ideas. Siggelkow (2007) argues that case studies have three important uses; to motivate, to inspire, and to illustrate. In short, case studies can motivate research questions, they can inspire new ideas, and can contribute conceptually by forming an illustration. Finally, the flexibility provided by this method was useful in this study, since the scope of investigation could be adjusted when necessary. Thus, changes in the research focus could be made, and it was thus possible to explore additional research areas as they emerged. It should be noted that this research is a part of a larger VINNOVA project ${ }^{1}$.

In this study, the research area was modified and further developed throughout the course of the study, as new research ideas and questions emerged during the study. The initial idea was to study knowledge integration in NPD. However, the focus changed to supplier selection in this context (cf. Melander, 2011). Thereafter, the study was expanded to include collaboration and coordination. The data collection was iterative and new research questions emerged during the data collection.

Case studies can be classified according to the number of cases that are studied; single case studies and a series of case studies. Additionally, a case study can be classified according to the dimension of time; retrospective studies, snapshots, and longitudinal studies. The present study started with a single case, with additional cases added later. Dubois and Gadde (2002 p 554) argue that:

Learning from a particular case (conditioned by the environmental context) should be considered a strength rather than a weakness.

Single case studies are valuable for creating understanding in situations where the context has been properly selected. All the case studies that were conducted were retrospective studies,

\footnotetext{
${ }^{1}$ VINNOVA is the Swedish Governmental Agency for Innovation Research. The research project indicated was called: "Managing external knowledge acquisitions: sources and strategies", where collaborating firms were $\mathrm{ABB}$, Ericsson, Saab and Scania.
} 
meaning that the study started at the end phase of the NPD projects, during the time when the projects were being finalized and industrialized. In retrospective studies, the study's boundaries need to be defined and informants who are relevant to the study have to be selected (Flick, 2006). One advantage of a retrospective study is that the outcome of the project is known. However, one disadvantage is that the informants might not recognize an event as important and thus do not remember it (Leonard-Barton, 1990), even if it is important to the researcher. Another disadvantage is that it may be difficult to remember dates and details from occurrences that took place some years ago. Furthermore, key individuals could have left the firm by the time the study commences, thus making it difficult to interview them.

The research design can be understood as being the logic which connects the collected data to the research questions (Yin, 2009). It embodies the researcher's plan for conducting the investigation and defining cases to study. Figure 3-2 visualizes the research design and the process that was undertaken during this study. The formulation of the purpose of the thesis and the inclusion of the literature to include in the study were processes that went on throughout the study. The define and design phase of the study consisted of a case sampling and the selection of the cases that were included in the study. The cases were selected sequentially, first ABB-1 was selected, with the intention to analyse additional cases. Six cases were studied in total. In the second phase, case studies were conducted and detailed case descriptions for each case were written up (Miles \& Huberman, 1984). Here, data was collected and analysed. Each case includes a detailed case description that is available in the case study database. Moreover, workshops at ABB and Ericsson were performed to validate findings and to provide additional data to the study. Previously collected data was gathered and verified at the workshops. The third phase consisted of comparing the cases, analysing them, and writing papers based on the case studies, and finalizing the synthesis of these papers in this dissertation.

During the research design phase, some activities were conducted in parallel. For instance, the papers and the compiled summary were written partly parallel with each other. Figure 3-2 illustrates the research design, but not the complete research process. In the process, there were elements of writing, re-writing, and additional data collection which are not included in the figure. However, the figure does describe how the process developed in principle and how it consisted of three phases. The elements in each phase and their connections with each other are also indicated. In case studies, there is often an overlap of data collection and data analysis; this allows the researcher to modify the data collection by being flexible (Eisenhardt, 1989a), illustrated in Figure 3-2. 


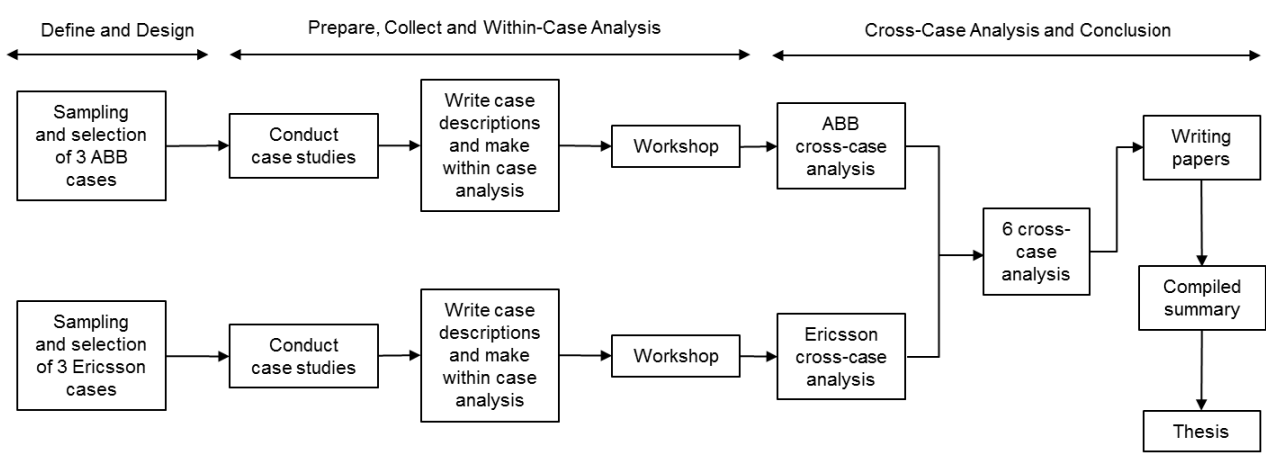

Formulation of Purpose and Literature Study

Figure 3-2 Research design (modified from Yin 2009, p 57)

Figure 3-3 shows the points in time when interviews were conducted for each case. A more elaborate description of the data collection process is presented in section 3.3.

\begin{tabular}{|l|l|l|l|}
\hline & 2010 & 2011 & 2012 \\
\hline ABB-1 & & & \\
ABB-2 & & & \\
ABB-3 & & & \\
Ericsson-1 & & & \\
Ericsson-2 & & & \\
Ericsson-3 & & & \\
\hline
\end{tabular}

Figure 3-3 Data collection (interviews) over time

Empirical research begins with a review of literature, finding a research gap, and composing research questions that address the gap identified (Eisenhardt \& Graebner, 2007). Literature was searched on the Internet (ISI Web of Science) in order to gain an understanding of the research field. The publications that were searched for were limited to the fields of operations research management science, management, and business. Key words in the literature search included: uncertainty, technology, supplier involvement, NPD project and supplier, Purchasing and NPD, and supplier selection. These broad searches resulted in a large number of hits. Therefore, the publications were sorted by number of citations. Thereafter, I read the abstracts for each study in order to determine which of the publications were relevant to this study. Articles that focused on a context other than NPD or focused on collaboration partners other than suppliers were omitted. For example, articles on service collaborations with competitors were omitted.

Additionally, more articles were discovered by finding key references in the articles that were discovered during the initial search. Although the key words lead to central references in this thesis, some of the hits on the ISI Web of Science database were not relevant. Some articles, for example, investigated collaboration between firms and universities or a firm's outsourcing and joint ventures. However, in general the snowball effect proved to be very important to find new relevant papers, and references used in these papers often led to other relevant papers. It can be argued that additional key words could have been used. However, in order to 
try to limit the study very general key words such as innovation and alliance were omitted since there is already extensive research related to a number of literature streams linked to these key words.

\subsection{Qualitative sampling}

The sampling consisted of finding suitable firms, projects, and respondents to interview. I searched for two firms to compare; both to compare projects between the firms and compare projects within the firms. In this comparison, I wanted to keep several variables constant, therefore firms that were system integrators who produce complex products and sell their products business-to-business were selected (for more information about system integrators in technical systems, see Tell (2003)). System integrators are used to collaborating with suppliers in NPD and organizing several collaborative NPD projects simultaneously. The firms also had to be in an industry where there is fast technological change, which leads to a high level of uncertainty. The uncertainty and complexity of collaborating with external partners made these projects interesting to study. However, in this field of research, a number of studies of small and medium sized firms have been conducted (De Toni \& Nassimbeni, 2003; Knudsen \& Servais, 2007).

The first industry that was selected is the power generation industry. This industry has seen a great deal of technological development in recent years due to investments in renewable energy sources, such as wind and solar power. The second industry that was selected is the telecommunications industry because it is the cutting-edge of technology development and has focused on developing new products due to the dramatic increase in data traffic that has taken place recently. The firms $\mathrm{ABB}$ and Ericsson were selected to study, which was partly due to previous contacts with these firms, and for the reason that they were engaged in interesting research projects with high uncertainty. These are large firms, which makes them interesting to research since larger firms actively seek and find external collaborations for R\&D more often than smaller firms (Hagedoorn \& Schakenraad, 1994). These firms are market leaders in their respective industries and can be expected to demonstrate 'best practice' in involving suppliers in NPD projects. They have complex products, are used to collaborating with external firms, and are technically competent in their field.

In the beginning of the study, there were discussions with the firms regarding suitable NPD projects that could be studied. A number of criteria were used to identify projects. After a project had been selected, the appropriate respondents were sampled. An overview of the sampling process is shown in Figure 3-4. As can be seen in the figure, there were three instances of the sampling process: firm sampling, case sampling, and respondent sampling. 


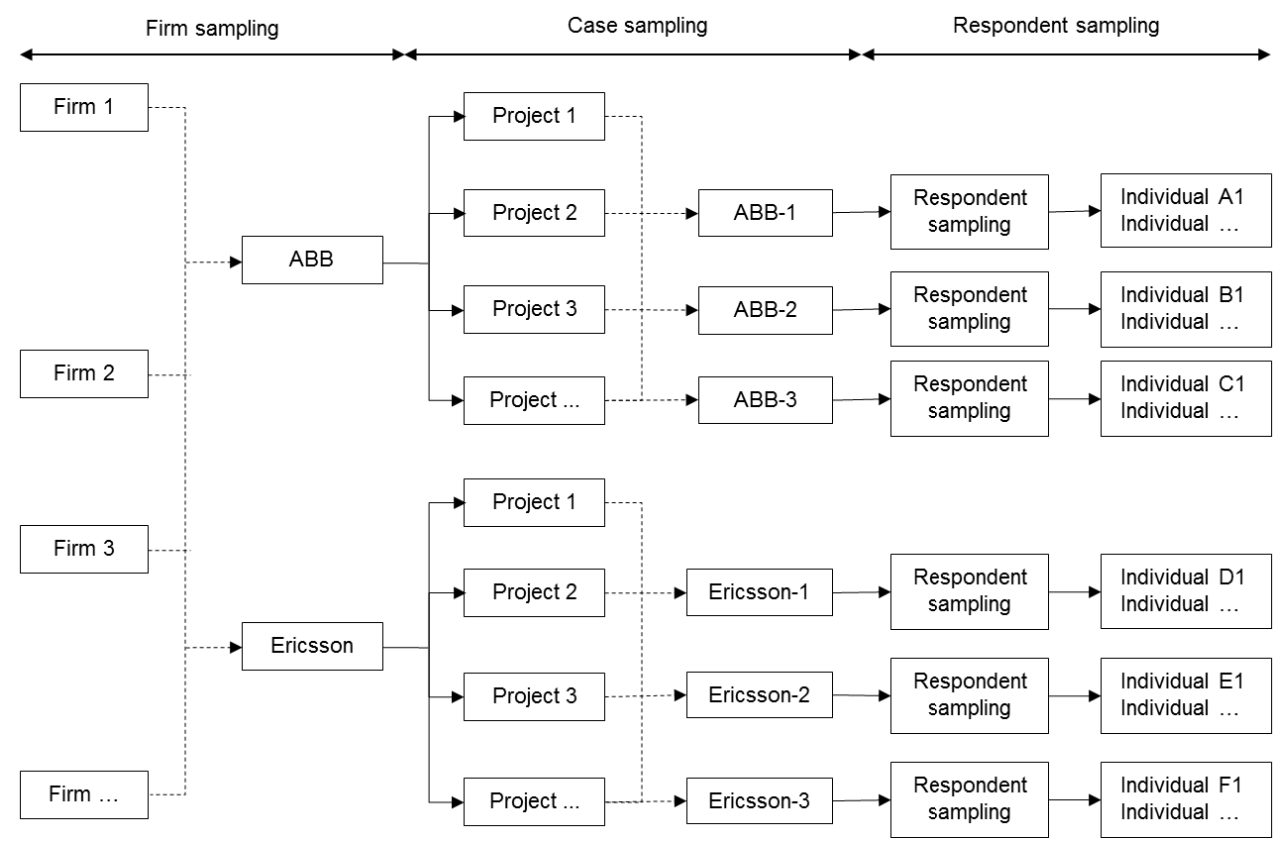

Figure 3-4 Sampling processes

\subsubsection{Firm sampling}

The first firm that was chosen to be a part of this study was $\mathrm{ABB}$, and the second firm was Ericsson. Both firms are system integrators. System integrators are used to incorporating external technology and components into their systems (Marshall, 1996; Tell, 2003). For this reason, they are assumed to have processes in place to deal with supplier involvement in NPD. These firms were selected by using purposeful sampling and representative sampling. First, these firms were rich in information about collaborative R\&D. Second, these firms are representative of a group of firms (according to the sampling criteria) and suitable for indepth investigation because they have collaborated with suppliers in R\&D for many years. The sampling was based on gaining an in-depth understanding instead of searching for generalizations (Patton, 2002). It was believed that much could be learned from how these firms collaborate with suppliers in NPD. ABB and Ericsson were also selected partly because they too were interested in the proposed research project. Strategies concerning how to work more closely with suppliers in R\&D were being discussed at these firms. In addition, projects were being performed where suppliers were closer to the buying firm than ever before. Consequently, the firms were experiencing challenges in the NPD projects and in the new ways of working. An overview of the participating firms, buying firms, and suppliers where interviews were conducted, can be seen in Table 3-1. 
Table 3-1 Overview of participating firms (from 2012)

\begin{tabular}{lrrcll}
\hline Firm & $\begin{array}{l}\text { Number of } \\
\text { employees }\end{array}$ & Sales $(\mathrm{M} €)$ & $\begin{array}{l}\text { R\&D } \\
\text { as } \% \text { of revenue }\end{array}$ & $\begin{array}{c}\text { spending } \\
\text { Main industry }\end{array}$ & $\begin{array}{l}\text { Project } \\
\text { location }\end{array}$ \\
\hline ABB & 134000 & 47488 & $4 \%$ & Power and automation & Sweden \\
Saft & 4100 & 629 & $7 \%$ & Batteries & France \\
SKF & 46000 & 7557 & $2 \%$ & Bearings & Austria, Sweden \\
Borealis & 5100 & 7069 & $1 \%$ & Plastic materials & Sweden \\
Ericsson & 104500 & 25213 & $13 \%$ & Telecommunication & Sweden \\
Kathrein & 6700 & 1323 & $10 \%$ & Antennas & Germany \\
Intel & 82500 & 41000 & $15 \%$ & Processors & USA \\
\hline
\end{tabular}

\subsubsection{Case sampling}

It is argued that the decision and strategy for sampling cases depends on the research question (Flick, 2006). The sample size and sample strategy depends on the unit of analysis (Patton, 2002). In qualitative research, the sample may be small and sometimes limited to a few case studies. In such situations, these cases are selected purposefully. This is described by Patton (2002 p 230) who points out that:

Purposeful sampling focuses on selecting information-rich cases whose study will illuminate the questions under study.

By using purposeful sampling to find suitable cases, the sampling is aimed at gaining as much insight about the phenomenon being studied as possible. The sampling strategy used here was based on finding cases that were rich in information and demonstrated supplier involvement in NPD. A sampling strategy that consists of sampling information-rich cases that are not extreme, but demonstrate the phenomenon intensely is called intensity sampling (Patton, 2002). The sampling method was used to maximize the helpful information from each case, also known as an information-oriented selection (Flyvbjerg, 2004). The firms actively participated in the sampling. Thus, projects were discussed, and those that were perceived as relevant to this study were selected. To capture this information, interviews were conducted with individuals who were involved in the NPD projects under study. In the sampling, it was necessary to consider the fact that the cases were to be used in five different academic articles for this thesis. This affected the sampling somewhat; cases needed to be relevant on the individual level, in addition to being comparable with each other.

In addition to using the sampling strategies known as purposeful sampling, intensity sampling, and information-orientation in the literature, criterion sampling was also used. Criterion sampling is a sampling strategy where all the cases meet some predetermined criteria (Patton, 2002). In this study, these criteria were: (i) the project is an NPD project with external supplier, (ii) the project has at least one supplier contributing with technology that is either new to the market or to the buying firm, (iii) a component, product or system is being developed, (iv) the project is in its end-phase, in the industrialization phase, or has been terminated. In addition to the above, access to the different functions that were involved in the projects and access to documents were required. Finally, one criterion was desired but not fulfilled in all the cases, that was the criterion of gaining access to the supplier. The original objective was to include the suppliers in the all studies. However, this was not possible in one 
case (Ericsson-2) due to restrictions imposed by the buying firm, and therefore only the buying firm was studied in this one case.

Sampling at ABB was conducted at three different points in time: the end of 2009, spring 2010, and autumn 2012. The sampling at ABB was sequential, that is to say, only once data from one case was collected was the sampling for the next case started. The sampling of ABB-1 started with an initial meeting at the firm. In this meeting, the research idea was presented to the senior vice president, the technology manager, the manager of marketing and sales, and the manager of business development. The firm's managers discussed which of their NPD projects would be most appropriate to study. It was important to them that the project fit the following criteria: (i) it should be a NPD project involving an extrenal supplier with new technology, and (ii) it should be in its end phase. These criteria were developed to facilitate data gathering and to ensure that a suitable project for the purpose of this study was selected. Other important criteria involved secrecy and resources; it had to be possible to gain access to the project and information involving it. In addition, project members also needed to be able and willing to reserve time for interviews. A number of different NPD projects were assessed, and a suitable NPD project (ABB-1) that fitted my criteria was selected in agreement with the firm.

The sampling process of the second case (ABB-2) was similar to the first, but with the difference that the firm, $\mathrm{ABB}$, and the department, Machines, were identified from the researcher's personal connections. The technical manager at the firm was contacted to see whether it was possible to conduct a study at the firm and whether he knew of any suitable projects. The technical manager expressed an interest in the research and a meeting was set up to discuss the possibility of conducting a case study there. The criteria were the same as for the first case, with the addition that it should allow access to the external supplier in the NPD project and that the supplier should be included in the study. During the sampling process at the initial meeting, the technical manager presented several NPD projects with external suppliers. One project was chosen since it was about to be finalized. This project was successful, involved new technology, and included an international supplier. The technical manager contacted the supplier, and when the supplier agreed to be included in the study, the project was selected. As in the first case study, the selection was also based on the expectation that this research would provide the firm with information relevant to my research interests in the case.

ABB-3 was accessed through another personal contact. An interesting R\&D project with strategic value was presented. This project fit my criteria: (i) the project was in its end-phase, (ii) it involved an external supplier that contributed with new technology, (iii) the project involved close collaboration between the buyer and supplier, (iv) the project was more research-based than applied development-based, and (v) the project was strategically important to the firm. My personal contact enabled access to the project manager, who arranged participation from the supplier.

The sampling of the three Ericsson cases was done simultaneously, in the autumn of 2011. At Ericsson there were first two meetings with individuals that did not lead anywhere except to the direction to other individuals within the firm. At a third meeting, four individuals at Ericsson participated, two design managers and two sourcing managers at the higher strategic level within Ericsson. This group was interested in the research and could provide NPD projects to be studied. They were gate-openers to projects and identified projects according to 
several sampling criteria. These criteria included the following: (i) the project involved an external supplier that provided new technology to the product, (ii) the project was in its endphase, (iii) both radical and incremental product developments were included, and (iv) the projects were on different products from different parts of Ericsson. By following these criteria, three projects were selected. Access to the suppliers was requested but could not be guaranteed from Ericsson.

\subsubsection{Respondent sampling}

The selection of respondents involved two principles: representativeness and quality sampling (Alvesson, 2011). The first principle focuses on giving the researcher a clear picture of the phenomenon and avoids skewed views of the phenomenon that is to be studied. Thus, the sampling should be wide and include a variety of respondents. The second principle focuses on the respondents; especially on their insight and the relevance of their information. In these cases, a sampling of individuals that included both principles was made. By selecting individuals who had access to the NPD projects, who could influence the projects or were project members, the respondents had insight into the project and could provide relevant information.

Regarding representativeness, interviews with individuals with different areas of responsibility, who belong to different departments, and who had different roles, responsibilities and functions within the project, were conducted. Thus, it was possible to obtain different views towards the projects, processes, meetings, and decisions that the firms made. In general, for all cases, the gate-openers for each project helped to initiate the sampling of respondents. Additional respondents were identified by snowball sampling (Patton, 2002). That is to say, respondents indicated individuals or functions that had been involved in the project and could provide me with more information. It can be argued that for the sampling of the respondents several strategies were used; intensity sampling, variation sampling, and snowball sampling.

In the project $\mathrm{ABB}-1$, the strategic group from first meeting helped in sampling respondents by identifying the functions that could be included in the study. The individuals who were mentioned to me were interviewed and from these interviews additional informants were identified as important individuals in the project. Thus, snowball sampling was used to identify additional respondents, such as the first project manager and the supplier's project manager. In the ABB-2 project, the technical manager (the gate-opener) identified the project team members at ABB and the key account manager at SKF. The key account manager then provided access to SKF's project team members. At both firms, the complete project teams were interviewed. In the third $\mathrm{ABB}$ project (ABB-3), the sampling of respondents started in a discussion between the project manager at $\mathrm{ABB}$ and me. I wanted to interview individuals in the project who worked with the supplier and had different roles. I also wanted to talk to individuals who had been involved in the beginning, of the project. The project manager gave suggestions to me about respondents at both $\mathrm{ABB}$ and the supplier. This sampling was confirmed after talking to members of the project's steering committee from ABB and the supplier.

At Ericsson, the gate-openers helped by choosing individuals who were relevant to the study. They provided me with the names of respondents with similar functions in all projects, namely strategic product management, R\&D, sourcing, and supply. In addition, snowball 
sampling was used to find additional respondents. Interviewees gave suggestions of people at Ericsson and the suppliers that had been involved in the project. Thus, project managers and additional supply respondents were identified and included in the study. More importantly, snowball sampling was used to gain access to the suppliers. In Ericsson-1, the strategic product manager provided access to the supplier, and the sourcing manager at Ericsson-3 provided access to the supplier in that project.

\subsection{Data collection}

In case study research, several data collection methods are often combined (Eisenhardt, 1989a), which was what I did in my data collection. My data collection included three different data sets: interviews, workshops, and secondary data, such as documents and factory visits. This is in accordance with the suggestion that researchers should use triangulation to acquire data, thus applying a number of different methods to search for and gather data (Golafshani, 2003).

\subsubsection{Interviews}

The main data was collected during interviews with individuals who were involved in the NPD projects. Interviews can be distinguished and categorised according to their structure, size, communication, and type of interview (Alvesson, 2011). The degree of structure of the interview, can be divided into three levels: structured, semi-structured, and unstructured. The interviews in this study can be classified as semi-structured, since the interview focused on the NPD project and themes regarding it. Before starting the interviews, an interview guide that contained the main topics for discussion with the respondents was prepared (the Interview Guide can be found in Appendix A). The interview guide was developed to be flexible and allow for follow-up questions to be asked. With regards to the number of interviewees, an interview can be conducted with only one individual, or an interview can be with a group of people. The interviews in this study were conducted with one respondent at a time in order to gain that respondent's view of the project. A group interview could have resulted in some respondents refraining from speaking freely; this was avoided by conducting the interviews individually. However, during the workshop sessions, individuals discussed questions/issues in groups.

Interviews can be made face-to-face, over the phone, via video session or in writing. Here, my ambition was to conduct face-to-face interviews, but when that was not possible, phone interviews were conducted. Face-to-face interviews allow the researcher a more in-depth understanding than a phone interview. Thus, in order to gain as much information as possible, face-to-face interviews are to be preferred. Conducting interviews is a highly efficient method for gathering detailed empirical data (Eisenhardt \& Graebner, 2007). In this study, the respondents often answered questions with a great amount of detail and with rich information. The interviews were formal, professional exchanges that did not concern sensitive or personal information, as discussed by Alvesson (2011), namely death, disease, and violence. The interviews that were conducted did not touch upon the respondents' private lives.

The interviews were based on a semi-structured interview guide (see Appendix A) where questions were used to start a conversation. In good qualitative research, as argued by Gioia, Corley, \& Hamilton (2013 p 19): 
[T] he heart of these studies is the semi-structured interview - to obtain both retrospective and real-time accounts by those people experiencing the phenomenon of theoretical interest.

I used semi-structured interviews in order to gain in-depth responses about each respondent's experience, perceptions, and knowledge (Patton, 2002). By using open-ended questions, predetermination of answers and a limitation of discussion points were avoided. Moreover, such questions allows for an understanding of the respondent's point of view without assuming pre-determined categories (Patton, 2002). The interview data was gathered with the goal of recording quotations that could be interpreted more fully at a later date. Some interviews were made in collaboration with other researchers. In ABB-1, two interviews were conducted in collaboration with Fredrik Tell. In Ericsson-1, Ericsson-2, and Ericsson-3, the majority of the interviews were made in collaboration with David Rosell. An overview of the data collected through interviews is presented in Table 3-2, where each case is presented separately. In total, 53 interviews, including interviews with the suppliers, were conducted during January 2010 to October 2012.

Table 3-2 Interview overview

\begin{tabular}{lcll}
\hline Case & Number of interviews & Interview time & Time period \\
\hline ABB-1 & 11 & $14 \mathrm{~h}$ & January - August 2010, March 2012 \\
ABB-2 & 11 & $16 \mathrm{~h} 30 \mathrm{~min}$ & April - September 2010 \\
ABB-3 & 9 & $10 \mathrm{~h} 10 \mathrm{~min}$ & September - October 2012 \\
Ericsson-1 & 10 & $11 \mathrm{~h} 20 \mathrm{~min}$ & November 2011 - March 2012 \\
Ericsson-2 & 6 & $7 \mathrm{~h}$ & December 2011 - January 2012 \\
Ericsson-3 & 6 & $6 \mathrm{~h} 10 \mathrm{~min}$ & January 2012 - May 2012 \\
Total & 53 & $65 \mathrm{~h} 10 \mathrm{~min}$ & January 2010 - October 2012 \\
\hline
\end{tabular}

In the first case study (ABB-1), the interview data was collected through semi-structed interviews which were mainly conducted face-to-face. However, it was not possible to conduct three of the interviews face-to-face, and thus phone interviews were made. The respondents were individuals who were involved in the project, and they were selected in close discussion with the managers at the firm. The supplier's view was represented by the project manager at the supplier. In total, 11 interviews were conducted. These are presented in Table 1 in Appendix B, where information regarding each respondent, the duration of the interview, and interviewers are included. During the project, there were two different project managers who were responsible for the project. Both of whom were included in the study and were interviewed.

The data collected in the second ABB case (ABB-2) came from ABB and the supplier, SKF. In this study, individuals from two different firms and with different positions within the respective firms were interviewed. This approach limited potential bias in the study. The study began by conducting semi-structured interviews at $\mathrm{ABB}$, with the employees involved in the NPD project. This project team comprised of four project members; the project manager, the technical manager, the supply manager, and the general manager. After completing the interviews at ABB, the study at the supplier SKF began. First, the supplier's project team in Sweden were interviewed, consisting of the key account manager, the project manager, and the application engineer. Thereafter, the supplier's project team in Austria were interviewed: a development engineer, the product manager, and a business engineer. Table 2 
in Appendix B lists the project members who were interviewed for their respective companies, the duration of the interviews, and each project member's role(s) in the project. The interviews made for ABB-3, displayed in Table 3 in Appendix B, consisted of six interviews with $\mathrm{ABB}$ and three interviews with the supplier. The interviews were recorded, transcribed, and sent to the respondents for comments, clarification, and approval.

In the Ericsson cases, the interviews were semi-structured and based on an interview guide with topics concerning the project, challenges, strategies, competences, roles, organization, and selection. The majority of the interviews were conducted together with a colleague, David Rosell, Linköping University. Data collection, structuring, and analysis were also done in collaboration with David Rosell.

All of the interviews were recorded and transcribed. Thereafter, each transcript was sent to the respondent for clarification and comments on the interview transcript. In total, 22 interviews were conducted in the Ericsson cases. In the first project (Ericsson-1), ten interviews were conducted, three of them were with the supplier. (See Table 4 in Appendix B.) In the second Ericsson project (Ericsson-2), a total of six interviews were conducted. (See Table 5 in Appendix B.) Unfortunately, it was not possible to conduct interviews at the supplier firm because Ericsson did not grant the researcher permission to contact the supplier. This was due to sensitive negotiations that were being conducted with the supplier at the time. Two R\&D managers and two supply managers were interviewed, indexed with ' $A$ ' and ' $B$ ' in the table. The third project at Ericsson (Ericsson-3), included six interviews where one was with the supplier. (See Table 6 in Appendix B.)

\subsubsection{Workshops}

Workshops at $\mathrm{ABB}$ and Ericsson were conducted to verify results from the case studies and provide additional data-gathering. The workshops had slightly different set-ups, but contained elements of presenting results, and asking the participants to actively take part in discussions and comment on findings. The topics that were discussed evolved around collaborative R\&D where external suppliers are involved. Within this topic, specific elements such as supplier selection, control issues, and challenges were discussed. Information about the workshops is presented in Table 3-3.

Table 3-3 Workshop details

\begin{tabular}{lclll}
\hline Case & Firm participants & Research participants & Date & Topics covered \\
\hline ABB-1 & 10 & $\begin{array}{l}\text { Fredrik Tell and Lisa } \\
\text { Melander }\end{array}$ & $\begin{array}{l}\text { May 29 } \\
2012\end{array}$ & $\begin{array}{l}\text { Supplier selection, collaborative R\&D } \\
\text { strategies, purchasing's role in R\&D, } \\
\text { challenges }\end{array}$ \\
$\begin{array}{l}\text { Ericsson- } \\
1,2,3\end{array}$ & 7 & $\begin{array}{l}\text { David Rosell, } \\
\text { Nicolette Lakemond } \\
\text { and Lisa Melander }\end{array}$ & $\begin{array}{l}\text { June 19 } \\
2012\end{array}$ & $\begin{array}{l}\text { Collaborative R\&D, open innovation, } \\
\text { knowledge integration, future } \\
\text { challenges }\end{array}$ \\
\hline
\end{tabular}

After the interviews had taken place at ABB-1, a workshop was organized at ABB where ten individuals from $A B B$ participated. Participants were $R \& D$ engineers, system engineers, supply managers, the strategic purchasing manager, and the head of the R\&D department. The case study was presented, including an analysis of the challenges that emerge in collaborative $\mathrm{R} \& \mathrm{D}$. The workshop was of an interactive nature where topics of supplier selection, strategies, 
problems and challenges (both concerning the specific project but also concerning collaborative $R \& D$ projects in general) were discussed. This workshop was used to verify findings and to gather more data. The workshop enabled further discussion about the research project and provided additional data to the case study.

For the Ericsson cases, we (David Rosell, Nicolette Lakemond, and I) planned a workshop with participants from the gate-openers and individuals from the projects that we had we had studied. After completing the interviews and data analysis, a report was sent to Ericsson. This report contained a brief description of the study and each project. Thereafter, the projects were analysed, compared, and finally conclusions and challenges were presented. Approximately two weeks after the report was sent, a workshop was held at Ericsson where the gate-openers and respondents were invited. In total, seven individuals from Ericsson participated. Three individuals from the strategic group, two from Ericsson-1, and two from Ericsson-3 participated. Representatives from the projects included two from sourcing, one $\mathrm{R} \& \mathrm{D}$ manager, and one strategic product manager.

A brief presentation of the projects was made where the participants could comment on the presentation. Thereafter, each participant was asked to write three down challenges that they had experienced in the project. This was done individually, and thereafter each challenge was put on a whiteboard under each project name. Each participant explained the challenge he or she had written down and it was discussed in the larger group. This enabled us to verify findings and discuss challenges in each of the projects. Finally, the participants were given the opportunity to comment on the report. At this stage, findings were discussed, as well as points that had not been previously highlighted in the report. After the workshop, the report was modified according to the discussion at the workshop and sent to Ericsson again.

\subsubsection{Secondary data}

Secondary data (mainly documents) were collected from internal organizational documents, brochures, home pages, and technical information documents. This data was used to define the characteristics of the industries and firms, the characteristics of the products, and the history and organization of the firms. To gather information about the products, factory visits with a guide were made and a technical fair was visited.

Company material for ABB-1 was collected through the firm's home page and internal documents. In addition, extensive marketing material in the form of brochures, presentations, and other documents were studied. Additional secondary data about the project included the company's internal documents, such as the description of the stage-gate system used for project development. Technical information about the product's technlogies was collected through articles about technology, technical brochures, technical descriptions of the technologies, and the supplier's home page and other marketing materials. Information about the development of energy storage systems included reports available from the DoE, the United States Department of Energy.

Complementary data sources in ABB-2 were gathered through company documents, catalogues, technical information sheets, home pages, and marketing materials. Extensive marketing materials were studied, including videos, catalogues, brochures, presentations, and information sheets. Additionally, competitor suppliers were studied through their homepages, brochures, and other marketing materials. Innotrans, the world's largest railway fair (which 
was held in September 2010 in Berlin) was visited in order to learn more about the railway industry. $\mathrm{ABB}, \mathrm{SKF}$, and their potential customers and competitors participated at Innotrans. In order to better understand the products, that is to say, traction motors and hybrid bearings, both ABB's and SKF's factories were visited. The factory visits and the fair visit were rich in information and enhanced our understanding of the product and the industry. Viewing the product and the production processes facilitated an understanding of the information in the documents about the product and what the respondents had been describing. The fair visit helped to contextualise and understand where the products were integrated, and how the new technology would have an impact on the end product.

For ABB-3, internal documents, consisting of product descriptions and market information, were studied. In addition, information about the industries and markets were collected from technical reports and other external materials. Finally, at ABB, I received a presentation about the product's historical evolution.

Additional information about the projects that were studied at Ericsson consisted of internal and external documents, as well as tours at Ericsson where products were described. External documents consisted of firm information, industry information, product information, and market information. Internal documents consisted of product descriptions and information about how NPD projects are run at Ericsson. Moreover, Ericsson presented their different NPD project stages and described the different decision processes that needed to be made during the new product development process. In addition to learning about how NPD projects are run, Ericsson also held a PPT presentation on how they work to improve their collaborative NPD by implementing new methods in several projects. During the visits at Ericsson, we (David Rosell and I) also got a tour of the laboratory (where there was R\&D activity) of two of the products that we had studied at Ericsson. We visited the Antenna laboratory and we were able to follow how the radio and antenna were merged into the final product. We also got to see how the processor was tested and how Ericsson worked with debugging the product.

\subsection{Data analysis}

Qualitative analysis helps the researcher understand different occurrences of the studied phenomenon and explain why differences exist. The data analysis was systematically conducted and analysed. The collected data was analysed, organized, categorised, and coded to facilitate the analysis for the case studies. The data analyses were conducted with a similar systematic structure. Interpretation of the gathered data is very important in a researcher's work; an awareness of the topic, assumptions, and pre-understanding are important elements in the interpretive work (Alvesson \& Sköldberg, 2009). Using the interview-data that was collected, a microanalysis was made, which took the interviewees' interpretations of the projects into consideration (Strauss \& Corbin, 1998). What the respondent said, as well as how it was said, was taken into account. Because the majority of the interviews were face-toface interviews, it was easier to understand the respondents.

\subsubsection{Within-case analysis}

Eisenhardt (1989a) recommends within-case analysis in case study research, which includes detailed case write-ups. A careful examination of the collected data was conducted, and it was thereafter classified into groups according to its properties and similarities. I have performed a 
within-case analysis on all projects that were studied. Data can be organized according to a time perspective by which the researcher tries to create a story from the different occurrences that are presented in the data (Fejes \& Thornberg, 2009). In this study, time lines were created to facilitate an understanding of important milestones in the projects. In this chronological mapping, core situations were identified and interpreted. Furthermore, detailed case descriptions were written in which the respondents' views of important episodes are presented.

Yin (2009) suggests that case study analysis requires a case description and analysis by the researcher. In accordance with his suggestion, I wrote up elaborate and detailed case descriptions, which included data from both the interview sessions and additional data. Such data included, for instance, data collected from marketing materials, internal documents, and technical descriptions. The papers that are included in this thesis draw upon the information found in the case descriptions. The process of writing the papers included studying the literature and analysing the case descriptions. According to Eisenhardt (1989a), the researcher works systematically to compare theory with data in an iterative process. Therefore, throughout these studies, I have searched for and read the relevant literature. This study started with a general theory about NPD and supply management, and then it evolved to incorporate literature about supplier involvement in NPD, supplier selection, purchasing, uncertainties, integration, and control. Thus, the theory started as being quite broad, became narrow and more specific, and finally developed into a perspective that includes the only the relevant subjects for this research (such as: supplier selection, supplier collaboration and internal coordination).

\subsubsection{Cross-case analysis}

Cross-case analysis involves the comparison of a number of different case studies. By using methodological rigor and by comparing case studies, the research can gain valuable theoretical insights. (Eisenhardt, 1991). It is argued that, in a comparative analysis, the focus should be on the key variables (Lijphart, 1971). This is to avoid the risk of the researcher becoming overwhelmed by a large number of variables. Thus, to facilitate the comparison, key events in the NPD projects were identified and the process was divided into different stages of the NPD project. For instance, the projects were divided into three approximate timeframes: (i) technology selection, (ii) supplier selection, and (iii) supplier involvement in the project. The cases were subsequently compared, both within the ABB and Ericsson cases respectively (paper 2, 3 and 4), and across the two firms (paper 5). (See Figure 3-5.) 
A

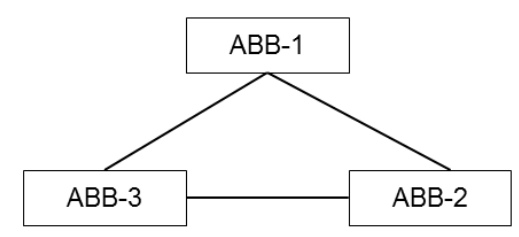

B

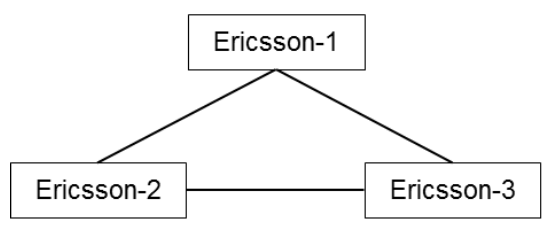

C

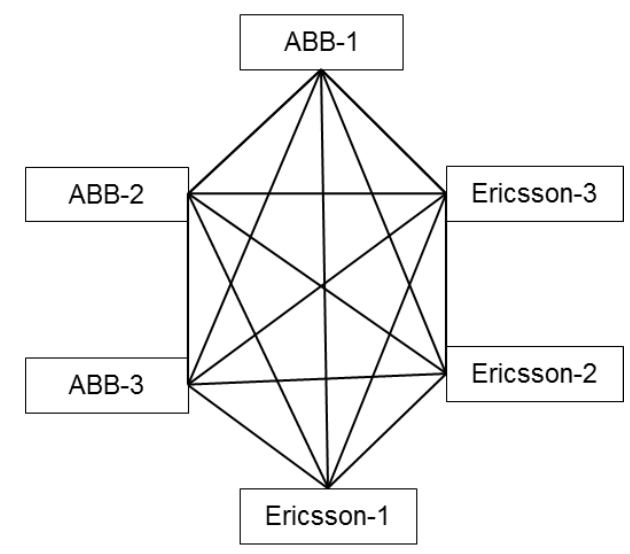

Figure 3-5 Cross-case comparison (A: paper 2 and 3, B: paper 4, C: paper 5)

In cross-case analysis, it is preferable that the researcher is intimately familiar with each case; something which can be achieved through case write-ups (Eisenhardt, 1989a). In the research described in this thesis, case descriptions were written by the author and were often returned to and re-read. At times it was necessary to return to the raw material/data in order to check that a particular case description did not omit any valuable information. Eisenhardt (1989a) describes three strategies for cross-case comparison (Table 3-4), which I used.

Table 3-4 Strategies for performing cross-case comparisons

\begin{tabular}{cll}
\hline Strategy & Eisenhardt & This study \\
\hline 1 & $\begin{array}{l}\text { Select categories or dimensions, } \\
\text { and look for within-group } \\
\text { similarities coupled with }\end{array}$ & $\begin{array}{l}\text { Following Eisenhardt's suggestions, specific dimensions were } \\
\text { selected. Dimensions were identified from the literature. For } \\
\text { example, constructs from agency theory were used (see Appendix }\end{array}$ \\
& $\begin{array}{l}\text { intergroup differences } \\
\text { Select pairs of cases and list } \\
\text { similarities and differences } \\
\text { between each pair }\end{array}$ & $\begin{array}{l}\text { Within these dimensions, similarities and differences between the } \\
\text { projects were searched for. Thereafter, the similarities that were } \\
\text { discovered were listed in one matrix and the differences in another } \\
\text { matrix } \\
\text { The third strategy employed for cross-case analysis was used in } \\
\text { part, and the data was divided by source in the form of 'the }\end{array}$ \\
& $\begin{array}{l}\text { Divide data by data source } \\
\text { informant'. For instance, the data obtained from the supplier was } \\
\text { separated from the informants from the buying firm in the } \\
\text { comparisons }\end{array}$ \\
&
\end{tabular}

Another method that was used to collocate data from a number of cases was to present information in one chart; the unordered meta-matrix (Miles \& Huberman, 1984). This method is similar to the strategy described by Eisenhardt (1989a). By managing to categorise the data, the researcher allows the comparison to become clearer. Therefore, a matrix for the comparison and identification of similarities and differences in the NPD projects was made. Relevant descriptive data was assembled in this way, and from this starting point, it was possible to divide the data into distinct and relevant categories. 
The key variables are connected to the relevant dimensions of comparison and searched for in the data in order to identify similarities and differences. For example, for Paper 4, I used constructs from agency theory. A more elaborate matrix is available in Appendix D, while Table 3-5 provides an example to demonstrate the method that was used. In the table, the analytical dimensions are constructs of control from agency theory (Aulakh \& Gencturk, 2000; Rijsdijk \& van den Ende, 2011). The cases from Ericsson are compared in the table by providing quotations from interviews that align with specific analytical dimensions. In Appendix C, the same method is used as an example of constructs with respect to goal alignment. 
Table 3-5 Case comparison, constructs from agency theory (full table in appendix D)

\begin{tabular}{|c|c|c|c|}
\hline $\begin{array}{l}\text { Analytical } \\
\text { dimensions }\end{array}$ & Ericsson-1 & Ericsson-2 & Ericsson-3 \\
\hline \multirow[t]{2}{*}{$\begin{array}{l}\text { Output control } \\
\text { (monitoring and } \\
\text { evaluation) }\end{array}$} & $\begin{array}{l}\text { From my point of view, we } \\
\text { don't let go of the control. } \\
\text { We enhance it in contracts } \\
\text { and are much tougher than } \\
\text { when we simply buy a }\end{array}$ & $\begin{array}{l}\text { We speak to the suppliers } \\
\text { and give them a } \\
\text { specification. Then we } \\
\text { follow-up. We monitor them } \\
\text { (R\&D Manager } G)\end{array}$ & $\begin{array}{l}\text { We have meetings each week } \\
\text { where we follow-up progress } \\
\text { and view difficulties that we } \\
\text { have. (Project Manager) }\end{array}$ \\
\hline & $\begin{array}{l}\text { product. In that way, it's a } \\
\text { better control, but can we } \\
\text { trust them? (Sourcing } \\
\text { Manager) }\end{array}$ & $\begin{array}{l}\text { We qualify and verify that it } \\
\text { meets our spec (Sourcing } \\
\text { Manager) }\end{array}$ & $\begin{array}{l}\text { Radcomp wants to keep up the } \\
\text { pressure and they do this by } \\
\text { saying that they are looking at } \\
\text { other alternatives. Then we get } \\
\text { a sense of urgency to improve } \\
\text { and do things better (KAM, } \\
\text { Prosup2) }\end{array}$ \\
\hline $\begin{array}{l}\text { Process control } \\
\text { (monitoring and } \\
\text { evaluation) }\end{array}$ & $\begin{array}{l}\text { This is a new concept for } \\
\text { us, we don't buy a product } \\
\text { instead we buy a service, a } \\
\text { capacity to deliver, a } \\
\text { competence, a supply chain } \\
\text { monitoring service. We } \\
\text { need to have a very close } \\
\text { collaboration if it's to work. } \\
\text { We need total transparency } \\
\text { in their supply chain } \\
\text { without controlling them. } \\
\text { We need visibility to make a } \\
\text { contract that pushes them to } \\
\text { perform at a certain level. } \\
\text { It's a difficult balance. } \\
\text { (Supply Manager) }\end{array}$ & $\begin{array}{l}\text { We contact the supplier and } \\
\text { then take the role to } \\
\text { monitor what's going on. } \\
\text { We know what we can or } \\
\text { can't say. We don't want to } \\
\text { reveal our systems to a } \\
\text { supplier. That's how spies } \\
\text { put together a puzzle, so it's } \\
\text { up to us to give them as few } \\
\text { pieces as possible. (R\&D } \\
\text { Manager G) }\end{array}$ & $\begin{array}{l}\text { We monitor what technology } \\
\text { roadmaps the suppliers have. } \\
\text { We know where Prosup } 2 \text { and } \\
\text { the others will be in one year. } \\
\text { (Project Manager) }\end{array}$ \\
\hline \multirow[t]{2}{*}{$\begin{array}{l}\text { Social control } \\
\text { (shared values, } \\
\text { adaptability, } \\
\text { oriented towards } \\
\text { principal's goal) }\end{array}$} & $\begin{array}{l}\text { We learned a lot about how } \\
\text { Radcomp do things and we } \\
\text { try to learn from it, } \\
\text { especially in this project } \\
\text { and we adapt the ways we } \\
\text { do it. (Project Manager B, }\end{array}$ & $\begin{array}{l}\text { They listen a lot to us and } \\
\text { that way they might take the } \\
\text { wrong track. They often do } \\
\text { exactly what we tell them to } \\
\text { and then they make that } \\
\text { solution even if there might }\end{array}$ & $\begin{array}{l}\text { On a higher level there is } \\
\text { collaboration, Technology } \\
\text { Alignment Program, it's a } \\
\text { group of top technical } \\
\text { managers. (R\&D Manager } J)\end{array}$ \\
\hline & Antsup) & $\begin{array}{l}\text { be a better one. They } \\
\text { choose the track we have } \\
\text { pointed to and don't look at } \\
\text { other options (R\&D } \\
\text { Manager } H)\end{array}$ & $\begin{array}{l}\text { At Prosup } 2 \text { there is no need for } \\
\text { consensus. Radcomp on the } \\
\text { other hand has much } \\
\text { consensus in their culture } \\
\text { (KAM, Prosup } 2)\end{array}$ \\
\hline $\begin{array}{l}\text { Clan control } \\
\text { (communication, } \\
\text { form) }\end{array}$ & $\begin{array}{l}\text { We have permanent } \\
\text { meetings with top- } \\
\text { management, where we look } \\
\text { deep into each other. Also } \\
\text { we have everyday } \\
\text { communication, e-mails and } \\
\text { telephone calls. (R\&D } \\
\text { Manager } J, \text { Antsup) }\end{array}$ & $\begin{array}{l}\text { With the suppliers we have } \\
\text { project meetings (Sourcing } \\
\text { Manager) }\end{array}$ & $\begin{array}{l}\text { I can't say that we see a lot of } \\
\text { Prosup2. (R\&D Manager J) }\end{array}$ \\
\hline
\end{tabular}

\subsubsection{Content analysis and categories}

Miles and Huberman (1984) suggest that the researcher should conduct analysis during the data collection phase in order to collect better data and generate reports during the field work. 
As demonstrated in the research design of the present thesis, the analysis was partly made during the same phase as the data collection for the case studies. The analysis procedure must be unambiguous (Paisley, 1969) and this can be difficult to achieve since there is a large volume of text to be analysed. In this analysis, no computer software for structuring or identifying categories was used. Since I was very familiar with the material, the traditional pen-and-paper approach worked well. However, in retrospect, I would have complemented this method by using computer software, because it can facilitate the structuring and labelling of texts.

Content analysis was used to analyse the interview transcripts and additional data. Content analysis is a collection of techniques which enables interpretation of text (Weber, 1996). Its objective is to provide interpretations which investigate possible themes (Deese, 1969). Examples of themes would be: technology selection, supplier selection and purchasing's participation. Furthermore, it is a process that allows for the systematic analyse of textual information from interviews (Kondracki, Wellman, \& Amundson, 2002). My transcripts (text) were classified into content categories in order to structure the data. As an example, the data from ABB-1 was structured into (i) first selection phase, (ii) collaboration with the first supplier, (iii) second selection phase, and (iv) collaboration with the second supplier for Paper 1. This facilitated the analysis of the data. To facilitate comparison between cases, for example, I structured the Ericsson cases in terms of (i) project start, (ii) collaboration, and (iii) industrialization. However, there are disadvantages to this method, since selection and classification limits data. Despite this, the advantages to this approach were considered to outweigh the disadvantages. I did not use computer software to conduct these comparisons; they were done manually.

As Miles and Huberman (1984) argue, data analysis includes selecting and transforming data in an organized way in order to be able to draw conclusions. To find categories, the data was first studied to identify differences and similarities in the material, and then it was structured. A part of the collected data was coded according to classifications, in order to facilitate the identification of different themes. This was done manually, by reading the case description and the transcriptions from the interviews and identifying the relevant units of comparison. These were then transformed into a code. To categorize, I structured text, mostly transcripts from interviews, to make it easier to manage the material. Thus, the large data content was reduced. Categories were developed from both the empirical material and from theory. Theory was thus an important part of the interpretation of the data, because I used several constructs from theory in my analysis. These are displayed in Tables 3-5, 3-6, and 3-7. These examples are analyses that were made for specific papers. The analyses of the Ericsson cases were, in part, performed in collaboration with another researcher, David Rosell. This was useful in the coding phase of the work, since we sometimes interpreted informants differently. We could then return to the data, discuss our different interpretations with each other, and reach a consensus while further develop our understanding of the data (Gioia et al., 2013).

Table 3-6 is an example of several categories that were identified by using agency theory, and were used in an early version of Paper 3 and Paper 4 . The units that were identified in each case are presented in the table, namely 'goal incongruence', 'information asymmetry', and 'technical knowledge'. In this table, these units are embodied in quotations from the interviews. By using direct quotations, it is possible for the researcher to reveal an individual's view of the project, an individual's sense of collaboration, this person's reflections on what happened in the project, and other perceptions (Patton, 2002). In a similar 
fashion, I mapped citations from the purchasing constructs. See Appendix E for an example, where that constructs are adapted from Nijssen, Biemans, \& De Kort (2002).

Table 3-6 Examples of the categories used in early versions of Paper 3 and Paper 4

\begin{tabular}{ll}
\hline Category & Identified unit \\
\hline Goal & ABB-1: Powcom did what it could to save the situation. I think Powsupl's owner realized that \\
incongruence & the structure and strategy that was decided from the beginning didn't work. Powcom did not \\
& fit their strategy. [...JPowcom was too big. They wanted to sell smaller batteries to car \\
& manufacturers. (Manager AI)
\end{tabular}

ABB-2: Powsup3 wanted to design custom-made bearings to each motor. But we wanted to standardize everything and thus said "no" (Manager AK)

Ericsson-1: We found out that Telsup1 and Telcom had a common view on strategy and on $R \& D$ along with our technology roadmaps. (Manager $B H$ )

Ericsson-2: Previously, when they came to us, they said "Here is a component, can you use it?" (Manager BK)

Ericsson-3: I think that Telsup3b wants something from us. I'm talking about knowledge. For them to be able to do [the system] themselves is probably something that is tempting. Today they don't have the right type of processors to do it. (Manager BT)

Information $\quad A B B-1:$ We realized that in order to make progress to reach an end product we had to help asymmetry them. They had a reasonable production but we wanted to develop a battery. That's when we noticed that they did not possess the knowledge and we had to help them. (Manager AI)

Technical knowledge

ABB-1: They (Powsup2) manufacture batteries for space and air transportation industry, which has a broad field of security and processes to handle complex systems. They asked a lot of questions about our design that we did not understand in the beginning. They used terms that we were not familiar with. (Manager AA)

Ericsson-1: In this project we have patents on our bearings but Powcom has patents on the system around it. Some parts are possible to patent while other parts are well known technology. (Manager AN)

As we (Telsup1) never can do radios while Telcom has the understanding (of antennas) (Manager BI)

Ericsson-2: We are driving it (technical development). So we're pushing their technology and our specifications are very tough. (Manager BM)

Ericsson-3: It' not 0 and 1.I't almost a miracle that it works. You can't measure it any longer because it is too fast. (Manager $B Q$ )

Table 3-7 provides examples of analytical categories with respect to 'clan control' (Rijsdijk \& van den Ende, 2011) also adapted from agency theory. However, in this table, the units that were identified are not quotations but information about the project that specifies the unit. This form of analysis was used in Paper 4. 
Table 3-7 Example of categories identified in Paper 4

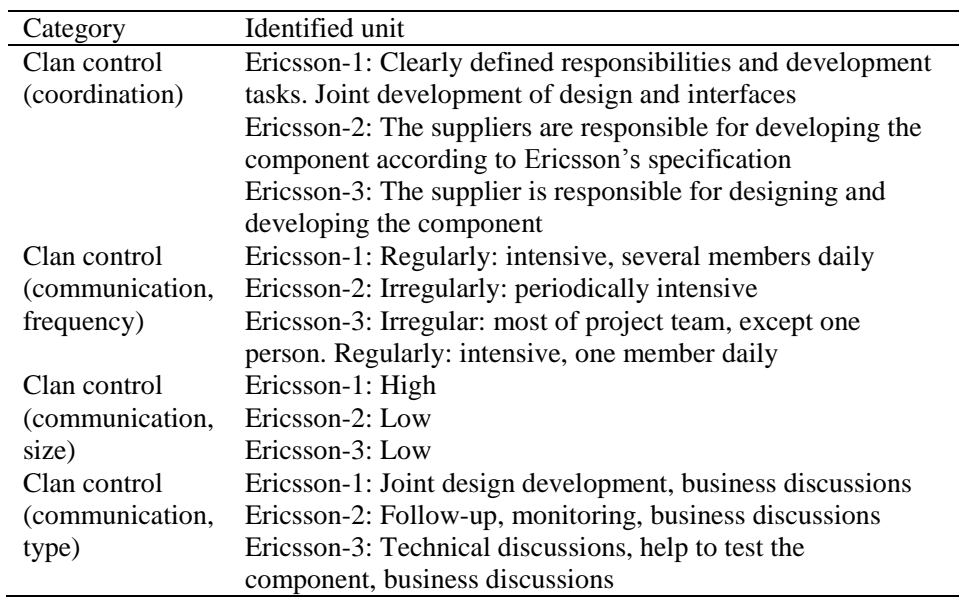

\subsection{Validity and reliability}

\subsubsection{Construct validity}

To perform construct validity is to identify correct operational measurements for the case that is under investigation. To ensure construct validity during data collection, it is important to use multiple sources to gather data, to establish a chain of evidence, and to have key informants review the draft analysis. Yin (2009) identifies this as problematic due to the fact that researchers fail to develop sufficient operational sets of measures. Data triangulation, which is the use of multiple data sources, is recommended during the data collection phase of a study (Eisenhardt, 1989a; Patton, 2002; Riege, 2003; Yin, 2009). By using data triangulation, the researcher can view the same phenomenon via multiple sources of evidence. Triangulation should, at best, support findings by revealing agreement among independent measures and the data collection, or should at least not contradict these independent measures (Miles \& Huberman, 1984). In this thesis, the data triangulation consisted of interviews, taking both the buying firms' and the suppliers' perspectives into account. In addition, data triangulation included workshops that were conducted to verify findings from the one-on-one interviews. Moreover, observations at the factories were made, internal and external documents were perused, and other technical information was collected.

The principle behind 'the chain of evidence' is to allow an external observer to follow the evidence, from research question to research conclusions (Yin, 2009). In this study, key informants were offered the possibility to review the case drafts. However, of these key informants, not all of them commented on the drafts. However, the comments I did receive included the advice to highlight important occurrences during the project. Respondents were given the opportunity to review their interview transcripts. Respondents could edit, comment, clarify, and add information to the transcripts. In addition to this, the workshops were constructed in such a way so as to draw comments from the participants on the findings that were presented at the workshops. Providing results to interviewees is one way for researchers to verify findings (Miles \& Huberman, 1984). To summarize, respondents had the possibility 
to (i) individually reflect on their interview transcripts, (ii) discuss the projects in groups during the workshops, and (iii) comment on case-study reports.

\subsubsection{Internal validity}

Internal validity can be described as something that ascertains whether there is a match between the researcher's observations and the idea that being developed (Bryman \& Bell, 2007). Thus, the researcher must ensure that the conclusions are correctly drawn and that rival explanations have been addressed. As Miles and Huberman (1984 p 278) ask:

Do the findings of the study make sense?

According to Yin (2009), it is difficult to identify a strategy that will ensure internal validity. However, several strategies can be used in the data analysis phase of the study. These include pattern matching, explanation building, addressing rival explanations, and using logic models. In pattern matching, the empirical pattern is compared to a predicted pattern and coinciding patterns can strengthen the internal validity. For instance, according to the literature on supplier operations, purchasing is becoming more strategic (Cousins \& Spekman, 2003). Thus, it was predicted that purchasing's involvement would have a positive influence on the NPD project. In the some of the cases that I studied, it was believed that purchasing had a positive effect on the NPD projects and thus, the pattern coincided. However, with regards to technological uncertainty, it is not obvious that purchasing contributes to the NPD project. On the contrary, purchasing can be perceived as interfering in such projects, because of purchasing's tendency to raise commercial issues during technical discussions.

Explanation building involves an analysis of the case study data and develops an explanation of the case. This explanation can be based on propositions taken from the literature. During the data analysis, I reviewed the relevant literature on the subject and thus could better understand the phenomenon that was under investigation. Examining rival explanations entails defining and testing rival explanations; for example, a rival theory may explain the phenomenon better. A thorough search of the literature for different explanations was conducted, and potential explanations were not dismissed at an early stage. According to Eisenhardt (1989a), examining conflicting literature is important for two reasons:

1) If conflicting literature is ignored, then confidence in the findings is reduced

2) Conflicting literature forces the researcher into creative thinking

Consequently, I reviewed conflicting literature. For example, there are many studies that demonstrate the benefits of supplier involvement in NPD (see Johnsen, 2009). However, there are also studies that find no associated benefits (Eisenhardt \& Tabrizi, 1995). By being aware of this conflict in the literature, it was possible to address various possibilities. My perspective on whether it is beneficial to involve suppliers is somewhat flexible, as I would say that it depends on how you measure benefits. In the literature, benefits have been measured by (i) the speed which a product is introduced to the market, (ii) lowering costs, or (iii) developing more advanced products. Consequently, a supplier's involvement in an NPD project may be beneficial because it speeds up the introduction to the market, but that does not necessarily mean that it will be less costly or be more advanced. I would also acknowledge the fact that there are downsides to collaborating with suppliers in NPD, such as the need for more 
communication, discussions on how to agree on goals, the issue of trust and control, and other aspects that involve collaboration with an external partner. It is has been argued that internal validity can be strengthened if the researcher ties the findings to existing literature (Eisenhardt, 1989a). In this research, results from the case studies have been connected to the literature. Many cause-effect patterns have been used to describe and present the case study data and these have been compared with patterns identified in the literature.

\subsubsection{External validity}

External validity refers to whether or not a study is generalizable to other fields or research areas. Generalization from case studies can be problematic, although, at the same time, case studies can be valuable to understand or explain a phenomenon. Generalization is based on extrapolation. Yin (2009) argues that, even if case studies are not generalizable to populations, they are generalizable to theoretical propositions. Such an analytical generalization links theories to a case study, something that is possible to do with just a few cases (Firestone, 1993). Hillebrand et al. (2001) argue that there exists two approaches to generalize from case studies. The first, more traditional, approach is to predict outcomes for the cases that have been studied by using theory. However, to generalize by using this approach, it is necessary to have a large number of confirming cases. The second approach is to test theory. In this approach, generalization will be on a theoretical basis rather than a statistical basis. The authors define theoretical generalization as:

[D]eclaring the results of case research valid for a larger population on the basis of both structural similarity and logical argumentation. (Hillebrand et al., 2001 p 653)

Normann (1976) claims that whether it is possible to generalize from one or a few cases depends on whether it is possible to reach an understanding of the phenomenon. Merriam (1994) however, reasons that generalization of a case study is pointless since the reason for selecting this method (a case study) is to investigate a phenomenon in-depth in a certain situation, and not to generalize to all possible units. My view is similar. By my choice of method, case studies, I have also chosen not to generalize to a larger population. Instead, I want to conduct an in-depth investigation to better understand collaborative NPD. However, my findings are related to previous empirical findings.

Generalization is often referred to as 'to a larger population', but to what extent is case study research generalizable? It is often argued that case study research cannot be generalized to a larger population. But case studies can be generalized to similar or equal situations because of the very fact that the same type of situation has been studied with consideration given to the same investigated constructs or variables (Hillebrand et al., 2001). Following from this argument, it would be possible to generalize this study to other NPD projects that involve similar situations, and where the same variables are present. However, as argued previously, each NPD project is unique, involving specific suppliers, technologies, and individuals. Thus, to generalize from this study would be difficult, but not impossible. As Hillebrand et al. (2001 p 656) reason:

Generalization based on case research is theoretically possible but often limited in practice. 
In a research design, theory can be used in single case studies and replication can be used in multiple cases to ensure external validity. Case studies can be used to understand a behaviour, if the argument is provided by the explanation of the analysis of the case study and not by the case itself (Nightingale, 2000). Cases may be selected to replicate a previous case or to provide examples of polar types ${ }^{2}$ (Eisenhardt, 1989a). In this study, cases were added sequentially and were replications. The sampling consisted of finding cases by using similar sampling criteria for all cases. By doing this, I aimed to find cases that were comparable, but in this study I did not predict outcomes, because the cases are not as similar as repeated experiments would be.

\subsubsection{Reliability}

Reliability refers to whether it is possible for another researcher to follow the procedures of the first researcher and conduct the same case study again. This means that if a study is reliable, then if a second researcher were to conduct the same study, the second researcher would make the same findings as the first researcher. But because each NPD project is unique it may not be possible to repeat a study of a project and obtain the same findings. However, to ensure that it is hypothetically possible, documents of the procedures that were following during the study are needed. Yin (2009) recommends researchers to use case study protocols and to develop a case study database during the data collection phase of a study. The case study protocol is the researcher's guide in data collection. A case study database contains the researcher's raw data material, and this enables other researchers to study the evidence directly. In the early stages of the present research, a case study protocol which included several phases of the data collection process was prepared. During the case studies, a case study database was created, which included the recorded interviews, transcriptions, notes from the workshops, different documents that were collected, as well as case write-ups.

To summarize, various tests for validity and reliability are presented in Table 3-8 and include the strategies that are recommended in the literature, and the strategies that I used in my case studies.

\footnotetext{
${ }^{2}$ Polar cases would be opposite cases regarding a certain aspect. For example: one case was successful in entering the market while the other case was a failure.
} 
Table 3-8 Tests for validity and reliability

\begin{tabular}{|c|c|c|}
\hline Test & $\begin{array}{l}\text { Recommended } \\
\text { strategies }\end{array}$ & Strategies used \\
\hline \multirow[t]{3}{*}{$\begin{array}{l}\text { Construct } \\
\text { validity }\end{array}$} & $\begin{array}{l}\text { Multiple sources of } \\
\text { evidence }\end{array}$ & $\begin{array}{l}\text { Data triangulation and collection of multiple data from interviews, } \\
\text { internal and external documents, observation and technical information. } \\
\text { Interviews from the buying firms' perspectives and the supplying firms' } \\
\text { perspectives }\end{array}$ \\
\hline & Chain of evidence & Presentation and discussion in the workshops \\
\hline & Draft review & $\begin{array}{l}\text { Key informants were offered the possibility to review drafts of the case } \\
\text { study report. In the Ericsson cases and ABB-3, respondents were sent } \\
\text { their interview transcript for comments and clarification }\end{array}$ \\
\hline \multirow{5}{*}{$\begin{array}{l}\text { Internal } \\
\text { validity }\end{array}$} & Pattern matching & Empirical patterns are compared with predicted patterns \\
\hline & Explanation building & Studies of the relevant literature and explaining propositions \\
\hline & $\begin{array}{l}\text { Address rival } \\
\text { explanations }\end{array}$ & $\begin{array}{l}\text { Searching the literature to find different explanations for the } \\
\text { phenomenon }\end{array}$ \\
\hline & Existing literature & Results were connected to existing literature \\
\hline & Logic models & $\begin{array}{l}\text { Many cause-effect patterns in case descriptions that are compared with } \\
\text { theoretical predicted patterns }\end{array}$ \\
\hline \multirow{4}{*}{$\begin{array}{l}\text { External } \\
\text { validity }\end{array}$} & Use theory & Generalization was aimed towards theory \\
\hline & $\begin{array}{l}\text { Analytical } \\
\text { generalization }\end{array}$ & $\begin{array}{l}\text { Generalization was not aimed towards a general population (of case } \\
\text { studies) but rather towards theory, where explanation carries the } \\
\text { argument and not the case itself }\end{array}$ \\
\hline & Use replication & $\begin{array}{l}\text { Similar sampling criteria for firm-sampling, case-sampling, and } \\
\text { respondent-sampling }\end{array}$ \\
\hline & $\begin{array}{l}\text { Compare evidence } \\
\text { with extant literature }\end{array}$ & I compared my findings with existing research and findings \\
\hline \multirow[t]{4}{*}{ Reliability } & Study protocol & Creation of case study protocols \\
\hline & Record data & $\begin{array}{l}\text { Interviews were recorded and transcribed. Discussions in the workshops } \\
\text { were recorded through my own notes and notes from the participants }\end{array}$ \\
\hline & Case study database & $\begin{array}{l}\text { Raw data was stored in case study databases. Furthermore, case write- } \\
\text { ups are available in these databases as well }\end{array}$ \\
\hline & Peer review & $\begin{array}{l}\text { In parts of the analysis, I had discussions with other academics about the } \\
\text { findings and their implications }\end{array}$ \\
\hline
\end{tabular}

\subsection{Reflections by the researcher}

Reflexivity in the context of qualitative research concerns reflection by the researcher. For example, reflexivity emphasizes the researcher's self-awareness, political and cultural consciousness, and the researcher's own perspectives (Patton, 2002). Moreover, reflection on one's research involves considering the conditions under which the research is performed. For instance, the researcher can reflect on which ways theory, culture, and politics interact with the object of study (Alvesson \& Sköldberg, 2009). Reflection on the research that is being performed takes several aspects into consideration. Additionally, it puts much emphasis on the researcher, since the researcher has to pay attention to several different aspects simultaneously and to how they can affect the study. To be reflexive is to be self-questioning and self-understanding (Patton, 2002). So, how important is reflection when conducting research? Morgan and Smircich (1980) go as far as to claim that there needs to be a reflexive approach in qualitative research in order to understand social research.

However, reflexivity is not only limited to the researcher; it also considers the perspectives of the interviewees and those who take part in the research that is presented. These three 
perspectives (the researcher, respondents, and audience) is known as 'reflexive triangulation' (Patton, 2002).

Considering the respondents in this study, reflection on how they knew what they knew is of interest, i.e. did they know it through experience, had they gained the knowledge from someone else, or what did they base their knowledge on? It was important to understand what had actually happened, what was perceived, and what was learned from hearing stories from other colleagues. Moreover, I considered what may have shaped their worldview, that is to say, how long had they worked at the firm? In what position? What was their status at the firm? and Were they fully adjusted to the firm's culture, and so on? Finally, how they perceived me as a researcher was considered; were they interested in the research? Were they being interviewed voluntarily or because they were told to? Respondents ranged from individuals with an academic research background with genuine interest in research at the university, to individuals with little interest in my research. Several individuals showed interest in taking part in the published material (such as articles and the dissertation). However, not all of the respondents were enthusiastic about participating in the research. One respondent said that he did not want to be interviewed, but his manager forced him to participate in the interview. Thus it can be said with some confidence that the respondents' perceptions of the researcher varied within the projects.

As for the audience, this study included three audiences; the participating firms, additional practitioners that will read the thesis, and the academic audience. First, the reports of findings were made available to the participating firms, both in written form and by conducting workshops. In both instances, the participating firms had the possibility to comment on the material, either through writing or during the workshops, face-to-face. Reflections on how they interpreted the findings were considered. In this case, they could for instance provide insights from other NPD projects and what had happened since the case study was completed. In this forum, how they perceived the researcher was also considered. Similarly, the academic audience, which mostly consisted of audiences at conferences, was considered. On these occasions, additional theoretical perspectives were discussed with fellow academics.

Reflection with respect to the researcher also needs to be considered. Questions around my own knowledge, theories, and perspectives were considered. Moreover, how to present findings, both to the participating firms and to the academic audience was an issue. In the end, the firms received reports and workshops that provided insights into the projects. The firms also had access to several academic papers (i.e. the licentiate thesis). Finally, after finalizing the empirical studies, I have reflected upon what I could have done differently.

\subsection{The research journey through the appended papers}

In order to better understand how the papers in the thesis have been developed, I will provide a brief summary of the contextual representation of each paper, thus describing the journey that lead to this thesis. Figure 3-6 shows which projects were included in which papers. 


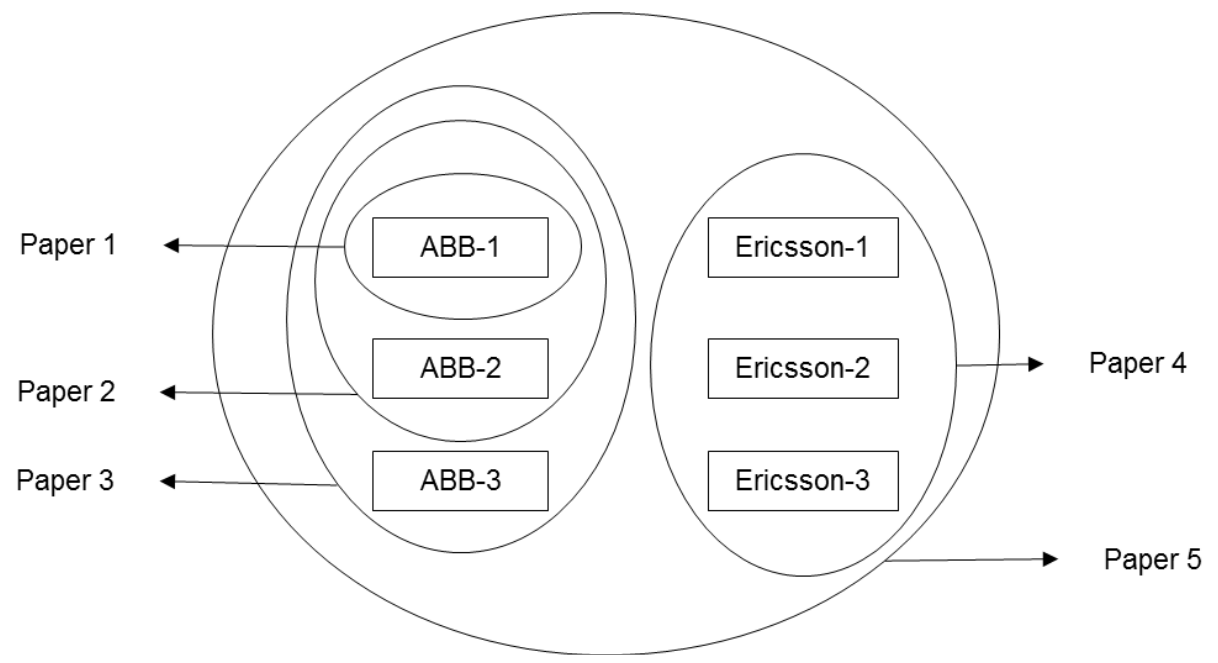

Figure 3-6 Paper development

The choice of case methodology was based on my keen interest in exploring how firms collaborate with suppliers and my interest in gaining in-depth understanding of NPD projects. I conducted literature studies whilst I collected and analysed data. The papers were presented at conferences before being submitted to journals for publication.

My first case study as a PhD student was ABB-1. This case very clearly showed the influence of uncertainty and its influence on supplier selection in NPD. Based on this case study, Fredrik Tell and I wrote the first paper. After having finalized the case study of ABB-1, I searched for another NPD project at ABB and was able to study ABB-2. At this point in my research, I was interested in purchasing's involvement in NPD and compared the two cases. Together with Nicolette Lakemond, I wrote Paper 2. When exploring the role of purchasing in NPD projects, I noted that there were internal issues within the buying firm that could be further explored. Paper 3 was developed after I had terminated my last case study at ABB (ABB-3). In my cross-case analysis, the relationship between purchasing and $R \& D$, and their responsibilities were examined, because they varied among the projects. I had already presented a preliminary discussion about this topic in Paper 2. The literature contains several studies that stress the importance of including purchasing in NPD, however, my case studies with high technological uncertainty showed a different view. In order to analyse the cases, I used TCE theory, since important constructs in that theory are 'uncertainty', 'asset specificity', and 'frequency'. These constructs helped structure the analysis and explain our findings. Paper 3 evolved from ideas that were presented in Paper 2, and, as we worked on this study, our focus evolved into investigating transactional governance and relational governance.

Together with David Rosell, I conducted three case studies at Ericsson (Ericsson-1, Ericsson2, and Ericsson-3). Based on these three cases, we wrote Paper 4 together with Nicolette Lakemond. The focus of this paper is on control and governance of suppliers. The operationalization of the concepts in this paper originates from agency theory, since it adequately describes 'information asymmetry' and the relationship between an agent and a 
principal. Moreover, other important concepts in agency theory, such as 'goal alignment' and 'control' facilitated my understanding of the collaborations that took place at Ericsson.

Finally, I wrote my last paper, Paper 5, on all of the six case studies. This paper scrutinizes how firms select suppliers for their NPD collaborations. In this paper, I discuss the influence of technological uncertainty and how firms perform their selection of technologically competent suppliers. This paper originates from my interest in the conflict in the literature of whether it is more beneficial to collaborate with suppliers that the firm already knows or whether it is more beneficial to broaden the network and collaborate with new suppliers. Since the literature is not in agreement, I found it of interest to explore this venue of research further.

\subsection{Presenting the material}

To present case studies can be challenging, but it can be facilitated by presenting a complete story of the case. According to Eisenhardt and Graebner (2007 p 29):

The story typically consists of narrative that is interspersed with quotations from key informants and other supporting evidence.

In the papers, the empirical data, including quotations, is interwined with theories that are taken from the literature. Paper 1 is based on a single case study, whereas Paper 2 compares the ABB-1 and ABB-2 cases. Paper 3 includes all three ABB cases, while, in Paper 4, the three Ericsson cases are compared. Finally, Paper 5 is based on a comparison of six cases; ABB-1, ABB-2, ABB-3, Ericsson-1, Ericsson-2, and Ericsson-3. An overview of the empirical data pertaining to each paper is shown in Table 3-9.

Table 3-9 Mapping cases and papers

\begin{tabular}{lllllll}
\hline Firm & Project & Paper 1 & Paper 2 & Paper 3 & Paper 4 & Paper 5 \\
\hline ABB & ABB-1 & & & & \\
& ABB-2 & & & & \\
& ABB-3 & & & \\
Ericsson & Ericsson-1 & & & \\
& Ericsson-2 & & & & \\
& Ericsson-3 & & & & \\
\hline
\end{tabular}

The papers in this thesis were presented at several conferences before being submitted to scientific journals. After I received helpful comments at the conferences, the papers were further developed and thereafter submitted to academic journals. Information on the coauthors, conferences, and each paper's journal status can be seen in Table 3-10. 
Table 3-10 Papers, conferences, workshops, and journals

\begin{tabular}{|c|c|c|c|}
\hline Paper & Co-author(s) & Presented at conferences & Journal status \\
\hline Paper 1 & Fredrik Tell & DRUID Winter Conference 2011, Aalborg & $\begin{array}{l}\text { Published in the Journal of } \\
\text { Engineering and } \\
\text { Technology Management, } \\
\text { Vol. 31, No. 1, 2014,103- } \\
119 .\end{array}$ \\
\hline Paper 2 & $\begin{array}{l}\text { Nicolette } \\
\text { Lakemond }\end{array}$ & $\begin{array}{l}\text { R\&D Management Conference 2011, Norrköping; } \\
\text { Continuous Innovation Network (CINet) } \\
\text { Conference 2011, Aarhus; and IPSERA } \\
\text { Conference 2012, Napoli }\end{array}$ & $\begin{array}{l}\text { Published in the } \\
\text { International Journal of } \\
\text { Procurement Management, } \\
\text { Vol. } 7 \text {, No. 1, 2014, 103- } \\
118 .\end{array}$ \\
\hline Paper 3 & $\begin{array}{l}\text { Nicolette } \\
\text { Lakemond }\end{array}$ & $\begin{array}{l}\text { EURAM 2013, Istanbul; CINet Conference 2013, } \\
\text { Nijmegen }\end{array}$ & $\begin{array}{l}\text { Under review (after major } \\
\text { revisions) }\end{array}$ \\
\hline Paper 4 & $\begin{array}{l}\text { David Rosell } \\
\text { and Nicolette } \\
\text { Lakemond }\end{array}$ & $\begin{array}{l}\text { CINet Conference 2012, Rome; Academy of } \\
\text { Management Conference 2013, Orlando }\end{array}$ & Submitted \\
\hline Paper 5 & & $\begin{array}{l}\text { Nordic Workshop on Interorganisational Research } \\
\text { 2012, Trondheim, Nordic Academy of } \\
\text { Management Conference 2013, Reykjavik }\end{array}$ & Under review \\
\hline
\end{tabular}

It should be noted that, in Papers 2, 3, and 5, case ABB-1 is presented as two cases. In these papers, ABB-1 is divided into two projects due to the fact that the NPD project started with one supplier but this collaboration was later terminated. Thereafter, ABB re-started the NPD with a new technology and a new supplier. For this reason, it can be argued that this case included two projects, since the NPD had two distinct phases: phase 1 with supplier A and technology A, and phase 2 with technology B and supplier B. Moreover, ABB had to start the NPD almost from the beginning after terminating the collaboration with supplier A due to the change of technology and supplier. However, in Paper 1 and in the compiled summary ABB-1 is viewed as one case, despite the fact that it is presented in Papers 2, 3, and 5 as two distinct projects/cases.

\subsection{My contributions to the papers}

Paper 1 I wrote together with Fredrik Tell. For this paper, I made major contributions in terms of data collection and analysis. I did most of the writing on the methodological and empirical sections. Fredrik wrote most of the analysis section, and we contributed equally to the introduction, theoretical section, and conclusions.

Paper 2 was written in collaboration with Nicolette Lakemond. Here, I was the exclusive contributor for data collection and analysis. I made major contributions to the methodological and empirical sections. Nicolette made major contributions in the theoretical section. We contributed equally to the introduction, analysis, and conclusion sections.

Paper 3 was developed in collaboration with Nicolette Lakemond. I was the exclusive contributor for data collection and analysis. I made major contributions to the methodological and empirical sections. We contributed equally to the writing of the other parts of the paper.

Paper 4 was written in collaboration with David Rosell and Nicolette Lakemond. Here, David and I conducted the data collection together. I was responsible for the analysis of the cases 
and overall development of the paper. David and Nicolette took part in discussing ideas and framing of the paper.

Paper 5 I was the exclusive author of Paper 5. Part of the data collection was done in collaboration with David Rosell. 


\section{CHAPTER 4}

At least I have got a grip on the essential facts of the case. I shall enumerate them to you, for nothing clears a case so much as stating it to another person, and I can hardly expect your co-operation if I do not show you the position from which we start.

(Sherlock Holmes to Dr Watson in The Memoirs of Sherlock Holmes: Silver Blaze) 


\section{PAPER SUMMARY}

This chapter summarizes the main contributions to the field that are made by the five papers. The papers are available in their complete versions in Part II of this thesis. Table 4-1 presents the area(s) that the papers study and their relation to the research questions that are posed in the thesis. The findings presented in this chapter form the groundwork for the final discussion and conclusions, which are presented in the next chapter.

Table 4-1 Brief paper overview

\begin{tabular}{|c|c|c|c|}
\hline Paper & Area(s) studied & RQ addressed & Focus \\
\hline 1 & Supplier selection & RQ 1 & Supplier selection under uncertainty \\
\hline 2 & $\begin{array}{l}\text { Intra-firm relationships and } \\
\text { supplier selection }\end{array}$ & RQ 1,3 & $\begin{array}{l}\text { Purchasing's role in NPD projects and in } \\
\text { supplier selection }\end{array}$ \\
\hline 3 & $\begin{array}{l}\text { Inter-firm and intra-firm } \\
\text { relationships }\end{array}$ & RQ 2, 3 & $\begin{array}{l}\text { Transactional and relational governance of } \\
\text { suppliers }\end{array}$ \\
\hline 4 & Inter-firm relationship & RQ 2 & Control of suppliers \\
\hline 5 & Supplier selection & RQ 1 & How suppliers are selected in NPD \\
\hline
\end{tabular}

Paper 1 and Paper 5 focus on how firms select suppliers to include in NPD projects. In particular, the papers investigate the effects of technological uncertainty in the process of how suppliers are selected. Paper 2 contributes to the discussion of supplier selection under technological uncertainty by studying the role of purchasing during supplier selection for NPD projects under technological uncertainty. Papers 1, 2, and 5 contribute to answering the first research question in this thesis, which focuses on supplier selection.

The second research question, which focuses on supplier collaboration, is answered by Paper 3 and Paper 4. In Paper 3, governance of collaborative NPD projects under technological uncertainty is studied. Paper 4 shows how firms struggle with having control of powerful suppliers in NPD projects. In such projects, suppliers have more knowledge of the new technology and thus there is high information asymmetry between the buying firm and the supplier. In this form of collaboration, the buying firm strives to control the supplier, demonstrating an important aspect of the buyer-supplier collaboration relationship under technological uncertainty.

Finally, the third research question, concerning coordination of R\&D and purchasing departments in NPD projects under technological uncertainty, is answered by Paper 2 and Paper 3. Paper 2 focuses on purchasing's role in NPD projects, specifically in the technology selection and supplier selection phase. Paper 3 describes how responsibilities are divided during NPD projects involving suppliers. This paper shows that R\&D and purchasing have clearly distinct responsibilities in projects with technological uncertainty. 


\subsection{Paper 1}

\section{Uncertainty and supplier selection in collaborative NPD projects: a case study}

Paper 1 analyses uncertainties in supplier selection for NPD projects. The selection of suppliers for NPD collaboration involves a number of uncertainties with respect to the supplier and the technology that is to be adopted. The paper examines how different types of uncertainty affect technology selection and supplier selection. Moreover, the paper discusses how uncertainties influence selection outcomes, in terms of flexibility or commitment to suppliers.

This paper reports on a case study of a collaborative NPD project. The NPD project was conducted by the firm with the aim to develop an energy storage unit for integration in advanced power grid applications. The case is used to illustrate a number of uncertainties related to the supplier selection, (Siggelkow, 2007) but not to make a generalization concerning these uncertainties. By using the TCOS framework developed by Hall et al. (2011), the paper analyses technological, organizational, and commercial uncertainties.

While previous studies have indicated that uncertainty in buyer-supplier collaborations calls for a joint co-design process and commitment to the relationship (Spina, Verganti, \& Zotteri, 2002), the paper shows that firms need a measure of flexibility in uncertain situations. There exists a tension between supplier flexibility and supplier commitment, due to uncertainty in collaborative NPD. The paper discusses uncertainty as a precondition for the execution of collaborative NPD, and suggests that uncertainty can be classified according to Hall et al. (2011) and Hall and Martin (2005), as 'technological uncertainty', 'commercial uncertainty', and 'organizational uncertainty'. Once the case study was completed, a number of problems related to each uncertainty were identified (table 4-2).

Table 4-2 Problems related to type of uncertainty

\begin{tabular}{ll}
\hline Type of uncertainty & Problem \\
\hline Technological uncertainty & Techno-paradigmatic \\
& Technological complexity \\
Organizational uncertainty & Intra-organizational fit \\
& Inter-organizational fit \\
Commercial uncertainty & Buyer composition \\
& Supplier appropriation of technology \\
& Anticipated future vertical scope of supplier \\
& Cost development \\
\hline
\end{tabular}

Based on our study that is presented in Paper 1, we propose that technological uncertainty may require that the firm be flexible and not commit to one particular supplier or technology in order to be able to quickly change technology if another technology proves to be superior to the technology currently under consideration. This finding is similar to another recent study, which shows that firms use flexible and open-ended contracts as a way to manage technological uncertainty (Bhattacharya et al., 2013). Commercial uncertainty, on the other hand, may also imply a need for flexibility due to cost, appropriation, competition, and leakage parameters. Despite current arguments that can be found in the literature on the 
importance of commitment to key suppliers, such commitment may be limited by both technological uncertainty, as well as commercial uncertainty.

In line with previous research, our study shows the importance of managing organizational uncertainty, including both intra-organizational and inter-organizational fits. With regard to the intra-organizational fit, we find that the individual project should contribute to the firm's long-term objectives (Wheelwright, 1992). Our study indicates that problems pertaining to the inter-organizational fit were not considered at the beginning of the NPD project that was examined, but note that the first supplier collaboration had to be aborted later. This was partly due to organizational non-compatibility, but also due to the changed production strategy of the supplier. Our findings confirm other studies that point to the importance of organizational fit (Hoegl \& Wagner, 2005; Petersen et al., 2005; Lakemond et al., 2006) and capability fit (McCarthy, Silvestre, \& Kietzmann, 2013) between the partners in NPD. In addition, our discussion of what is to be considered in the context of uncertainty contributes to current research on alignment (Emden et al., 2006), where technological-, organizational-, and commercial uncertainties in supplier selection are important factors with respect to successful technological-, strategic-, and relational alignment.

Figure 4-1 illustrates Paper 1's contribution to the study. The paper contributes to an understanding of supplier selection under technological uncertainty.

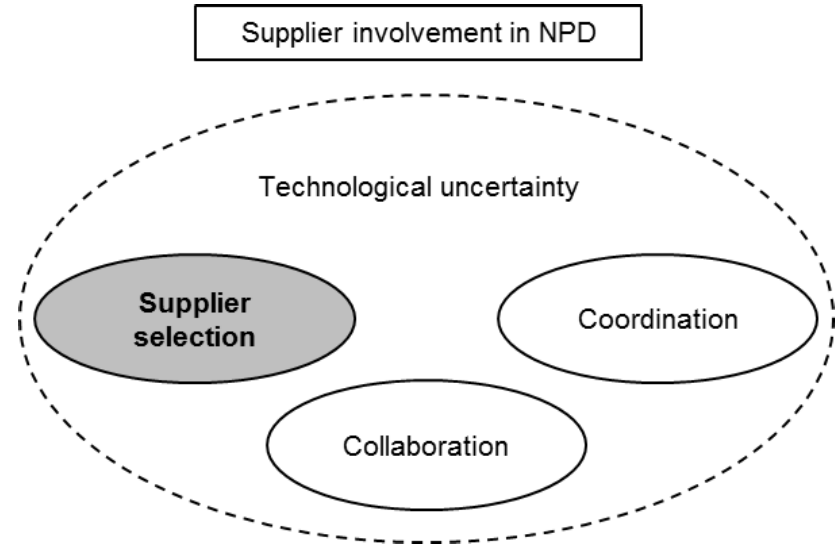

Figure 4-1 Paper 1's contribution to the study

\subsection{Paper 2}

\section{Variation of purchasing's involvement: case studies of supplier collaborations in new product development}

Paper 2 investigates purchasing's role in NPD projects under technology uncertainty where external suppliers provide technology to the projects. In such projects, a firm needs to make important decisions before a supplier is included in the project. These decisions include the selection of technology and the selection of a supplier of this technology. The purpose of paper 2 is to explore purchasing's role in technology selection, supplier selection, and its level of participation in NPD projects involving suppliers. 
In this paper, three projects were studied. The projects belonged to the same firm. To learn about purchasing's involvement in these projects, we interviewed NPD project members, strategic purchasers, and managers who were in a position to make decisions about the NPD projects. We found that the level of involvement with respect to the purchasing department varied across the three projects.

The results of our study show that purchasing has limited influence in the technology selection process; it was not involved in any of the projects' technology evaluation and selection processes. However, purchasing fulfils an important role in the selection of the supplier. In two of the projects, purchasing participated in the selection of the supplier. During the project, we found that purchasing took on the role of a trouble-shooter. We conclude that purchasing does not necessarily need to be involved in solving daily, routine problems only, but can serve as a trouble-shooter to solve problems related to the supplier's strategy, the relationship with the supplier, and commitment issues.

Similar to McDermott \& Handfield (2000), we found that engineers are responsible for selecting the technology and that purchasing is not involved in that process. Paper 2 thus supports previous findings that show how purchasing contributes in the supplier selection in NPD (McGinnis \& Vallopra, 1999; Schiele, 2006). Table 4-3 provides a summary of the projects.

Table 4-3 Variation in purchasing's role in the NPD projects

\begin{tabular}{lllll}
\hline Project & Technology selection & Supplier selection & Team member & Role in project \\
\hline Alpha & $\begin{array}{l}\text { No participation from } \\
\text { purchasing. Selection made } \\
\text { by project team }\end{array}$ & $\begin{array}{l}\text { No participation from } \\
\text { purchasing. Only one } \\
\text { supplier provided the } \\
\text { selected technology }\end{array}$ & $\begin{array}{l}\text { Purchasing was } \\
\text { not a member of } \\
\text { the NPD team }\end{array}$ & $\begin{array}{l}\text { Purchasing was involved } \\
\text { in the NPD project as a } \\
\text { trouble-shooter }\end{array}$ \\
Beta & $\begin{array}{l}\text { No participation from } \\
\text { purchasing. Selection made } \\
\text { by project team }\end{array}$ & $\begin{array}{l}\text { Purchasing selected } \\
\text { the most suitable }\end{array}$ & $\begin{array}{l}\text { Purchasing was } \\
\text { not a member of } \\
\text { the NPD team }\end{array}$ & $\begin{array}{l}\text { Purchasing was involved } \\
\text { in the NPD project as a } \\
\text { trouble-shooter }\end{array}$ \\
Gamma & $\begin{array}{l}\text { No participation from } \\
\text { purchasing. Selection made } \\
\text { by the R\&D department in } \\
\text { consultation with an external } \\
\text { expert }\end{array}$ & $\begin{array}{l}\text { Purchasing and the } \\
\text { R\&D department } \\
\text { selected the supplier } \\
\text { together }\end{array}$ & $\begin{array}{l}\text { Purchasing was } \\
\text { a member of the } \\
\text { NPD team }\end{array}$ & $\begin{array}{l}\text { Purchasing was involved } \\
\text { continuously in the NPD } \\
\text { project as a team } \\
\text { member }\end{array}$ \\
& & & & \\
\hline
\end{tabular}

To conclude, Paper 2 demonstrates that purchasing's role in NPD projects under technological uncertainty is limited. Purchasing is not involved in the technology selection process, but does have an important role as a contributor in the supplier selection process. During the other parts of the NPD project, purchasing's role was to solve strategic issues that arose between the buying firm and its suppliers. Problems that were deal with by purchasing included (i) a lack of commitment and interest from the supplier, (ii) conflicts where the supplier has changed its strategy, and (iii) conflicts regarding the cost of the technology. To solve these problems, purchasing can, but does not necessarily have to, be a member of the NPD project. 
Figure 4-2 illustrates Paper 2's contribution to the study. The paper contributes to an understanding of intra-firm coordination under technological uncertainty. More specifically, the paper discusses the coordination between the purchasing department and the R\&D department at the buying firm.

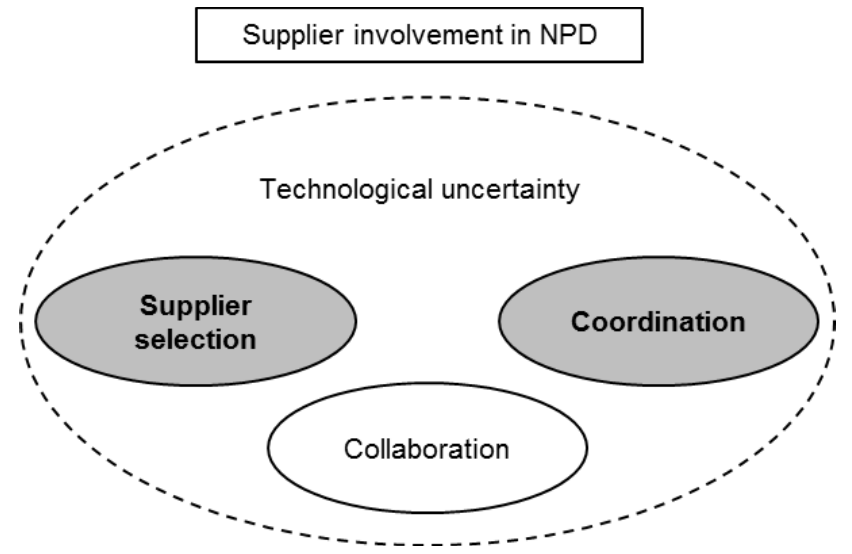

Figure 4-2 Paper 2's contribution to the study

\subsection{Paper 3}

\section{Organizational separation of technologically uncertain NPD projects involving suppliers}

Increasingly, firms are searching for new technologies from suppliers through collaborative NPD projects. In order to actually achieve the benefits from collaborating with suppliers, governance of the buyer-supplier relationship becomes crucial. From a transaction cost economics (TCE) perspective, contracts are proposed as the primary mechanism to craft governance arrangements (Jagdev \& Thoben, 2001). Frequently, trust, shared goals, and repeated transactions are proposed to substitute for contractual arrangements. These relational governance mechanisms and transactional, contract-based mechanisms, can be used separately or as a complement to each other (Blomqvist et al., 2005; Liu et al., 2009). Under circumstances of technological uncertainty, the importance of relational governance increases (Zhou, Poppo, \& Yang, 2008). Consequently, transactional and relational governance both play an important role, but it is not evident how firms achieve complementarity of the two. Our study of technologically uncertain NPD projects reveals that organizational separation is used as a way to achieve complementarity of relational and transactional governance.

It has been claimed that purchasing fulfils an important role in supplier involvement in NPD projects alongside the R\&D department (Dowlatshahi, 1998; van Echtelt et al., 2007). In inter-organizational collaborations, it has been argued that purchasers become relationship managers (Walter, 2003), suggesting that purchasing also takes on a 'relationship governing' role. Empirical evidence to what extent R\&D engineers and purchasers take on responsibility for relational and transactional governance, and how firms organize themselves to achieve the benefits of their complementary use in projects with technological uncertainty is lacking however. 
Paper 3 is based on four NPD projects, where TCE constructs were used in the analysis. Table 4-4 provides information on how the responsibilities were divided in each NPD project that was studied.

Table 4-4 Findings on organizational separation

\begin{tabular}{|c|c|c|c|c|}
\hline & Battery project & Storage project & Cable project & Hybrid project \\
\hline \multicolumn{5}{|c|}{$\begin{array}{l}\text { Transactional } \\
\text { mechanisms }\end{array}$} \\
\hline Contracts & $\begin{array}{l}\text { R\&D and purchasing: } \\
\text { project manager and } \\
\text { purchasing manager }\end{array}$ & $\begin{array}{l}\text { Purchasing } \\
\text { manager }\end{array}$ & $\begin{array}{l}\text { R\&D: steering } \\
\text { committee }\end{array}$ & Purchasing manager \\
\hline $\begin{array}{l}\text { Patent } \\
\text { discussions }\end{array}$ & R\&D: project manager & $\begin{array}{l}\text { Purchasing } \\
\text { manager }\end{array}$ & $\begin{array}{l}\text { R\&D: steering } \\
\text { committee }\end{array}$ & $\begin{array}{l}\text { R\&D and purchasing: } \\
\text { project team }\end{array}$ \\
\hline $\begin{array}{l}\text { Specific } \\
\text { investments }\end{array}$ & R\&D: project manager & $\begin{array}{l}\text { R\&D: project } \\
\text { manager }\end{array}$ & $\begin{array}{l}\text { R\&D: steering } \\
\text { committee }\end{array}$ & $\begin{array}{l}\text { R\&D and purchasing } \\
\text { manager: project team }\end{array}$ \\
\hline \multicolumn{5}{|l|}{$\begin{array}{l}\text { Relational } \\
\text { mechanisms }\end{array}$} \\
\hline Trust & $\begin{array}{l}\text { R\&D: project manager } \\
\text { and to some extent the } \\
\text { project team }\end{array}$ & $\begin{array}{l}\mathrm{R} \& \mathrm{D} \text { : project } \\
\text { team }\end{array}$ & $\begin{array}{l}\text { R\&D: steering } \\
\text { committee and } \\
\text { project team }\end{array}$ & $\begin{array}{l}\text { R\&D and purchasing: } \\
\text { project team }\end{array}$ \\
\hline $\begin{array}{l}\text { Goal } \\
\text { alignment }\end{array}$ & R\&D: project manager & $\begin{array}{l}\text { R\&D: project } \\
\text { manager }\end{array}$ & $\begin{array}{l}\text { R\&D: steering } \\
\text { committee and } \\
\text { project team }\end{array}$ & \\
\hline $\begin{array}{l}\text { Relational } \\
\text { norms }\end{array}$ & R\&D: project manager & $\begin{array}{l}\text { R\&D: project } \\
\text { manager }\end{array}$ & $\begin{array}{l}\text { R\&D: steering } \\
\text { committee and } \\
\text { project team }\end{array}$ & R\&D and purchasing \\
\hline $\begin{array}{l}\text { Frequent } \\
\text { transactions }\end{array}$ & No previous transactions & $\mathrm{R} \& \mathrm{D}$ & $\mathrm{R} \& \mathrm{D}$ & R\&D and purchasing \\
\hline
\end{tabular}

The study stresses that, although transactional and relational governance are complementary mechanisms, they are implemented in separate, but parallel processes in order to avoid distortion of relational rents. While R\&D engineers fulfil an important role in relational governance in technological uncertain NPD projects, purchasing fulfils transactional governance tasks and is placed outside the NPD project. The study questions some of the literature that argues that purchasing fulfils an ever more important role as relationship managers in NPD.

Our findings support previous findings which claim that transactional and relational governance are used as complementary modes (Poppo \& Zenger, 2002; Blomqvist et al., 2005), and show clear indications that organizational separation of governance issues is used particularly for projects with high asset specificity and high technological uncertainty. Transactional mechanisms, such as contracts, commercial agreements, and patent discussions can be enabled by an actor outside the project organization, as a way to avoid distrust, as suggested by Jap and Ganesan (2000), and as a way to avoid distortion of relational rents. Organizational separation allows project teams to focus on technological issues and not be involved in transactional discussions. In contrast to previous studies, which have pointed to purchasing as having an increasing role in coordinating cross-functional responsibilities in NPD (McGinnis \& Vallopra, 1999; van Echtelt et al., 2008; Schiele, 2010), our study shows that purchasing enables transactional governance but not necessarily relational governance with suppliers, at least in situations of technological uncertainty. Previous studies have also indicated that the dynamics of purchasing and supplier involvement are different for NPD 
projects that are characterized by a high degree of technological uncertainty (Oh \& Rhee, 2010).

Similar to the findings of Tassabehji and Moorhouse (2008), purchasing was considered to be strategic at the studied firm, but the R\&D organization did not always view purchasing as such. It seems that in projects with a high degree of technological uncertainty, the relational rents are fragile entities, and are managed separately from transactional issues. This represents a classical organizational dilemma; organizational separation increases the number of possibilities to benefit from specialization, but also creates challenges related to integration between functions in the organization (Lawrence \& Lorsch, 1967). Our study provides clear indications that the dynamics of differentiation and integration are different, depending on the degree of technological uncertainty. However, more specifically, our study indicates that, for NPD projects with high asset specificity and high technological uncertainty, relational mechanisms such as trust, goal alignment, relational norms, and previous transactions are enabled by the R\&D organization, and not through purchasing.

Figure 4-3 illustrates Paper 3's contribution to the study. The paper contributes to an understanding of intra-firm coordination under technological uncertainty. The paper discusses the organizational separation of transactional and relational governance of suppliers involved in NPD projects.

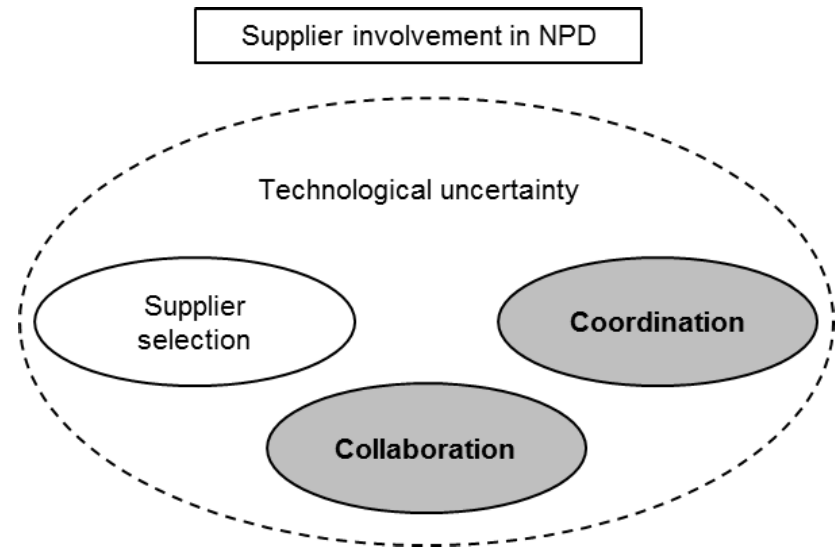

Figure 4-3 Paper 3's contribution to the study

\subsection{Paper 4}

\section{In pursuit of control: involving suppliers of critical technologies in new product development}

Paper 4 investigates how a firm collaborates with technology suppliers by exploring the dynamics of management and control in collaborations with suppliers of critical technology. Agency theory has been proposed as a useful perspective from which to study the problems related to principle-agent structures (Eisenhardt 1989). Agency problems involve issues such as goal alignment (Eisenhardt 1989), different forms of controlling the agent, through monitoring (Rijsdijk and van den Ende 2011), contracts, and trust (Blomqvist et al. 2005). 
Problems related to principal-agent structures are particularly prevalent when technology suppliers are involved. As these suppliers provide specialized or unique resources to a buying firm (Nair et al. 2011), and buying firms have only limited knowledge regarding these technologies, it is not always possible to control the activities of the suppliers. Buying firms may, however, be inclined to be in control as technology suppliers provide critical technologies to the NPD project. Gaining control in these situations can be a challenging task.

It has been suggested that efforts on a strategic level can complement and facilitate the control of supplier activities on an NPD project level. Top management support has been found to be an important success factor in supplier involvement in NPD (Ragatz et al. 1997a), which can facilitate alignment of the firms' interests on a strategic level (Johnsen et al. 2009). Technology roadmaps can be used as important tools to connect innovation strategies with sourcing strategies (Schiele 2010). They provide a long-term vision to help firms with strategic decisions (Phaal et al. 2004) and can be used as a tool for communicating technology, product and market perspectives.

When possible, managers prefer to achieve control by having a dominant position in a joint decision-making process (Kim and Oh 2005). In collaborations with technology suppliers, however, buying firms may not necessarily have a dominant position. Consequently, they may pursue control in different ways, by making use of the project level as well as the strategic level. Contracts and monitoring in NPD can be regarded as project level control mechanisms, as they are usually related to specific NPD projects. Technology roadmaps concern long-term perspectives on technology development and are consequently strategic control mechanisms. Trust and goal alignment can be established on a project as well as a strategic level between the decision makers at the respective firms. This is supported by studies that indicate that transfer of information facilitates the development of trust in the supply chain (Pérez and Sánchez 2001). Control may thus be pursued on different levels as well as through different mechanisms. This is summarized in Figure 4-4, which provides an overview of the concepts used in this paper.

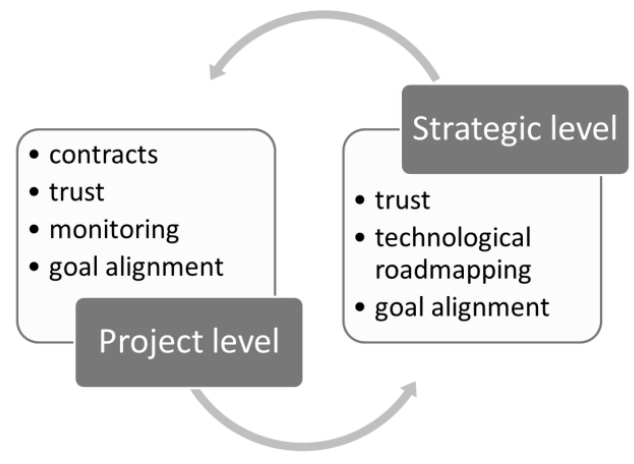

Figure 4-4 Control on a project and strategic level

Data collection relied mainly on interviews, but additional secondary data was gathered from project documents, company policies, and general company and branch information. Respondents were individuals who were directly involved in the projects. Hence, knowledgeable informants who view the phenomenon from diverse competencies were 
interviewed (Eisenhardt and Graebner 2007). Individuals with similar functional responsibilities were interviewed in all the projects. These included project managers, $R \& D$ managers, sourcing and supply managers, and strategic product managers. In total, 22 interviews were conducted, with each interview lasting between 45 and 90 minutes.

Our results show that the collaboration with suppliers of critical technologies in NPD projects represents a complex situation of simultaneous high dependency, information asymmetry and consequentially limited possibilities to achieve control. In pursuit of control, firms may complement output control with process control, use black box and disconnected development in combination with regular joint problem solving, use contracts and trust simultaneously, and perform alignment efforts on project as well as on strategic levels. In addition, the study points to the importance of technological roadmaps as a mechanism not only on a strategic level but also on project level (cf. van Echtelt et al. 2008). In the pursuit of control, firms need to consider several possible dilemmas. First, the use of process monitoring can increase control, but too much monitoring can limit the supplier's level of freedom. The study shows that process monitoring can influence creativity, where our finding is supported by previous studies (Carson 2007). Second, control needs to be balanced with trust, an important prerequisite in all three projects in our study and also supported by evidence in previous research (Blomqvist et al. 2005).

Figure 4-5 illustrates Paper 4's contribution to the study. The paper contributes to an understanding of inter-firm coordination under technological uncertainty. The collaboration between a buying firm and its suppliers is investigated, with focus on the buying firm needs to take into consideration in the pursuit of controlling suppliers.

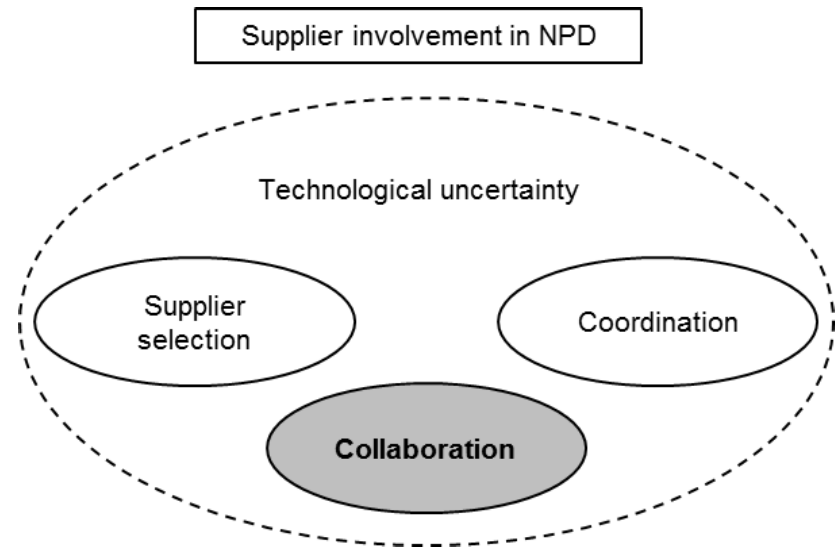

Figure 4-5 Paper 4's contribution to the study 


\subsection{Paper 5}

\section{To evaluate or to use past experience? Collecting information for supplier selection under technological uncertainty in new product development projects}

There has been extensive research into supplier involvement in NPD. Many studies have been conducted to investigate the effect of technological uncertainty on supplier involvement in NPD (Johnsen, 2009). Different degrees of technological uncertainty, ranging from low uncertainty to high uncertainty, influence the supplier capabilities that firms prefer (Wasti \& Liker, 1999). When searching for suppliers, the buying firm needs to collect information about potential suppliers. When buying firms collect information, there is a risk of adverse selection, because suppliers can provide information that is not completely accurate.

This paper aims to investigate how firms evaluate and select suppliers for collaborative NPD under different levels of technological uncertainty. In particular, the paper focuses on how firms manage information asymmetry in supplier selection for NPD projects. The research question that is investigated is: How do firms collect information about suppliers and their capabilities under technological uncertainty? The paper reports on a study of supplier selection in seven NPD projects at two system integrators; four projects with a high level of technological uncertainty and three projects with a low level of technological uncertainty. In total, 53 interviews, and two workshops were conducted to collect data.

The paper shows that firms evaluate suppliers on the basis of two distinct evaluations. First, firms collect information about the current situation of the supplier. Secondly, they evaluate suppliers on the basis of the firms' previous collaborations with the suppliers. These two forms of evaluation complement each other and the firms in the study applied both evaluations when it was possible to do so. Figure 4-6 provides an overview of how the buying firms managed uncertainty, which method they used, from where they got the necessary information and, finally, what they actually assessed in the supplier selection. 


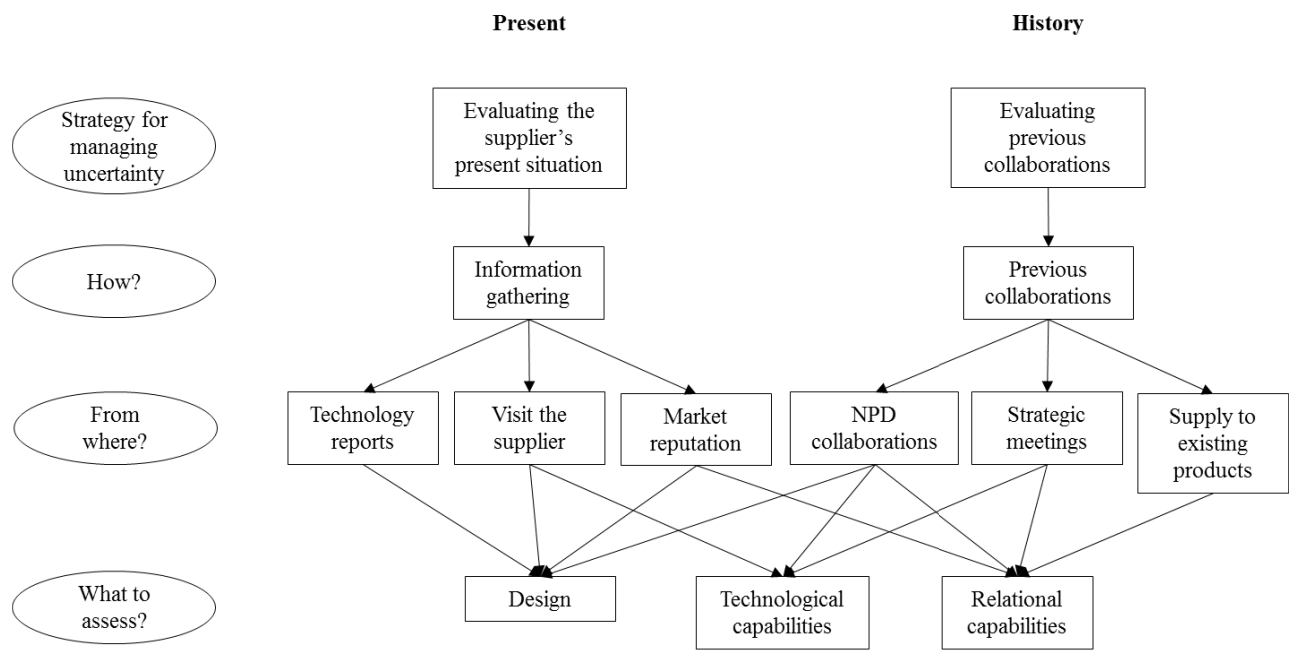

Figure 4-6 Strategies for managing technological uncertainty

The findings of our study concern situations of low and high technological uncertainty, in which the firms that were studied made supplier selections for collaborative NPD projects. The main contribution of this paper is a model that can be used to describe how firms manage technological uncertainty in the supplier selection by evaluating the suppliers' current situation, as well as their earlier collaborations with the firm. Several authors stress the importance of making a careful assessment of suppliers before one is selected for NPD projects (Hoegl \& Wagner, 2005; Petersen et al., 2005; Handfield \& Lawson, 2007; Un et al., 2010). In order to evaluate the current situation of different suppliers, firms collect information from technology reports, from visiting them, and investigating the suppliers' reputations. In this way, the design of the product/component, the supplier's technological capabilities, and relational capabilities are assessed. These observations support the claim that supplier's individual capabilities as well as collaborative capabilities should be assessed (Feng et al., 2010). By evaluating their prior history, firms scrutinise previous collaborations with the suppliers'. These include collaborations that were not limited to NPD but also include previous strategic meetings and the supply of existing products. By collecting this information, firms can assess the suppliers' design, technological capabilities, and relational capabilities. The two strategies for evaluating suppliers complement each other.

An additional contribution of this paper is the observation that technological capabilities were found to be an important criterion in the assessment of suppliers, in projects with both low and high technological uncertainty. This study thus confirms the importance of the supplier's design (Rundquist \& Halila, 2010), as well as the supplier's technological capabilities under conditions of technological uncertainty (Wasti \& Liker, 1999). It seems that technological capabilities are important in development projects, whatever the degree of technological uncertainty. With regard to relational capabilities, these were found to be more important in the projects with high technological uncertainty than in the projects with low technological uncertainty. This finding supports Tyler's (2001) suggestion that relational capabilities are important in NPD with high technological uncertainty. 
While some authors indicate that, under technological uncertainty, familiar suppliers are not involved in product development (Wasti \& Liker, 1999), others point to the fact that firms select suppliers with whom they are familiar, and with whom they have a prior history (Lorenzoni \& Lipparini, 1999; Hoetker, 2005). This study supports the claim that firms tend to select suppliers who they are familiar with. No difference was found between projects with low or high technological uncertainty. An advantage from having collaborated previously is that it becomes easier for the buying firms to evaluate the supplier's capabilities. However, other studies point to disadvantages of collaborating with a former partner, due to the fact that certain influences (mental models) of the previous project might hamper creativity and innovation in the new project (Skilton \& Dooley, 2010).

Figure 4-7 illustrates Paper 5's contribution to the study. The paper contributes to an understanding of supplier selection under technological uncertainty. The paper discusses two approaches which can be used to deal with uncertainty in the supplier selection: (i) evaluate suppliers based on the present situation, or (ii) evaluate suppliers based on previous collaborations.

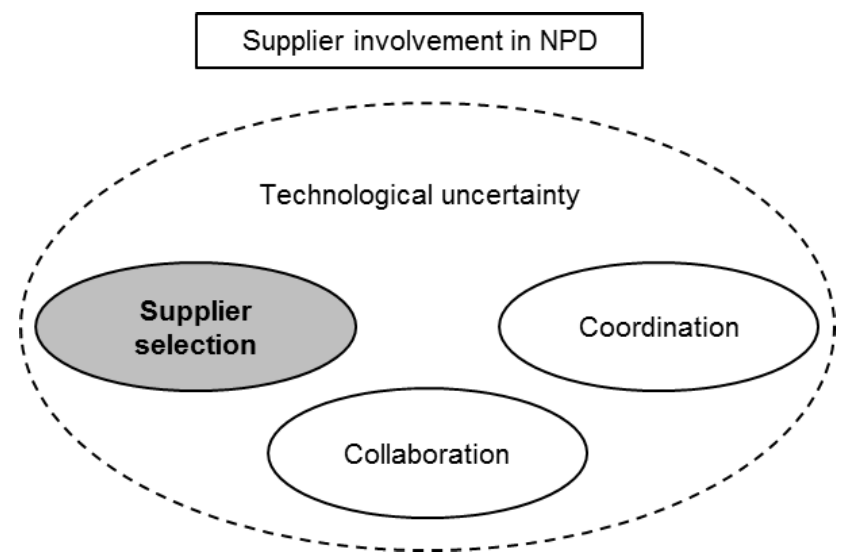

Figure 4-7 Paper 5's contribution to the study 


\section{CHAPTER 5}

Is there any point to which you would wish to draw my attention?

To the curious incident of the dog in the night-time.

The dog did nothing in the night-time.

That was the curious incident, remarked Sherlock Holmes.

(Dr Watson and Sherlock Holmes in The Memoirs of Sherlock Holmes: Silver Blaze) 


\section{DISCUSSION AND CONCLUSIONS}

This chapter answers the research questions that are posed in this thesis by discussing three different areas of interest: supplier selection, supplier collaboration, and internal coordination. Findings from each area that was studied, which are related to the three research questions, are also discussed. It is noted that the three areas, supplier selection, supplier collaboration, and internal coordination are related, and is discussed in the section below, on reflections on the study.

\subsection{Selection, collaboration and coordination}

In this section, challenges that are related to supplier selection, supplier collaboration, and internal coordination are presented respectively (see Figure 5-1). The research questions are answered. First, RQ1 regarding supplier selection is answered. Thereafter, RQ2 concerning collaboration, and finally RQ3 involving coordination are discussed.

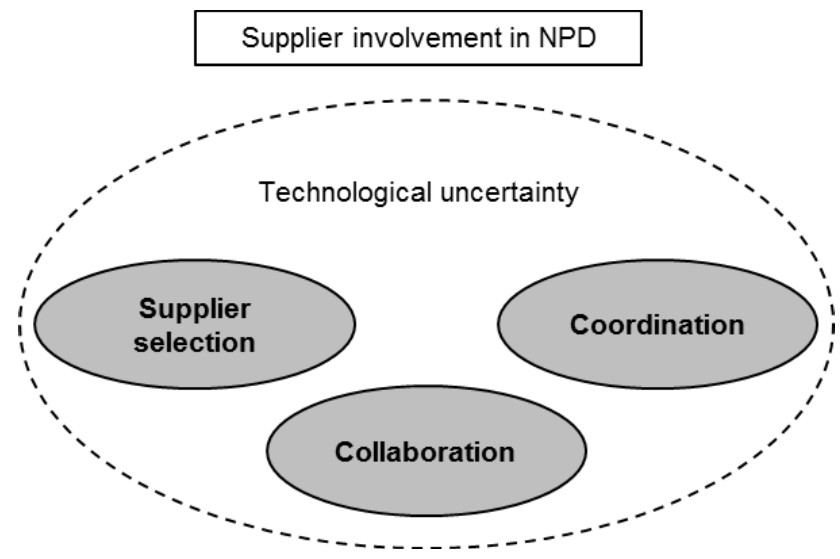

Figure 5-1 The three areas that were studied respectively

\subsubsection{Supplier selection for collaborative NPD}

The results of the study show that supplier selection is important and that firms need to consider not only the suppliers' technology but also how well the firms can work together. Similarly, many studies stress the importance of making a careful assessment of suppliers before selecting one for NPD projects (Hoegl \& Wagner, 2005; Petersen et al., 2005; Handfield \& Lawson, 2007; Un et al., 2010). The findings from this study points to the fact that a NPD project can fail if the supplier is not a suitable collaboration partner; even though the technology might be suitable for the project at hand (see Paper 1). For this reason, academics suggest that buying firms perform a rigorous evaluation of potential suppliers, because the potential partner that seems to be the most capable may not necessarily be the most suitable (Diestre \& Rajagopalan, 2012).

Studies indicate that firms find it more problematic to involve suppliers in projects with a higher level of technological uncertainty (Eisenhardt \& Tabrizi, 1995) than with a lower level 
of technological uncertainty, particularly because such partnerships are more difficult to sustain (Lhuillery \& Pfister, 2009). As a way to manage technical uncertainty, firms use flexible and open-ended contracts (Bhattacharya et al., 2013). Paper 1 is based on an in-depth case analysis where the theoretical framework developed by Hall \& Martin (2005) and Hall et al. (2011) is expanded upon. In this paper, it is shown how the firm managed uncertainty by deciding to keep the supplier 'at arm's length'. In this way, the decision to prioritize flexibility formed the relationship with the supplier. Uncertainty can also be described as a situation where information is lacking (Galbraith, 1974), which would make an accurate evaluation of a supplier difficult. It is suggested that buying firms should gather information about the supplier for the purpose of learning about the supplier's nature and actions (Holmström, 1979). However, it may be difficult for buying firms to access such information about the supplier. In Paper 5, the study shows how firms use different ways to gather information from suppliers; they can use databases and technical information, visit the suppliers, and examine previous collaboration projects. Paper 5 explores seven supplier selections in NPD projects, and describes how firms evaluate potential suppliers.

Previous research points to the importance of the suppliers' technological capabilities (Bailey et al., 1998; Le Dain et al., 2011), however, these capabilities are difficult to assess before a supplier is selected (Håkanson, 1993). In Paper 1, it is shown that merely assessing a supplier's technology is not sufficient. Relational capabilities and whether long-term alignment can be achieved are also important factors that need to be evaluated. Due to a supplier selection that was based solely on technological capabilities, the buying firm failed to see that the supplier was not actually suitable as a partner for a particular collaborative NPD project. The collaboration was terminated, and the firm searched for a new supplier, this time including 'relational capabilities' in their assessment criteria. In Paper 5, the data shows that the two most important supplier selection criteria are 'technological capacities' and 'relational capabilities'.

There exists a conflict in the literature as to whether firms should select new suppliers or keep old acquaintances for NPD projects with technological uncertainty. Some studies indicate that, under technological uncertainty, firms tend to involve new suppliers (Wasti \& Liker, 1999) and encourage firms to search for new suppliers in order to broaden their network (Beckman et al., 2004; Johnsen, 2011; Raassens et al., 2012). Other studies point to the fact that that some firms select suppliers with whom they have a prior history (Lorenzoni \& Lipparini, 1999; Hoetker, 2005), and that prior relationships improve the chances of a successful collaboration (Håkanson, 1993). This thesis supports the claim that firms tend to select suppliers with whom they are familiar because they can build long-term relationships and align each firms' capabilities. As shown in Paper 5, by having collaborated previously with a supplier, the buying firms found it easier to evaluate such a supplier's capabilities. Moreover, in technological uncertain projects, relational capabilities such as trust are important. Consequently, firms may tend to select suppliers with whom they already have an established working relationship. However, potential drawbacks from selecting familiar suppliers are that familiar suppliers are less innovative due to lock-in situations (Handfield et al., 1999) or that creativity is hampered due to a project team's adoption of established models from previous projects (Skilton \& Dooley, 2010).

Some studies have highlighted the importance of involving purchasing in NPD projects (McGinnis \& Vallopra, 1999; Schiele, 2010), but they do not discuss purchasing's role under technological uncertainty. However, under technological uncertainty, it is has been suggested 
that purchasing's role is suppressed (Oh \& Rhee, 2010). The results of my study show that purchasing's involvement in supplier selection varied between the projects. In Paper 1, which investigated a project with high technological uncertainty, purchasing was not involved in the selection process with respect to the first supplier. However, once that collaboration failed, purchasing was involved in the subsequent selection process where the second supplier was selected. Paper 2 demonstrates purchasing's limited influence in the projects, but does show that purchasing contributes to the supplier selection process. In Paper 3, there is a clear distinction between the projects with high technological uncertainty and the low technological uncertainty project. It was also clear to see that purchasing had more influence in the low technological uncertainty project. Paper 5 shows how much of the work done in terms of information gathering and evaluation of suppliers is handled by the R\&D department.

\subsubsection{Collaboration between buyer and supplier in NPD projects}

To collaborate with an external firm (in this study, a supplier) can be problematic. Previous studies have focused on integration (Petersen et al., 2005), coordination (Lakemond et al., 2006), joint location (Lakemond \& Berggren, 2006), technology roadmaps (Petrick \& Echols, 2004), knowledge sharing (Tell, 2011), trust (Das \& Teng, 1998), and a number of other related issues concerning supplier involvement in NPD projects. However, this study is limited to but a few issues regarding buyer and supplier collaboration.

Previous research highlighted the importance of control when incorporating new knowledge (Turner \& Makhija, 2006). The results of my study indicate that it is difficult to limit control to one dimension. Instead, a combination of controls needs to be used. That is to say, as shown in Paper 4, the supplier should be monitored on several levels. However, at the same time, the buying firm also employs goal alignment, joint problem-solving, contracts, and trust to control the supplier. Notwithstanding this, buying firms need to find a balance in their level of control; in particular, a balance in three areas when controlling suppliers in NPD collaborations. First, monitoring abilities influence what level of control is possible, while, at the same time, allowing the supplier a certain level of freedom. Second, control needs to be balanced with trust, as seen in previous research (Blomqvist et al., 2005). Finally, firms need to remember that control influences creativity. Again, this is a finding that is supported by previous studies (Carson, 2007). Paper 4 is based on three cases, where the analysis was made by using constructs found in agency theory.

The results of the study indicate, as shown in Paper 4, that there is no one best solution available for the problem of how to control suppliers in product development. Similarly to Blomqvist et al. (2005), Paper 4 demonstrates that contracts alone are not sufficient to control suppliers; there needs to be trust between the firms as well. In agreement with previous research, Paper 4 finds that contracts and trust are complementary modes of governance (Gulati, 1995; Poppo \& Zenger, 2002; Liu et al., 2009; Arranz \& Arroyabe, 2011). Even when tougher contracts are formulated, the issue of trust remains. Consequently, there exists a difficult balance between pushing suppliers to perform on time, on the one hand, and being cost-efficient and maintaining a good relationship with a supplier of technical solutions, on the other hand. In Paper 3, the findings support the observation that transactional and relational governance are used as complementary modes (Poppo \& Zenger, 2002; Blomqvist et al., 2005). Contracts and additional transactional mechanisms are not enough to control the projects; relational mechanisms are also needed. 'Transactional mechanisms' are identified as contracts, patent discussions, and specific investments, while 'relational mechanisms' are 
identified as trust, goal alignment, relational norms, and the frequency of transactions. Paper 3 examines four NPD cases, and the analysis uses of a combination of constructs from agency theory and TCE theory.

The results of the study show the difficulties that are involved in achieving alignment when there is little possibility to control the supplier. Particularly difficult to deal with is the situation where the buying firm is limited in its influence over the project, while finding it difficult to control the supplier in the project. In Paper 4, it is shown that technological roadmaps were used to facilitate alignment in the projects. However, in situations where suppliers are in a powerful position and do not allow buying firms to control the project, it is difficult for the buying firm to influence the supplier. A way to deal with limited influence on an operational level is to influence the supplier on a strategic level; by collaborating on a strategic level that supports alignment and complements the issue of control. In this way, although there may be limited influence on an operational level, strategic collaboration may facilitate alignment and control of future projects indirectly. By controlling technological development in the long term, the buying firm can achieve better operational goal alignment for future collaborative projects.

\subsubsection{Coordinating $R \& D$ and purchasing in NPD projects involving suppliers}

The results from this study point to the existence of limited coordination between the purchasing department and the R\&D department, (as described in Paper 1, Paper 2, Paper 3, and Paper 5). In Paper 1, Paper 2, and Paper 5, it is shown that purchasing had but a limited influence on the supplier selection process. This is in contrast to prior research, which highlights claims such that purchasing should identify suppliers (McGinnis \& Vallopra, 1999). This contrasting stance with respect to purchasing's role could be due to the level of technological uncertainty, where purchasing's influence is assumed to be limited (Oh \& Rhee, 2010). Paper 5 makes the observation that the evaluation of suppliers is mainly made by $R \& D$ engineers in high technological uncertainty projects. Purchasing has thus but a limited role in these projects. However, as shown in Paper 2, in projects with low technological uncertainty, purchasing has a more prominent role.

The results from this study provide a more nuanced view of purchasing's importance in NPD than what is found in much of the previous literature on this subject. This is because the data that was used in this thesis is not limited to purchasers only, but includes project members and decision makers as well. Many studies that highlight purchasing as a strategic function which contributes to NPD are based on data from the purchasing organization or purchasers only (Wynstra et al., 1999; Stanley \& Wisner, 2001; Carr \& Pearson, 2002).

The results of the study show how transactional and relational governance requires different skills and thus can be challenging for firms. Firms can divide these responsibilities between different departments. In Paper 3, it is shown that transactional mechanisms can be enabled by an actor outside the project organization, namely the purchasing organization, as a way to avoid distrust, as suggested by Jap and Ganesan (2000). Organizational separation allows project teams to focus on technological issues and not be involved in transactional discussions. In contrast to previous studies, which have identified purchasing as having an increasing role in coordinating cross-functional responsibilities in NPD (McGinnis \& Vallopra, 1999; van Echtelt et al., 2008; Schiele, 2010), Paper 3 shows that purchasing enables transactional 
governance but not necessarily relational governance with suppliers, at least in situations of technological uncertainty.

Similar to the findings made by Tassabehji and Moorhouse (2008), the results of this study show that purchasing was considered to be strategic unit at the firms that were studied, but the R\&D departments did not always view purchasing as such. It has been suggested that purchasing should expand their capabilities to deal with complex contracts and crossfunctional collaboration (von Corswant \& Tunälv, 2002). On the one hand, the results of the study confirms this, as it is clear that the R\&D department was not always convinced of purchasing's' capability with respect to its involvement in strategically important NPD projects with high technological uncertainty. On the other hand, organizational separation, used as a deliberate strategy to achieve complementarity of transactional and relational governance, highlights a more limited, but still important, role of purchasing in dealing with transactional issues. This represents a classical organizational dilemma; organizational separation increases the possible benefits of specialization, but it also creates challenges that are related to the integration of functions within the organization (Lawrence \& Lorsch, 1967).

The study provides distinct indications that the dynamics of differentiation and integration are different depending on the degree of technological uncertainty that prevails at the time. More specifically, in Paper 3, it is indicated that, for NPD projects with high technological uncertainty, relational mechanisms are enabled by the R\&D organization and not through purchasing. Similarly, Paper 2 provides evidence that collaboration with suppliers under technological uncertainty is managed differently in NPD projects with low technological uncertainty where the supplier's input is limited to manufacturing issues. In these latter projects, purchasing may have a more prominent role than in NPD collaborations under high levels of technological uncertainty. To some extent, purchasing may even facilitate innovation by supporting $\mathrm{R} \& \mathrm{D}$, but collaborative innovation is still primarily realised in interaction between R\&D engineers and supplier engineers. These intra-firm challenges specifically focus on individuals, such as purchasers and R\&D engineers, and on NPD projects. However, this has implications on organizational levels as well, where functional units (the purchasing department and the R\&D department) interact. This is important to note, as interaction on individual, project, and organizational levels is facilitated when dealing with problems within the firm (Prencipe \& Tell, 2001).

\subsection{Integrating the three areas}

Three areas have been studied in this thesis: supplier selection, collaboration, and coordination. These areas are not isolated islands of activity, but they affect each other and are related to each other. The results from the study show, however, that supplier selection, buyer-supplier collaboration, and R\&D-purchasing coordination are affected by uncertainty and specialization in slightly different ways.

First, uncertainty in supplier selection is demonstrated in terms of information asymmetry and the possibility of adverse selection (see Papers 1, and 5). The results of the study show that information asymmetry is problematic in the supplier selection process, because the buying firms experience difficulty in verifying the capabilities of the suppliers with respect to the required technology. Therefore, buying firms use a variety of sources (see Paper 5) to find information about potential suppliers, in an attempt to avoid adverse selection. The study also shows that during the NPD collaboration, uncertainties evolve around questions as to whether 
the most suitable technology is being implemented, and how the buying firm can align the supplier towards the firm's goals and control the supplier (see Papers 3 and 4). Research findings indicate that when the supplier is powerful, buying firms use goal alignment on a strategic level to assert control on the project level.

Uncertainty also affects the internal coordination between $R \& D$ and purchasing, since purchasing's role in NPD under technological uncertainty is ambiguous (see Papers 2 and 3). The study indicates that uncertainty undermines purchasing's influence, because some R\&D representatives believe that purchasing cannot contribute during the development of the product, and that purchasing should only be involved once the product is developed and moves into the industrialization phase. Consequently, although much research points to the strategic value of purchasing in NPD projects involving suppliers (Walter, 2003; Luzzini \& Ronchi, 2011), this study shows that purchasing's involvement in NPD can still be questioned.

Second, the influence of specialization is evident in the three areas as well. It is not possible to possess all the necessary technologies in-house (Johansson et al., 2011). Therefore, firms need to select specialized suppliers that can contribute with the required technology (see Papers 1 and 5). The findings from the study show that the firms evaluated specialized suppliers. Due to their respective specializations, the buying firms would not invest in the required technology (to possess it in-house), but instead they relied on specialized suppliers. For this reason, an increase in specialization demands very close interaction between firms (Brusoni \& Prencipe, 2001). These specialized suppliers need to be controlled, but not too much because they are the ones who are the specialists in the relevant technology (see Paper 4). The results of the study indicate that specialized suppliers require freedom to venture into potential avenues of the technology; too much involvement from the buying firm may cause the supplier to not explore all potential solutions (see Papers 3 and 4).

Specialization is also present within the firm (Grant, 1996), which means that cross-functional teams need to coordinate specialists within the firm (see Papers 2 and 3). The study shows that coordination between $\mathrm{R} \& \mathrm{D}$ and purchasing is not well established in technological uncertain NPD projects involving suppliers (see Papers 1, 2, and 3). These departments were not always in accordance with who should perform what activities. More communication between the departments could clarify responsibilities related to the project. Starting within the buying firm, it can coordinate internally between $R \& D$ and purchasing as early as the supplier selection stage, and together evaluate and select a supplier (see Papers 1 and 2). Once a supplier is selected, the collaboration in the NPD project between the buying firm and the supplier begins. From this point onwards, internal coordination influences how the supplier is controlled, and transactional and relational governance is applied (see Papers 3 and 4). For these reasons, supplier selection, collaboration, and coordination are all very important areas within the research field of supplier involvement in NPD.

\subsection{Concluding remarks}

The three areas of study (supplier selection, collaboration, and coordination) have theoretical contributions as well as managerial implications. First, theoretical implications will be presented. Thereafter, practical implications, limitations of the study, and future research are discussed. 


\subsubsection{Theoretical contributions}

The study's contribution in terms of theory development is to the literature on supplier involvement, especially with respect to transaction cost economics (TCE) theory and agency theory. First, with regards to agency theory, a vital problem in collaboration is whether one can verify that the agent has the skills it claims to have (Eisenhardt, 1989b). The problem originates from information asymmetry (Akerlof, 1970), more precisely, in situations where the principal has less information than the agent. As external relationships become more important in product development, firms face challenges in the selection of partners (Galbraith, 1995). These issues are explored in this thesis by studying supplier selection for collaborative NPD projects. The challenges that have been discussed concern the issue of whether a firm should involve new suppliers or rely on old acquaintances. Verification is more easily achieved for previous collaboration partners. Additional support for the selection of known suppliers are the observations that (i) the firm and the supplier already have established relationships and (ii) there exists trust between individuals and the organizations. However, it has been observed that, under technological uncertainty, firms tend to involve new suppliers (Wasti \& Liker, 1999). In contrast, the results of the present study showed that in projects with high technological uncertainty, firms tend to select suppliers with whom they are familiar. By collaborating with familiar suppliers and by building long-term relationships with key suppliers, the firms' capabilities can be mutually aligned in a way that they is useful for future projects (van Echtelt et al., 2008). The results of the study indicate that technological uncertainty in a project influences the choice of supplier. In projects with uncertainty, firms tend to select suppliers who they know well, and with whom they believe they can discuss problems and reach agreement. Personal relationships and trust in the suppliers' technological capabilities were important factors in the selection. However, by continuing collaboration with a long-term supplier, the buying firm limits its options to change supplier. Therefore, firms face the dilemma of whether to commit to long-term relationships, or to maintain flexibility.

Second, as firms evolve, so do their relationships with external organizations (Burns \& Stalker, 1961). In general, tensions in collaborations between organizations evolve around control and governance of the partner (Burns \& Stalker, 1961; Williamson, 1991). When collaborating with external partners, it is important that the two organizations strive towards a similar goal in the collaborative project. In agency theory, the difficulty of achieving goal alignment between the principal and the agent is highlighted as particularly problematic. In the present study of buyers and suppliers in NPD, the data shows the importance of balancing control, since it can affect: how a supplier is to be monitored, trust between the firm and the supplier, and degree of creativity. Too much control can hamper creativity, which could result in a supplier's failure to explore potential avenues of development. This is problematic in situations when the buying firm has less information than the supplier, but gives the supplier suggestions on how to proceed in developing the technology. The supplier may decide to avoid exploring an avenue of development that could be potentially fruitful. Too much control could thus result in the development of a product that does not have the most suitable technology. This study demonstrates the importance of achieving goal alignment, and that, in relationships that are difficult to control through contracts and trust, firms can use goal alignment as a way to control the relationship. In collaborations with a powerful supplier, it may be difficult to control the supplier within the specific project. In such a scenario, the buying firm can control the supplier on the project level by reaching an agreement with the supplier on the strategic level. By aligning goals on the strategic level, the firms can reach 
alignment on the project level as well. Goal alignment is important because the firms should strive towards a shared outcome of the project, otherwise the project may not result in the desired outcome. The findings of this thesis also highlight the importance of managing transactional and relational governance. The study confirms previous findings, showing that firms tend to implement a combination of these two governance forms (Blomqvist et al., 2005; Arranz \& Arroyabe, 2011).

Third, activities performed with an external partner influence the internal organization of the buying firm. As organizational separation increases, so do the potential benefits from specialization. But organizational separation also creates challenges that are related to integration between departments within the organization (Lawrence \& Lorsch, 1967). Firms need to achieve both differentiation and integration (Lawrence \& Lorsch, 1967) and coordination activities should be spread out across a number of organizational departments (Galbraith, 1995). In cross-functional coordination within a firm, there is potential for interdepartmental conflicts to arise (Lawrence \& Lorsch, 1967). This thesis studies these tensions by investigating the coordination between the R\&D department and the purchasing department in NPD projects where suppliers are involved. The results indicate that, in projects with high technological uncertainty, there is limited coordination because purchasing has but little involvement in these projects. In these projects, there is organizational separation, where purchasing is mainly responsible for transactional governance and the R\&D department for relational governance. Hence, in contrast to previous studies, that point to purchasing as managing the relationship (Walter, 2003) the results in Paper 3 show that purchasing's involvement is limited to transactional issues. The limited involvement of purchasing could be due to purchasing's limited capabilities, since purchasing mainly manages operational issues at the buying firm. Another reason that purchasing was not involved in the project could be the fact that the innovation processes that were studied were limited to the selection phase and the development phase of the product. In such a case, the industrialization phase (where purchasing negotiates deliveries and prices) is not included. However, the involvement of purchasing in the industrialization phase would, in such a scenario, be more operational than strategic. In addition, it could be the case that the buying firm's organization does not support the involvement of purchasing in the innovation process, but, instead, R\&D is responsible for all parts of the development and contact with the supplier.

\subsubsection{Practical implications}

To develop new and innovative products is not an easy task. Reports from some of the most influential consultancy firms show that firms struggle to bring new products to the market (Capozzi et al., 2010; Silverstone et al., 2012; Tevelson et al., 2013). Some firms simply miss out on opportunities to collaborate with suppliers in NPD, while others could improve their collaborations with their suppliers. For these reasons, there is still room for improvement in collaborative NPD.

It can be challenging to find the most suitable partner for one's firm (Galbraith, 1995). Therefore, firms need to make a careful selection of suppliers and consider not only the suppliers' technological capabilities but also their relational capabilities. The issue of verifying whether the supplier has the skills it claims to have can be problematic (Eisenhardt, 1989b). Therefore, this thesis suggests that firms collect information about potential suppliers from a variety of sources. They can use technology reports to learn more about the suppliers' technologies, and even visit the supplier in order to learn more about the supplier and its 
technology. In addition, firms can study the supplier's market reputation by studying prior collaborations with other firms. Another aspect to consider with respect to supplier selection is whether to involve a previously known supplier or new supplier. A supplier can be 'known' from previous collaboration in either NPD projects or from supplying items to existing products. The supplier may also be known from strategic collaborations. The benefits to be enjoyed from involving known suppliers arise from (i) the existence of established relationships, and (ii) the fact that the supplier's capabilities are better known. However, new suppliers can contribute with new technology or new ideas to the project. It is challenging for firms to decide whether to involve a new supplier or to rely on old acquaintances. An additional challenge is whether the firms should commit to one supplier, or strive for flexibility and maintain the option to change supplier.

During the collaboration, the buying firm faces the challenge of balancing control over the supplier. The supplier should be allowed space for innovation, while it still strives towards the same goal as the buying firm. Tensions in collaborations between organizations evolve around control and governance of one of the partners (Burns \& Stalker, 1961; Williamson, 1991). The present study demonstrates the importance of the challenge of reaching goal alignment. Since the buying firm and supplier have separate teams that develop the product, it is important that both teams agree on the goal of the project. The goal may need to be revisited and adjusted as the product's development progresses. Each team working by themselves may result in difficulties in maintaining alignment, and thus follow-ups on the development process are necessary. In situations where relationships are difficult to control through contracts and trust, firms can use goal alignment as a way to control the relationship. In relationships where it is difficult to influence the supplier on the project level, the firm can try to influence the supplier on a strategic level. By influencing the supplier on a strategic level, the buying firm is able to influence future projects and technology developments. Technology roadmaps are also good instruments for discussing and comparing future developments. Furthermore, in collaborative developments, firms may try to control the supplier through the implementation of tough contracts. However, this study shows that it is important to remember that too much control may hamper the supplier's innovativeness. By exerting too much control, the firm may inadvertently hinder the supplier from exploring potential avenues of development. Therefore, there needs to be trust in the relationship as well. Buying firms need place trust in competent suppliers who can explore fruitful avenues and perhaps find a better solution to a problem than what the buying firm may have initially suggested. A level of freedom that is based on trust can result in the search for a more suitable solution to a problem.

Coordination with purchasing can be challenging and problematic, as shown in a consultancy report (Hardt et al., 2007), that claims that purchasing is too focused on costs and experiences difficulties in viewing the firm's overall strategy. I found limited coordination with purchasing in the NPD projects, particularly in projects with high technological uncertainty. It is challenging for firms to determine the level of involvement of purchasing in NPD projects and how purchasing should coordinate with the R\&D department. It seems that purchasing's main responsibility concerns transactional governance, while the R\&D department deal with the relational governance of the suppliers. Despite the existence of research that refers to the importance of having purchasing as the interface with the supplier (Walter, 2003; Luzzini \& Ronchi, 2011), I claim that there are benefits to be gained from limiting purchasing's role to one of transactional governance, because costs can be discussed outside of the NPD project organization. Although it can be argued that purchasing needs to be better coordinated with 
NPD projects, it can also be argued that it is beneficial for the firm to not involve purchasing in relational issues that concern the NPD project.

\subsubsection{Limitations}

Every man finds his limitations, Mr. Holmes, but at least it cures us of the weakness of self-satisfaction.

(Lord Cantlemere to Sherlock Holmes in The Case-Book of Sherlock Holmes: the Adventure of the Mazarin Stone)

There may be a number of limitations to this study, but by choosing the case study method it was possible for the researcher to gain a certain richness of data and to develop existing ideas (Stuart et al., 2002). In this thesis, the case study method was appropriate since it allowed for flexibility as the scope and aim of the study was adjusted over time. The method also inspired new ideas and was well suited for illustrative purposes (Siggelkow, 2007). However, a common critique to the method is its limitation in terms of generalizability. However, the thesis strives to increase our understanding by developing concepts and providing illustrations (Siggelkow, 2007). In addition, there were limitations within the selected method. The study is based on two buying firms, who are system integrators. Of the total of six projects, it was not possible to gain access to one of the suppliers (the Ericsson-2 project). Within the projects that were studied, the focus was on three areas, but, of course, other areas within the projects could have been studied. Some processes could have been more suitable to study through observations in real time, such as for instance the development of trust throughout the projects. However, that would have been too time-consuming for this study.

The case selection that was made implied other limitations. For example, the study employs a dyadic approach, but, alternatively, triads could have been studied by selecting cases that involved three organizations, for example. Similarly, within the buying firm, the departments that were studied were purchasing and R\&D. However, other alternatives could have included the study of other relationships, such as $R \& D$ and finance, or $R \& D$ and marketing. However, despite these limitations, the findings of the study should be of particular interest for firms that involve suppliers in their NPD projects and experience challenges related to technological uncertainty.

\subsubsection{Future research}

Future studies could investigate how technological uncertainty affects NPD project performance. A large scale study could examine variables that affect the success rate of such projects, which could possibly highlight problematic areas or potentials for improvement. Another area that has not been studied is how firms manage uncertainty in the selection of new technology, which, in turn, affects the selection of a supplier. With respect to supplier selection, there may exist alternative ways to evaluate potential suppliers while taking technological uncertainty under consideration. A survey could further investigate the results from Paper 5, to examine the extent to which firms examine the historical track record of other firms, collect information, or a combination of the two when they perform supplier selection under technological uncertainty. Another interesting area of investigation (which is 
only touched upon in this study, and not investigated thoroughly) is how firms manage lockin situations (Handfield et al., 1999).

With respect to the on-going relationship between a buying firm and a supplier, more investigation into goal alignment is needed, where it would of interest to see how firms solve conflicts. This could include an examination of the extent that contracts are used, and who (i.e., which function) is responsible for dealing with solving conflict. In this study, only relatively small projects, with approximately ten project members on each project team, have been studied. Future studies of larger projects, with more individuals involved, would provide data regarding more complex organization and coordination of projects. Projects with multiple suppliers could also provide additional insight into how firms collaborate in NPD. Another suggestion would be to study a larger part of the value chain, including, for example, suppliers and customers.

The literature is not unanimous on purchasing's role in NPD collaborative projects with technological uncertainty. For this reason, more investigation into purchasing's involvement in NPD under technological uncertainty is needed. What enables, or limits, purchasing's involvement? Do they need to improve their competency to be able to deal with technological uncertainty? Or is purchasing's involvement a question of collaboration capability? In present study, only two firms were examined. A larger sample of firms would provide us with a better picture of the situation. However, since many previous studies have collected data from purchasing's perspective, one suggestion would be to collect data that provides a wider perspective on the organization. Otherwise, conflicting beliefs within the firms may not be captured. This point is highlighted in Tassabehji \& Moorhouse's (2008) study, where purchasing viewed itself as strategic, while other parts of the organization did not recognise purchasing's role as being strategic.

The present study's main contribution is to the literature on supplier involvement in NPD projects. In particular, collaboration in NPD under technological uncertainty has been explored. Other contributions are made to our understanding of supplier selection, collaboration during the development of a product, and how the buying firm can coordinate between the R\&D department and the purchasing department in NPD. Contributions are also made by adopting analytical perspectives that are informed by TCE theory and agency theory. Although this study has not discussed open innovation, it does contribute to the open innovation literature, because the thesis has focused on collaborations in NPD with external partners. Future studies could include other perspectives, such as network theory and a knowledge integration perspective, which could develop our understanding of the field of supplier involvement even further.

To summarize, future studies could expand our knowledge and understanding of collaborative NPD under technological uncertainty. There is still room for improvement when firms involve suppliers in product development. This thesis has argued that specialization and integration are challenging, particularly under technological uncertainty. This research highlights the fact that it is important that a buying firm conduct a thorough supplier selection, manage supplier collaboration properly, and thoughtfully coordinate its R\&D and purchasing functions when involving suppliers in NPD. 


\section{REFERENCES}

Akerlof, G. A., 1970. The market for" lemons": Quality uncertainty and the market mechanism. The quarterly journal of economics, 84(3), 488-500.

Alon, A., and Chow, D. D., 2008. How to get the most from your best ideas. Outlook, 3, 1-12.

Alvesson, M., 2011. Intervjuer - genomförande, tolkning och reflexivitet. Malmö: Liber.

Alvesson, M., and Sköldberg, K., 2009. Reflexive methodology: New vistas for qualitative research. London: Sage Publications Ltd.

Andrew, J. P., Manget, J., Michael, D. C., Taylor, A., and Zablit, H., 2010. Innovation 2010: A return to prominence - and the emergence of a new world order. Report of Boston Consulting Group (April), 129.

Andrew, J. P., Stover DeRocco, E., and Taylor, A., 2009. The innovation imperative in manufacturing. Boston Consulting Group (Mars), 1-32.

Arranz, N., and Arroyabe, J., 2011. Effect of Formal Contracts, Relational Norms and Trust on Performance of Joint Research and Development Projects. British Journal of Management, 23, 575-588.

Aulakh, P. S., and Gencturk, E. F., 2000. International principal-agent relationships: Control, governance and performance. Industrial Marketing Management, 29(6), 521-538.

Axelsson, B., and Håkansson, H., 1984. Inköp för konkurrenskraft. Malmö: Liber ekonomi.

Bailey, W. J., Masson, R., and Raeside, R., 1998. Choosing successful technology development partners: a bestpractice model. International Journal of Technology Management, 15(1), 124-138.

Baldwin, C. Y., 2008. Where do transactions come from? Modularity, transactions, and the boundaries of firms. Industrial and Corporate Change, 17(1), 155-195.

Baum, J. A. C., Calabrese, T., and Silverman, B. S., 2000. Don't go it alone: Alliance network composition and startups' performance in Canadian biotechnology. Strategic Management Journal, 21(3), 267-294.

Beckman, C. M., Haunschild, P. R., and Phillips, D. J., 2004. Friends or strangers? Firm-specific uncertainty, market uncertainty, and network partner selection. Organization Science, 15(3), 259-275.

Belderbos, R., Carree, M., and Lokshin, B., 2004. Cooperative R\&D and firm performance. Research Policy, 33(10), 1477-1492.

Bengtsson, L., Lakemond, N., and Dabhilkar, M., 2013a. Exploiting supplier innovativeness through knowledge integration. International Journal of Technology Management, 61(3), 237-253.

Bengtsson, L., von Haartman, R., and Dabhilkar, M., 2013b. Outsourcing eller kunskapsintegration? In L. Bengtsson, and J. Lind (Eds.), Innovation eller kvartalskapitalism? Utmaningar för global svensk produktion. Stockholm: Liber.

Bhattacharya, A., Singh, P. J., and Bhakoo, V., 2013. Revisiting the outsourcing debate: two sides of the same story. Production planning \& control, 24(4-5), 399-422.

Birou, L. M., and Fawcett, S. E., 1994. Supplier involvement in integrated product development: a comparison of US and European practices. International Journal of Physical Distribution \& Logistics Management, 24(5), 4-14.

Blomqvist, K., Hurmelinna, P., and Seppanen, R., 2005. Playing the collaboration game right — balancing trust and contracting. Technovation, 25(5), 497-504.

Bozdogan, K., Deyst, J., Hoult, D., and Lucas, M., 1998. Architectural innovation in product development through early supplier integration. $R \& D$ Management, 28(3), 163-173.

Brusoni, S., 2005. The limits to specialization: problem solving and coordination in 'Modular Networks'. Organization studies, 26(12), 1885-1907.

Brusoni, S., and Prencipe, A., 2001. Unpacking the black box of modularity: technologies, products and organizations. Industrial and Corporate Change, 10(1), 179-205.

Brusoni, S., Prencipe, A., and Pavitt, K., 2001. Knowledge specialization, organizational coupling, and the boundaries of the firm: Why do firms know more than they make? Administrative Science Quarterly, 46(4), 597-621.

Bryman, A., and Bell, E., 2007. Business research methods. New York: Oxford University Press, USA.

Bunduchi, R., and Smart, A. U., 2010. Process innovation costs in supply networks: a synthesis. International Journal of Management Reviews, 12(4), 365-383.

Burns, T., and Stalker, G. M., 1961. The management of innovation. Oxford: Oxford University Press.

Burt, D. N., and Soukup, W. R., 1985. Purchasing's role in new product development. Harvard Business Review, 63(5), 90-97.

Börjesson, S., Dahlsten, F., and Williander, M., 2006. Innovative scanning experiences from an idea generation project at Volvo Cars. Technovation, 26(7), 775-783. 
Börjesson, S., and Elmquist, M., 2011. Developing innovation capabilities: A longitudinal study of a project at volvo cars. Creativity and Innovation Management, 20(3), 171-184.

Capozzi, M. M., Gregg, B., and Howe, A., 2010. McKinsey Global Survey Results: Innovation and commercialization, 2010. The McKinsey Quarterly, 2, 1-8.

Caputo, M., and Zirpoli, F., 2002. Supplier involvement in automotive component design: outsourcing strategies and supply chain management. International Journal of Technology Management, 23(1), 129-159.

Carlile, P. R., 2002. A pragmatic view of knowledge and boundaries: Boundary objects in new product development. Organization Science, 13(4), 442-455.

Carlile, P. R., and Rebentisch, E. S., 2003. Into the black box: The knowledge transformation cycle. Management Science, 49(9), 1180-1195.

Carr, A. S., and Pearson, J. N., 2002. The impact of purchasing and supplier involvement on strategic purchasing and its impact on firm's performance. International Journal of Operations \& Production Management, 22(9), 1032-1053.

Carr, A. S., and Smeltzer, L. R., 1999. The relationship of strategic purchasing to supply chain management. European Journal of Purchasing \& Supply Management, 5(1), 43-51.

Carson, S. J., 2007. When to give up control of outsourced new product development. Journal of Marketing, 71(1), 49-66.

Chesbrough, H., 2003. The era of open innovation. Sloan management review, 44(3), 35-41.

Chesbrough, H., Vanhaverbeke, W., and West, J., 2008. Open innovation: researching a new paradigm. New York: Oxford university press.

Choi, T., and Hartley, J., 1996. An exploration of supplier selection practices across the supply chain. Journal of Operations Management, 14(4), 333-343.

Chung, S. A., and Kim, G. M., 2003. Performance effects of partnership between manufacturers and suppliers for new product development: the supplier's standpoint. Research Policy, 32(4), 587-603.

Clark, K. B., and Fujimoto, T., 1991. Product development performance: strategy, organization, and management in the world auto industry. USA: Harvard Business Press.

Cousins, P. D., Lawson, B., and Squire, B., 2006. An empirical taxonomy of purchasing functions. International Journal of Operations \& Production Management, 26(7), 775-794.

Cousins, P. D., and Spekman, R., 2003. Strategic supply and the management of inter-and intra-organisational relationships. Journal of Purchasing and Supply Management, 9(1), 19-29.

Cox, A., 1996. Relational competence and strategic procurement management: towards an entrepreneurial and contractual theory of the firm. European Journal of Purchasing \& Supply Management, 2(1), 57-70.

Cuervo-Cazurra, A., and Un, C. A., 2010. Why some firms never invest in formal R\&D. Strategic Management Journal, 31(7), 759-779.

Dabhilkar, M., Bengtsson, L., von Haartman, R., and Åhlström, P., 2009. Supplier selection or collaboration? Determining factors of performance improvement when outsourcing manufacturing. Journal of Purchasing and Supply Management, 15(3), 143-153.

Das, A., and Narasimhan, R., 2000. Purchasing competence and its relationship with manufacturing performance. Journal of Supply Chain Management, 36(2), 17-28.

Das, T. K., and Teng, B.-S., 1998. Between trust and control: Developing confidence in partner cooperation in alliances. Academy of management review, 491-512.

David, R. J., and Han, S. K., 2004. A systematic assessment of the empirical support for transaction cost economics. Strategic Management Journal, 25(1), 39-58.

Davila, T., 2000. An empirical study on the drivers of management control systems' design in new product development. Accounting, Organizations and Society, 25(4-5), 383-409.

Day, E., and Barksdale, H. C., 2003. Selecting a professional service provider from the short list. Journal of Business \& Industrial Marketing, 18(6/7), 564-579.

De Toni, A., and Nassimbeni, G., 2003. Small and medium district enterprises and the new product development challenge: evidence from Italian eyewear district. International Journal of Operations \& Production Management, 23(6), 678-697.

Deese, J., 1969. Conceptual categories in the study of content. The Analysis of Communication Content: Development in Scientific Theories and Computer Techniques, 39-56.

Diestre, L., and Rajagopalan, N., 2012. Are all 'sharks' dangerous? new biotechnology ventures and partner selection in R\&D alliances. Strategic Management Journal, 33(10), 1115-1134.

Ditillo, A., 2004. Dealing with uncertainty in knowledge-intensive firms: the role of management control systems as knowledge integration mechanisms. Accounting, Organizations and Society, 29(3), 401-421.

Dosi, G., 1982. Technological paradigms and technological trajectories: A suggested interpretation of the determinants and directions of technical change. Research Policy, 11(3), 147-162. 
Dougherty, D., 1992. Interpretive barriers to successful product innovation in large firms. Organization Science, 3(2), 179-202.

Dowlatshahi, S., 1997. The role of product design in designer-buyer-supplier interface. Production planning \& control, 8(6), 522-532.

Dowlatshahi, S., 1998. Implementing early supplier involvement: a conceptual framework. International Journal of Operations \& Production Management, 18(2), 143-167.

Doyle, A. C., 1890. The sign of the four. UK: Lippincott's Monthly Magazine.

Doyle, A. C., 1892. The adventures of Sherlock Holmes. UK: George Newnes.

Doyle, A. C., 1894. The memoirs of Sherlock Holmes. UK: George Newnes.

Doyle, A. C., 1905. The return of Sherlock Holmes. UK: George Newnes.

Doyle, A. C., 1917. His last bow. UK: John Murray.

Doyle, A. C., 1927. The case-book of Sherlock Holmes. UK: John Murray.

Dubois, A., and Gadde, L. E., 2002. Systematic combining: an abductive approach to case research. Journal of Business Research, 55(7), 553-560.

Dyer, J. H., 1997. Effective interim collaboration: how firms minimize transaction costs and maximise transaction value. Strategic Management Journal, 18(7), 535-556.

Eisenhardt, and Graebner, 2007. Theory building from cases: Opportunities and challenges. Academy of management journal, 50(1), 25-32.

Eisenhardt, and Tabrizi, 1995. Accelerating adaptive processes: Product innovation in the global computer industry. Administrative Science Quarterly, 40(1), 84-110.

Eisenhardt, K., 1989a. Building theories from case study research. Academy of management review, 14(4), 532550 .

Eisenhardt, K. M., 1989b. Agency theory: An assessment and review. Academy of management review, 14(1), 57-74.

Eisenhardt, K. M., 1991. Better stories and better constructs: The case for rigor and comparative logic. The Academy of Management Review, 16(3), 620-627.

Emden, Z., Calantone, R. J., and Droge, C., 2006. Collaborating for new product development: selecting the partner with maximum potential to create value. Journal of Product Innovation Management, 23(4), 330-341.

Engelen, A., and Brettel, M., 2012. A coalitional perspective on the role of the R\&D department within the organization. Journal of Product Innovation Management, 29(3), 489-505.

Faems, D., Van Looy, B., and Debackere, K., 2005. Interorganizational collaboration and innovation: toward a portfolio approach*. Journal of Product Innovation Management, 22(3), 238-250.

Faes, W., Knight, L., and Matthyssens, P., 2001. Buyer profiles: an empirical investigation of changing organizational requirements. European Journal of Purchasing \& Supply Management, 7(3), 197-208.

Fejes, A., and Thornberg, R., 2009. Handbok $i$ kvalitativ analys. Stockholm: Liber.

Feng, B., Fan, Z. P., and Ma, J., 2010. A method for partner selection of codevelopment alliances using individual and collaborative utilities. International Journal of Production Economics, 124(1), 159-170.

Firestone, W. A., 1993. Alternative arguments for generalizing from data as applied to qualitative research. Educational researcher, 22(4), 16.

Flick, U., 2006. An introduction to qualitative research. London: Sage Publications Ltd.

Fliess, S., and Becker, U., 2006. Supplier integration-Controlling of co-development processes. Industrial Marketing Management, 35(1), 28-44.

Flyvbjerg, B., 2004. Five misunderstandings about case-study research. In C. G. Seale, G. Gubrium, JF Silverman, D. (Ed.), Qualitative research practice. London: Sage Publications Ltd, 420-434.

Gadde, L. E., and Håkansson, H., 1994. The changing role of purchasing: reconsidering three strategic issues. European Journal of Purchasing \& Supply Management, 1(1), 27-35.

Galbraith, J. R., 1974. Organization design: An information processing view. Interfaces, 4(3), 28-36.

Galbraith, J. R., 1995. Designing organizations: an executive guide to strategy, structure, and process. San Francisco: Jossey-Bass San Francisco, CA.

Gioia, D. A., Corley, K. G., and Hamilton, A. L., 2013. Seeking qualitative rigor in inductive research notes on the gioia methodology. Organizational Research Methods, 16(1), 15-31.

Golafshani, N., 2003. Understanding reliability and validity in qualitative research. The qualitative report, 8(4), 597-607.

Grant, R. M., 1996. Toward a knowledge-based theory of the firm. Strategic Management Journal, 17(Winter), 109-122.

Grant, R. M., and Baden Fuller, C., 2004. A knowledge accessing theory of strategic alliances. Journal of Management Studies, 41(1), 61-84. 
Gulati, R., 1995. Does familiarity breed trust? The implications of repeated ties for contractual choice in alliances. Academy of management journal, 38(1), 85-112.

Gupta, A. K., and Wilemon, D. L., 1990. Accelerating the development of technology-based new products. California Management Review, 32(2), 24-44.

Hagedoorn, J., and Schakenraad, J., 1994. The effect of strategic technology alliances on company performance. Strategic Management Journal, 15(4), 291-309.

Hall, J., Matos, S., Silvestre, B., and Martin, M., 2011. Managing technological and social uncertainties of innovation: The evolution of Brazilian energy and agriculture. Technological Forecasting and Social Change, 78(7), 1147-1157.

Hall, J. K., and Martin, M. J. C., 2005. Disruptive technologies, stakeholders and the innovation value added chain: a framework for evaluating radical technology development. R\&D Management, 35(3), 273-284.

Handfield, R., Ragatz, G., Peterson, K., and Monczka, R., 1999. Involving suppliers in new product development? California Management Review, 42(1), 59-82.

Handfield, R. B., and Lawson, B., 2007. Integrating suppliers into new product development. ResearchTechnology Management, 50(5), 44-51.

Hardt, C. W., Reinecke, N., and Spiller, P., 2007. Inventing the 21st-century purchasing organization. Mckinsey Quarterly, 4, 115-124.

Heide, J. B., Wathne, K. H., and Rokkan, A. I., 2007. Interfirm monitoring, social contracts, and relationship outcomes. Journal of marketing Research, 44(3), 425-433.

Henderson, R., and Clark, K., 1990. Architectural innovation: the reconfiguration of existing product technologies and the failure of established firms. Administrative Science Quarterly, 35(1), 9-30.

Henke, J. W., Krachenberg, A. R., and Lyons, T. F., 1993. Perspective: Cross-functional teams: Good concept, poor implementation! Journal of Product Innovation Management, 10(3), 216-229.

Hillebrand, B., Kok, R. A. W., and Biemans, W. G., 2001. Theory-testing using case studies: a comment on Johnston, Leach, and Liu. Industrial Marketing Management, 30(8), 651-657.

Ho, W., Xu, X., and Dey, P. K., 2010. Multi-criteria decision making approaches for supplier evaluation and selection: A literature review. European Journal of Operational Research, 202(1), 16-24.

Hoegl, M., and Wagner, S. M., 2005. Buyer-supplier collaboration in product development projects. Journal of Management, 31(4), 530-548.

Hoetker, G., 2005. How much you know versus how well I know you: Selecting a supplier for a technically innovative component. Strategic Management Journal, 26(1), 75-96.

Holmström, B., 1979. Moral hazard and observability. The Bell Journal of Economics, 10(1), 74-91.

Håkanson, L., 1993. Managing cooperative research and development: partner selection and contract design. $R \& D$ Management, 23(4), 273-285.

Jacobides, M. G., and Croson, D. C., 2001. Information policy: Shaping the value of agency relationships. Academy of management review, 26(2), 202-223.

Jagdev, H. S., and Thoben, K.-D., 2001. Anatomy of enterprise collaborations. Production planning \& control, 12(5), 437-451.

Jap, S. D., 1999. Pie-expansion efforts: collaboration processes in buyer-supplier relationships. Journal of marketing Research, 36(4), 461-475.

Jap, S. D., and Anderson, E., 2003. Safeguarding interorganizational performance and continuity under ex post opportunism. Management Science, 49(12), 1684-1701.

Jap, S. D., and Ganesan, S., 2000. Control mechanisms and the relationship life cycle: Implications for safeguarding specific investments and developing commitment. Journal of marketing Research, 37(2), 227-245

Johansson, M., Axelson, M., Enberg, C., and Tell, F., 2011. Knowledge integration in inter-firm R\&D relationships: How do firms balance problems of coordination with problems of cooperation? In A. Bergek, M. Hobday, C. Berggren, L. Bengtsson \& J. Söderlund (Ed.), Knowledge Integration and Innovation: Critical Challenges Facing International Technology-based Firms. Oxford: Oxford University Press.

Johnsen, T., Phillips, W., Caldwell, N., and Lewis, M., 2006. Centrality of customer and supplier interaction in innovation. Journal of Business Research, 59(6), 671-678.

Johnsen, T. E., 2009. Supplier involvement in new product development and innovation: Taking stock and looking to the future. Journal of Purchasing and Supply Management, 15(3), 187-197.

Johnsen, T. E., 2011. Supply network delegation and intervention strategies during supplier involvement in new product development. International Journal of Operations \& Production Management, 31(6), 686-708.

Kamath, R. R., and Liker, J. K., 1994. A second look at japanese product development. Harvard Business Review, 72(6), 154-170. 
Kindström, D., and Kowalkowski, C., 2009. Development of industrial service offerings: a process framework. Journal of service Management, 20(2), 156-172.

Knight, F. H., 1921. Risk, uncertainty and profit. Boston: Houghton Mifflin.

Knudsen, M. P., 2007. The relative importance of interfirm relationships and knowledge transfer for new product development success*. Journal of Product Innovation Management, 24(2), 117-138.

Knudsen, M. P., and Servais, P., 2007. Analyzing internationalization configurations of SME's: The purchaser's perspective. Journal of Purchasing and Supply Management, 13(2), 137-151.

Kondracki, N. L., Wellman, N. S., and Amundson, D. R., 2002. Content analysis: Review of methods and their applications in nutrition education. Journal of Nutrition Education and Behavior, 34(4), 224-230.

Koufteros, X., Edwin Cheng, T., and Lai, K., 2007. "Black-box" and "gray-box" supplier integration in product development: Antecedents, consequences and the moderating role of firm size. Journal of Operations Management, 25(4), 847-870.

Koufteros, X., Vonderembse, M., and Jayaram, J., 2005. Internal and external integration for product development: The contingency effects of uncertainty, equivocality, and platform strategy. Decision Sciences, 36(1), 97-133.

Kraljic, P., 1983. Purchasing must become supply management. Harvard Business Review, 61(5), 109-117.

Krishnan, V., and Bhattacharya, S., 2002. Technology selection and commitment in new product development: The role of uncertainty and design flexibility. Management Science, 48(3), 313-327.

Lakemond, N., and Berggren, C., 2006. Co-locating NPD? The need for combining project focus and organizational integration. Technovation, 26(7), 807-819.

Lakemond, N., Berggren, C., and Weele, A., 2006. Coordinating supplier involvement in product development projects: a differentiated coordination typology. $R \& D$ Management, 36(1), 55.

Lakemond, N., Echtelt, F., and Wynstra, F., 2001. A configuration typology for involving purchasing specialists in product development. Journal of Supply Chain Management, 37(4), 11-20.

Lamming, R., 1993. Beyond partnership: strategies for innovation and lean supply. New York: Prentice Hall.

Langerak, F., and Hultink, E. J., 2005. The impact of new product development acceleration approaches on speed and profitability: Lessons for pioneers and fast followers. Engineering Management, IEEE Transactions on, 52(1), 30-42.

Langner, B., and Seidel, V. P., 2009. Collaborative concept development using supplier competitions: Insights from the automotive industry. Journal of Engineering and Technology Management, 26(1-2), 1-14.

Lau, A. K. W., 2011. Supplier and customer involvement on new product performance: Contextual factors and an empirical test from manufacturer perspective. Industrial Management \& Data Systems, 111(6), 910942.

Lau, A. K. W., Tang, E., and Yam, R., 2010. Effects of supplier and customer integration on product innovation and performance: Empirical evidence in Hong Kong manufacturers. Journal of Product Innovation Management, 27(5), 761-777.

Laursen, K., and Salter, A., 2006. Open for innovation: the role of openness in explaining innovation performance among UK manufacturing firms. Strategic Management Journal, 27(2), 131-150.

Lawrence, P. R., and Lorsch, J. W., 1967. Organization and environment: managing differentiation and integration. Boston: Harvard University Press.

Le Dain, M. A., Calvi, R., and Cheriti, S., 2011. Measuring supplier performance in collaborative design: proposition of a framework. $R \& D$ Management, 41(1), 61-79.

Lee, J. H., Phaal, R., and Lee, C., 2011. An empirical analysis of the determinants of technology roadmap utilization. $R \& D$ Management, 41(5), 485-508.

Lee, P. K. C., Yeung, A. C. L., and Edwin Cheng, T., 2009. Supplier alliances and environmental uncertainty: An empirical study. International Journal of Production Economics, 120(1), 190-204.

Lee, S., and Park, Y., 2005. Customization of technology roadmaps according to roadmapping purposes: Overall process and detailed modules. Technological Forecasting and Social Change, 72(5), 567-583.

Leonard-Barton, D., 1990. A dual methodology for case studies: synergistic use of a longitudinal single site with replicated multiple sites. Organization Science, 1(3), 248-266.

Lhuillery, S., and Pfister, E., 2009. R\&D cooperation and failures in innovation projects: Empirical evidence from French CIS data. Research Policy, 38(1), 45-57.

Li, D., Eden, L., Hitt, M. A., and Ireland, R. D., 2008. Friends, acquaintances, or strangers? Partner selection in R\&D alliances. Academy of management journal, 51(2), 315-334.

Lijphart, A., 1971. Comparative politics and the comparative method. The American Political Science Review, 65(3), 682-693.

Liker, J. K., Kamath, R. R., Nazli Wasti, S., and Nagamachi, M., 1996. Supplier involvement in automotive component design: are there really large US Japan differences? Research Policy, 25(1), 59-89. 
Lindkvist, L., Söderlund, J., and Tell, F., 1998. Managing product development projects: on the significance of fountains and deadlines. Organization studies, 19(6), 931-951.

Liu, Y., Luo, Y., and Liu, T., 2009. Governing buyer-supplier relationships through transactional and relational mechanisms: Evidence from China. Journal of Operations Management, 27(4), 294-309.

Lockström, M., Schadel, J., Moser, R., and Harrison, N. J., 2010. Successful supplier integration in the Chinese automotive industry: a theoretical framework. International Journal of Integrated Supply Management, $5(3), 260-283$.

López-Vega, H. N. (2012). Open innovation: organizational practices and policy implications, ESADE Business School, Barcelona.

Lorenzoni, G., and Lipparini, A., 1999. The leveraging of interfirm relationships as a distinctive organizational capability: A longitudinal study. Strategic Management Journal, 20(4), 317-338.

Luzzini, D., and Ronchi, S., 2011. Organizing the purchasing department for innovation. Operations Management Research, 4(1), 14-27.

Malerba, F., and Orsenigo, L., 1996. The dynamics and evolution of industries. Industrial and Corporate Change, 5(1), 51-87.

Marshall, M. N., 1996. Sampling for qualitative research. Family Practice, 13(6), 522.

Mayer, K. J., and Teece, D. J., 2008. Unpacking strategic alliances: The structure and purpose of alliance versus supplier relationships. Journal of Economic Behavior \& Organization, 66(1), 106-127.

McCarthy, I. P., Silvestre, B. S., and Kietzmann, J. H., 2013. Understanding outsourcing contexts through information asymmetry and capability fit. Production planning \& control, 24(4-5), 277-283.

McCutcheon, D., and Stuart, F. I., 2000. Issues in the choice of supplier alliance partners. Journal of Operations Management, 18(3), 279-301.

McCutcheon, D. M., Grant, R. A., and Hartley, J., 1997. Determinants of new product designers' satisfaction with suppliers' contributions. Journal of Engineering and Technology Management, 14(3-4), 273-290.

McDermott, C., and Handfield, R., 2000. Concurrent development and strategic outsourcing: Do the rules change in breakthrough innovation? The Journal of High Technology Management Research, 11(1), 3557.

McDermott, C. M., 1999. Managing radical product development in large manufacturing firms: a longitudinal study. Journal of Operations Management, 17(6), 631-644.

McDonough, E. F., 2000. Investigation of factors contributing to the success of cross-functional teams. Journal of Product Innovation Management, 17(3), 221-235.

McGinnis, M., and Vallopra, R., 1999. Purchasing and supplier involvement: issues and insights regarding new product success. Journal of Supply Chain Management, 35(3), 4-15.

McIvor, R., and Humphreys, P., 2004. Early supplier involvement in the design process: lessons from the electronics industry. Omega, 32(3), 179-199.

McIvor, R., Humphreys, P., and Cadden, T., 2006. Supplier involvement in product development in the electronics industry: a case study. Journal of Engineering and Technology Management, 23(4), 374-397.

Melander, L. (2011). Collaborative new product development: supplier selection and purchasing, Linköping University, Linköping.

Merriam, S. B., 1994. Fallstudien som forskningsmetod. Lund: Studentlitteratur.

Mikkola, J. H., 2003. Modularity, component outsourcing, and inter firm learning. R\&D Management, 33(4), 439-454.

Miles, M., and Huberman, A., 1984. Qualitative data analysis: a sourcebook of new methods. Beverly Hills, CA: Sage Publ.inc.

Monczka, R. M., Petersen, K. J., Handfield, R. B., and Ragatz, G. L., 1998. Success Factors in Strategic Supplier Alliances: The Buying Company Perspective*. Decision Sciences, 29(3), 553-577.

Morgan, G., and Smircich, L., 1980. The case for qualitative research. Academy of management review, 5(4), 491-500.

Muethel, M., Siebdrat, F., and Hoegl, M., 2012. When do we really need interpersonal trust in globally dispersed new product development teams? R\&D Management, 42(1), 31-46.

Narasimhan, R., Nair, A., Griffith, D. A., Arlbjørn, J. S., and Bendoly, E., 2009. Lock-in situations in supply chains: A social exchange theoretic study of sourcing arrangements in buyer-supplier relationships. Journal of Operations Management, 27(5), 374-389.

Nightingale, P., 2000. The product-process-organisation relationship in complex development projects. Research Policy, 29(7-8), 913-930.

Nijssen, E., Biemans, W., and De Kort, J., 2002. Involving purchasing in new product development. $R \& D$ Management, 32(4), 281-289.

Normann, R., 1976. På spaning efter en metodologi. Stockholm: Scandinavian institutes for administrative research 
OECD, 2013. Expenditure on R\&D. OECD factbook 2013: economic, environmental and social statistics. OECD Publishing.

Oh, J., and Rhee, S. K., 2008. The influence of supplier capabilities and technology uncertainty on manufacturersupplier collaboration: A study of the Korean automotive industry. International Journal of Operations \& Production Management, 28(6), 490-517.

Oh, J., and Rhee, S. K., 2010. Influences of supplier capabilities and collaboration in new car development on competitive advantage of carmakers. Management Decision, 48(5), 756-774.

Okhuysen, G. A., and Bechky, B. A., 2009. 10 Coordination in Organizations: An Integrative Perspective. The Academy of Management Annals, 3(1), 463-502.

Olson, E. M., Walker, O. C., Ruekerf, R. W., and Bonnerd, J. M., 2001. Patterns of cooperation during new product development among marketing, operations and R\&D: Implications for project performance. Journal of Product Innovation Management, 18(4), 258-271.

Oxley, J. E., and Sampson, R. C., 2004. The scope and governance of international R\&D alliances. Strategic Management Journal, 25(8-9), 723-749.

Paisley, W. J., 1969. Studying style as deviation from encoding norms. In G. Gerbner, R. Holsti, W. J. Krippendorff, W. Paisley, and P. J. Stone (Eds.), The Analysis of Communications Content: Developments in Scientific Theories and Computer Techniques. New York: John Wiley, 133-46.

Patton, M. Q., 2002. Qualitative research and evaluation methods (3rd ed.). California: Thousand Oaks, CA: Sage Publications.

Perrone, V., Zaheer, A., and McEvily, B., 2003. Free to be trusted? Organizational constraints on trust in boundary spanners. Organization Science, 14(4), 422-439.

Petersen, K., Handfield, R., and Ragatz, G., 2003. A model of supplier integration into new product development. Journal of Product Innovation Management, 20(4), 284-299.

Petersen, K., Handfield, R., and Ragatz, G., 2005. Supplier integration into new product development: coordinating product, process and supply chain design. Journal of Operations Management, 23(3-4), 371-388.

Petrick, I. J., and Echols, A. E., 2004. Technology roadmapping in review: A tool for making sustainable new product development decisions. Technological Forecasting and Social Change, 71(1), 81-100.

Phaal, R., Farrukh, C. J. P., and Probert, D. R., 2004. Technology roadmapping-A planning framework for evolution and revolution. Technological Forecasting and Social Change, 71(1), 5-26.

Poppo, L., and Zenger, T., 2002. Do formal contracts and relational governance function as substitutes or complements? Strategic Management Journal, 23(8), 707-725.

Praest Knudsen, M., and Bøtker Mortensen, T., 2011. Some immediate-but negative-effects of openness on product development performance. Technovation, 31(1), 54-64.

Prencipe, A., and Tell, F., 2001. Inter-project learning: processes and outcomes of knowledge codification in project-based firms. Research Policy, 30(9), 1373-1394.

Raassens, N., Wuyts, S., and Geyskens, I., 2012. The market valuation of outsourcing new product development. Journal of Marketing Research, 49(5), 682-695.

Ragatz, G., Handfield, R., and Scannell, T., 1997. Success factors for integrating suppliers into new product development. Journal of Product Innovation Management, 14(3), 190-202.

Reger, G., 1999. How R\&D is coordinated in Japanese and European multinationals. R\&D Management, 29(1), 71-88.

Riege, A. M., 2003. Validity and reliability tests in case study research: a literature review with "hands-on" applications for each research phase. Qualitative Market Research: An International Journal, 6(2), 7586.

Rijsdijk, S. A., and van den Ende, J., 2011. Control combinations in new product development projects*. Journal of Product Innovation Management, 28(6), 868-880.

Ritter, T., and Walter, A., 2003. Relationship-specific antecedents of customer involvement in new product development. International Journal of Technology Management, 26(5), 482-501.

Rokkan, A. I., and Buvik, A., 2003. Inter-firm cooperation and the problem of free riding behavior: An empirical study of voluntary retail chains. Journal of Purchasing and Supply Management, 9(5-6), 247-256.

Rossetti, C. L., and Choi, T. Y., 2008. Supply management under high goal incongruence: An empirical examination of disintermediation in the aerospace supply chain. Decision Sciences, 39(3), 507-540.

Rundquist, J., and Halila, F., 2010. Outsourcing of NPD activities: a best practice approach. European Journal of Innovation Management, 13(1), 5-23.

Schiele, H., 2006. How to distinguish innovative suppliers? Identifying innovative suppliers as new task for purchasing. Industrial Marketing Management, 35(8), 925-935.

Schiele, H., 2010. Early supplier integration: the dual role of purchasing in new product development. $R \& D$ Management, 40(2), 138-153. 
Shenhar, A. J., and Dvir, D., 1996. Toward a typological theory of project management. Research Policy, 25(4), 607-632.

Siggelkow, N., 2007. Persuasion with case studies. The Academy of Management Journal 50(1), 20-24.

Silverstone, Y., Wallis, T., and Mindrum, C., 2012. Making cross-enterprise collaboration work. The journal of high-performance business, 1, 1-10.

Skilton, P. F., and Dooley, K. J., 2010. The effects of repeat collaboration on creative abrasion. Academy of management review, 35(1), 118-134.

Song, X. M., Montoya-Weiss, M. M., and Schmidt, J. B., 1997. Antecedents and consequences of crossfunctional cooperation: A comparison of R\&D, manufacturing, and marketing perspectives. Journal of Product Innovation Management, 14(1), 35-47.

Song, X. M., Thieme, R. J., and Xie, J., 1998. The impact of cross-functional joint involvement across product development stages: An exploratory study. Journal of Product Innovation Management, 15(4), 289-303.

Spina, G., Verganti, R., and Zotteri, G., 2002. A model of co-design relationships: definitions and contingencies. International Journal of Technology Management, 23(4), 304-321.

Stanley, L., and Wisner, J., 2001. Service quality along the supply chain: implications for purchasing. Journal of Operations Management, 19(3), 287-306.

Stjernström, S., and Bengtsson, L., 2004. Supplier perspective on business relationships: experiences from six small suppliers. Journal of Purchasing and Supply Management, 10(3), 137-146.

Strauss, A., and Corbin, J., 1998. Basics of qualitative research: techniques and procedures for developing grounded theory. Thousand Oaks: Sage Publications, Inc.

Stuart, I., McCutcheon, D., Handfield, R., McLachlin, R., and Samson, D., 2002. Effective case research in operations management: a process perspective. Journal of Operations Management, 20(5), 419-433.

Su, Y. S., Tsang, E. W. K., and Peng, M. W., 2009. How do internal capabilities and external partnerships affect innovativeness? Asia Pacific Journal of Management, 26(2), 309-331.

Takeishi, A., 2001. Bridging inter-and intra-firm boundaries: management of supplier involvement in automobile product development. Strategic Management Journal, 22(5), 403-433.

Tangpong, C., Michalisin, M. D., and Melcher, A. J., 2008. Toward a typology of buyer-supplier relationships: A study of the computer industry*. Decision Sciences, 39(3), 571-593.

Tassabehji, R., and Moorhouse, A., 2008. The changing role of procurement: Developing professional effectiveness. Journal of Purchasing and Supply Management, 14(1), 55-68.

Tegarden, L. F., Hatfield, D. E., and Echols, A. E., 1999. Doomed from the start: What is the value of selecting a future dominant design? Strategic Management Journal, 20(6), 495-518.

Tell, F., 2003. Integrating electrical power systems: from individual to organizational capabilities. In A. Prencipe, A. Davies, and M. Hobday (Eds.), The business of systems integration. New York: Oxford University Press, 56-77.

Tell, F., 2011. Knowledge integration and innovation: a survey of the field. In C. Berggren, A. Bergek, L. Bengtsson, M. Hobday, and J. Söderlund (Eds.), Knowledge integration and innovation: Critical challenges facing international technology-based firms. New York: Oxford University Press, 20-60.

Tevelson, R., Alsén, A., Rosenfeld, P., Benett, S., Farrell, P., and Zygelman, J., 2013. Buyer-Supplier Collaboration A Roadmap for Success. BCG perspectives, Aug(2013), 1-7.

Tosi, H. L., Katz, J. P., and Gomez-Mejia, L. R., 1997. Disaggregating the agency contract: The effects of monitoring, incentive alignment, and term in office on agent decision making. Academy of management journal, 40(3), 584-602.

Turner, K. L., and Makhija, M. V., 2006. The role of organizational controls in managing knowledge. Academy of management review, 31(1), 197-217.

Tyler, B. B., 2001. The complementarity of cooperative and technological competencies: a resource-based perspective. Journal of Engineering and Technology Management, 18(1), 1-27.

Un, C. A., Cuervo-Cazurra, A., and Asakawa, K., 2010. R\&D collaborations and product innovation. Journal of Product Innovation Management, 27(5), 673-689.

Wagner, S. M., and Hoegl, M., 2006. Involving suppliers in product development: Insights from R\&D directors and project managers. Industrial Marketing Management, 35(8), 936-943.

Walter, A., 2003. Relationship-specific factors influencing supplier involvement in customer new product development. Journal of Business Research, 56(9), 721-733.

van der Valk, W., and van Iwaarden, J., 2011. Monitoring in service triads consisting of buyers, subcontractors and end customers. Journal of Purchasing and Supply Management, 17(3), 198-206.

van Echtelt, F., Wynstra, F., van Weele, A. J., and Duysters, G., 2008. Managing supplier involvement in new product development: A multiple-case study. Journal of Product Innovation Management, 25(2), 180201. 
van Echtelt, F., Wynstra. F, and van Weele, A. J., 2007. Strategic and operational management of supplier involvement in new product development: A contingency perspective. Engineering Management, IEEE Transactions on, 54(4), 644-661.

Wasti, S. N., and Liker, J. K., 1999. Collaborating with suppliers in product development: a US and Japan comparative study. Engineering Management, IEEE Transactions on, 46(4), 444-460.

Weber, R., 1996. Basic content analysis. Newbury Park: Sage Publications, Inc.

Wernerfelt, B., and Karnani, A., 2006. Competitive strategy under uncertainty. Strategic Management Journal, 8(2), 187-194.

Wheelwright, S. C., 1992. Revolutionizing product development: quantum leaps in speed, efficiency, and quality. New York: Free Press.

Wheelwright, S. C., and Clark, K., 1992. Organizing and leading "heavyweight" development teams. California Management Review, 34(3), 9-28.

Williamson, O. E., 1991. Comparative economic organization: The analysis of discrete structural alternatives. Administrative Science Quarterly, 36(2), 269-296.

Womack, J. P., Jones, D. T., and Roos, D., 1991. The machine that changed the world: The story of lean production. New York: Free Press.

von Corswant, F., and Tunälv, C., 2002. Coordinating customers and proactive suppliers: A case study of supplier collaboration in product development. Journal of Engineering and Technology Management, 19(3-4), 249-261.

von Haartman, R., and Bengtsson, L., 2009. Manufacturing competence: a key to successful supplier integration. International Journal of Manufacturing Technology and Management, 16(3), 283-299.

von Hippel, E., 1988. The sources of innovation. New York: Oxford University Press.

Vonderembse, M., and Tracey, M., 1999. The impact of supplier selection criteria and supplier involvement on manufacturing performance. Journal of Supply Chain Management, 35(3), 33-39.

Wynstra, F., van Weele, A., and Axelsson, B., 1999. Purchasing involvement in product development: a framework. European Journal of Purchasing \& Supply Management, 5(3-4), 129-141.

Wynstra, F., Weggeman, M., and van Weele, A., 2003. Exploring purchasing integration in product development. Industrial Marketing Management, 32(1), 69-83.

Wynstra, F., von Corswant, F., and Wetzels, M., 2010. In chains? An empirical study of antecedents of supplier product development activity in the automotive industry*. Journal of Product Innovation Management, 27(5), 625-639.

Yan, T. (2011). Communication, goals and collaboration in buyer-supplier joint product design, Arizona state unversity, Phoenix.

Yin, R. K., 2009. Case study research: design and methods (4th ed.). Los Angeles, Calif.: Sage Publications.

Zhou, K. Z., Poppo, L., and Yang, Z. L., 2008. Relational ties or customized contracts? An examination of alternative governance choices in China. Journal of International Business Studies, 39(3), 526-534.

Zirpoli, F., and Camuffo, A., 2009. Product architecture, inter-firm vertical coordination and knowledge partitioning in the auto industry. European Management Review, 6(4), 250-264.

Zirpoli, F., and Caputo, M., 2002. The nature of buyer-supplier relationships in co-design activities: the Italian auto industry case. International Journal of Operations \& Production Management, 22(12), 1389-1410.

Zsidisin, G. A., and Smith, M. E., 2005. Managing supply risk with early supplier involvement: a case study and research propositions. Journal of Supply Chain Management, 41(4), 44-57. 


\section{PART II}

\section{THE PAPERS}

Sherlock Holmes was a man, however, who, when he had an unsolved problem upon his mind, would go for days, even for a week, without rest, turning it over, rearranging his facts, looking at it from every point of view until he had either fathomed it or convinced himself that his data was insufficient.

(Dr Watson describing Sherlock Holmes in The Adventures of Sherlock Holmes: the Man with the Twisted Lip) 



\section{Appended Papers}

The articles associated with this thesis have been removed for copyright reasons. For more details about these see:

http://urn.kb.se/resolve?urn=urn:nbn:se:liu:diva-103943 



\section{PART III}

\section{APPENDICES}

Education never ends, Watson. It is a series of lessons, with the greatest for the last.

(Sherlock Holmes to Dr Watson in His Last Bow: the Adventure of the Red Circle) 


\section{APPENDIX A - INTERVIEW GUIDE}

\section{$\underline{\text { Interview guide }}$}

Present a brief description of my research project.

\section{Questions:}

Background

- What is your role at the company? In the project?

- Could you describe the project briefly?

- How did the collaboration with the supplier start? Why did it start? Purpose?

\section{Project}

- How was the project organised at your firm? Number of project members? Responsibilities? How do you work internally with this project?

- How did you work together? (with the supplier)

- What kind of interaction did you have with the supplier? Work-shops, telephone conferences etc.?

- What happened at project meetings? (together with the supplier)

- Which milestones did you have in the project?

- Have there been any challenges in the project? Which? Elaborate.

- The developed product, is it developed only for your company? Can the supplier use it for other products? (asset specificity)

- Ownership of the product?

- What does the contract include? NDA, IP, risks, agreements, etc.

- Rotation of personnel in the project? Who? Why?

Collaboration

- What is your prior history/relationship with the supplier?

- How far do your future plans stretch with the supplier? Agreement for the future? Do you use technology roadmaps?

- Which competences/persons did you have contact with at the supplier? (project manager, any other competences? Technical support, marketing, purchasing?)

- What knowledge did you share within the project between the firms? (technical, industry, customers etc.)

- To what extent do you feel that you can trust the supplier? Why?

- Prior collaborations with suppliers in R\&D? What? How? Why?

- Which suppliers were considered in the beginning of the project? How did you select the supplier? Who were involved in the selection/evaluation?

- How open can you be with the supplier? Sharing information? Discussing problems?

- Do you use contracts? How are IP issues handled? 
- How do you solve problems together?

- Have there been any compromises in the project? Which? How managed?

- What is the level of integration in the project? Why?

- What is the level of insight (insyn) do you have in the developed component (buyer) or system? (supplier)

- What is the level of insight into the supplier's (buyer's) organisation?

- Self-interest - have you experienced that your partner has acted in its own interest? Taking advantage of a situation? When? Why? How did you react?

Technology

- Would you describe the technology as radical or incremental?

- Any technical uncertainties?

- Did you experience any technical difficulties during the project? Which?

o How did you solve these?

- Uncertainties: were there a number of different technologies that you considered in the beginning of the project? How did you select the technology? Who were involved in the evaluation/selection?

- Is it possible to change technology? Change supplier? What are the options? Consequences?

- What is the level of complexity of the technology? Explain.

- How important is it to understand the supplier's technology? Why?

Industry

- How would you describe the development of this industry?

- Is this product/project similar to other solutions that you have? Which? Impact?

- From your point of view, how has the market reacted to the product?

- Are there any market uncertainties?

$\circ$ Which?

Knowledge

- What is the level of common knowledge? How much do you need to understand of what the supplier does?

- Do you share knowledge in the project? How? What efforts have been made to facilitate learning?

Overall

- Are you satisfied with the project outcome? Why (not)?

- What are you most satisfied with? Why?

- If you could change anything in the project, what would that be?

Purchasing's responsibilities 
- Before the project: Technology selection? Supplier selection?

- During the project: Participate in the NPD team? Evaluate performance? Monitor technical development? Responsible for coordination? Assist in start of the production? Responsible for communicating changes to the supplier?

- Collaboration with R\&D?

- Who handles the day-to-day communication with the supplier? Examples.

- Who handles the strategic communication with the supplier? Examples.

Thank you! 


\section{APPENDIX B - INTERVIEWS AT ABB AND ERICSSON}

Table 1 Interviews ABB-1

\begin{tabular}{lllcl}
\hline Respondent & Firm & Duration & $\begin{array}{l}\text { Number of } \\
\text { interviews }\end{array}$ & $\begin{array}{l}\text { Interviewer (interview made face-to-face } \\
\text { if not stated otherwise) }\end{array}$ \\
\hline $\begin{array}{l}\text { Project Manager (second) } \\
\text { Technical Manager }\end{array}$ & ABB & $1 \mathrm{~h} 30 \mathrm{~min}$ & 1 & Fredrik Tell (FT) and Lisa Melander (LM) \\
$\begin{array}{l}\text { Market Communication } \\
\text { Business Development }\end{array}$ & ABB $1 \mathrm{~h} 30 \mathrm{~min}$ & 1 & FT, LM \\
Manager & ABB $1 \mathrm{~h} 30 \mathrm{~min}$ & 1 & LM \\
Manager Marketing and Sales & ABB $1 \mathrm{~h}$ & 1 & LM (by phone) \\
$\begin{array}{l}\text { Senior Vice President } \\
\text { Supply Manager }\end{array}$ & $\mathrm{ABB} \quad 1 \mathrm{~h}$ & 1 & LM (by phone) \\
$\begin{array}{l}\text { R\&D Manager } \\
\text { Regional Sales Manager }\end{array}$ & ABB $1 \mathrm{~h} 30 \mathrm{~min}$ & 1 & LM \\
$\begin{array}{l}\text { Project Manager (first) } \\
\text { Project Manager }\end{array}$ & ABB $1 \mathrm{~h}$ & 1 & LM \\
Total & ABB & $2 \mathrm{~h}$ & 1 & LM \\
\hline
\end{tabular}

Table 2 Interviews ABB-2

\begin{tabular}{lllll}
\hline Respondent & Firm & Duration & $\begin{array}{l}\text { Number of } \\
\text { interviews }\end{array}$ & $\begin{array}{l}\text { Interviewer } \\
\text { (interview made } \\
\text { face-to-face if not } \\
\text { stated otherwise) }\end{array}$ \\
\hline Project Manager & ABB & $1 \mathrm{~h} 30 \mathrm{~min}$ & 1 & Lisa Melander (LM) \\
Technical Manager & ABB & $2 \mathrm{~h} 30 \mathrm{~min}(1 \mathrm{~h}, 1 \mathrm{~h} 30 \mathrm{~min})$ & 2 & LM \\
Supply Manager & ABB & $2 \mathrm{~h}$ & 1 & LM \\
General Manager & ABB & $1 \mathrm{~h} 30 \mathrm{~min}$ & 1 & LM \\
Key Account Manager & SKF & $2 \mathrm{~h}$ & 1 & LM \\
Project Manager & SKF & $1 \mathrm{~h} 30 \mathrm{~min}$ & 1 & LM \\
Application Engineer & SKF & $1 \mathrm{~h} 30 \mathrm{~min}$ & 1 & LM \\
Development Engineer & SKF & $1 \mathrm{~h} 30 \mathrm{~min}$ & 1 & LM \\
Product Manager & SKF & $1 \mathrm{~h} 15 \mathrm{~min}$ & 1 & LM \\
Business Engineer & SKF & $1 \mathrm{~h} 15 \mathrm{~min}$ & 1 & LM \\
Total & & $16 \mathrm{~h} 30 \mathrm{~min}$ & 11 & \\
\hline
\end{tabular}

Table 3 Interviews ABB-3

\begin{tabular}{|c|c|c|c|c|}
\hline Respondent & Firm & Duration & Number of interviews & $\begin{array}{l}\text { Interviewer } \\
\text { (interview made } \\
\text { face-to-face if not } \\
\text { stated otherwise) }\end{array}$ \\
\hline Project Manager & $\mathrm{ABB}$ & $1 \mathrm{~h} 30 \mathrm{~min}$ & 1 & Lisa Melander (LM) \\
\hline Sales representative & $\mathrm{ABB}$ & $30 \mathrm{~min}$ & 1 & LM \\
\hline R\&D Manager, (previous Project Manager) & $\mathrm{ABB}$ & $1 \mathrm{~h} 20 \mathrm{~min}$ & 1 & LM \\
\hline Process Engineer & $\mathrm{ABB}$ & $1 \mathrm{~h} 20 \mathrm{~min}$ & 1 & LM \\
\hline Technical specialist & $\mathrm{ABB}$ & $1 \mathrm{~h} 30 \mathrm{~min}$ & 1 & LM \\
\hline Technical specialist & $\mathrm{ABB}$ & $55 \mathrm{~min}$ & 1 & LM (by phone) \\
\hline Technical specialist & Borealis & $1 \mathrm{~h} 25 \mathrm{~min}$ & 1 & $\mathrm{LM}$ \\
\hline Product Manager & Borealis & $55 \mathrm{~min}$ & 1 & LM \\
\hline Project Manager & Borealis & $45 \mathrm{~min}$ & 1 & LM \\
\hline Total & & $10 \mathrm{~h} 10 \mathrm{~min}$ & 9 & \\
\hline
\end{tabular}


Table 4 Interviews Ericsson-1

\begin{tabular}{lllcl}
\hline Respondent & Firm & Duration & Number of interviews & $\begin{array}{l}\text { Interviewer (interview made } \\
\text { face-to-face if not stated } \\
\text { otherwise) }\end{array}$ \\
\hline Supply Manager & Ericsson & $1 \mathrm{~h}$ & 1 & David Rosell (DR) and LM \\
R\&D Manager & Ericsson & $1 \mathrm{~h} 30 \mathrm{~min}$ & 1 & DR, LM \\
Strategic Product Manager & Ericsson & $1 \mathrm{~h} 15 \mathrm{~min}$ & 1 & DR, LM \\
Platform Manager & Ericsson & $1 \mathrm{~h}$ & 1 & DR, LM \\
Sourcing Manager & Ericsson & $1 \mathrm{~h}$ & 1 & DR, LM \\
Project Manager & Ericsson & $1 \mathrm{~h} 10 \mathrm{~min}$ & 1 & DR, LM \\
Supply Manager & Ericsson & $1 \mathrm{~h}$ & 1 & DR, LM (by phone) \\
R\&D Manager & Kathrein & $1 \mathrm{~h} 10 \mathrm{~min}$ & 1 & DR, LM \\
Senior Vice President & Kathrein & $1 \mathrm{~h} 15 \mathrm{~min}$ & 1 & DR, LM \\
Project Manager & Kathrein & $1 \mathrm{~h}$ & 1 & DR, LM \\
Total & & $11 \mathrm{~h} 20 \mathrm{~min}$ & 10 & \\
\hline
\end{tabular}

Table 5 Interviews Ericsson-2

\begin{tabular}{lllll}
\hline Respondent & Firm & Duration & Number of interviews & $\begin{array}{l}\text { Interviewer } \\
\text { (interview made } \\
\text { face-to-face if not } \\
\text { stated otherwise) }\end{array}$ \\
\hline R\&D Manager (A) & Ericsson & $1 \mathrm{~h}$ & 1 & DR \\
Supply Manager (A) & Ericsson & $1 \mathrm{~h}$ & 1 & DR \\
Sourcing Manager & Ericsson & $1 \mathrm{~h} 40 \mathrm{~min}$ & 1 & LM \\
R\&D Manager (B) & Ericsson & $1 \mathrm{~h} 20 \mathrm{~min}$ & 1 & LM \\
Strategic Product Manager & Ericsson & $1 \mathrm{~h}$ & 1 & DR, LM \\
Supply Manager (B) & Ericsson & $1 \mathrm{~h}$ & 1 & DR, LM (by phone) \\
Total & & $7 \mathrm{~h}$ & 6 & \\
\hline
\end{tabular}

Table 6 Interviews Ericsson-3

\begin{tabular}{lllcl}
\hline Respondents & Firm & Duration & Number of interviews & $\begin{array}{l}\text { Interviewer (interview } \\
\text { made face-to-face if } \\
\text { not stated otherwise) }\end{array}$ \\
\hline R\&D Manager (A) & Ericsson & $1 \mathrm{~h} 15 \mathrm{~min}$ & 1 & DR, LM \\
Strategic Product Manager & Ericsson & $1 \mathrm{~h} 10 \mathrm{~min}$ & 1 & DR, LM \\
R\&D Manager (B) & Ericsson & $1 \mathrm{~h}$ & 1 & DR, LM \\
Sourcing Manager & Ericsson & $1 \mathrm{~h}$ & 1 & DR, LM \\
Project Manager & Ericsson & $45 \mathrm{~min}$ & 1 & DR, LM \\
Key Account Manager & Intel & $1 \mathrm{~h}$ & 1 & DR, LM (by phone) \\
Total & & $6 h 10 \mathrm{~min}$ & 6 & \\
\hline
\end{tabular}




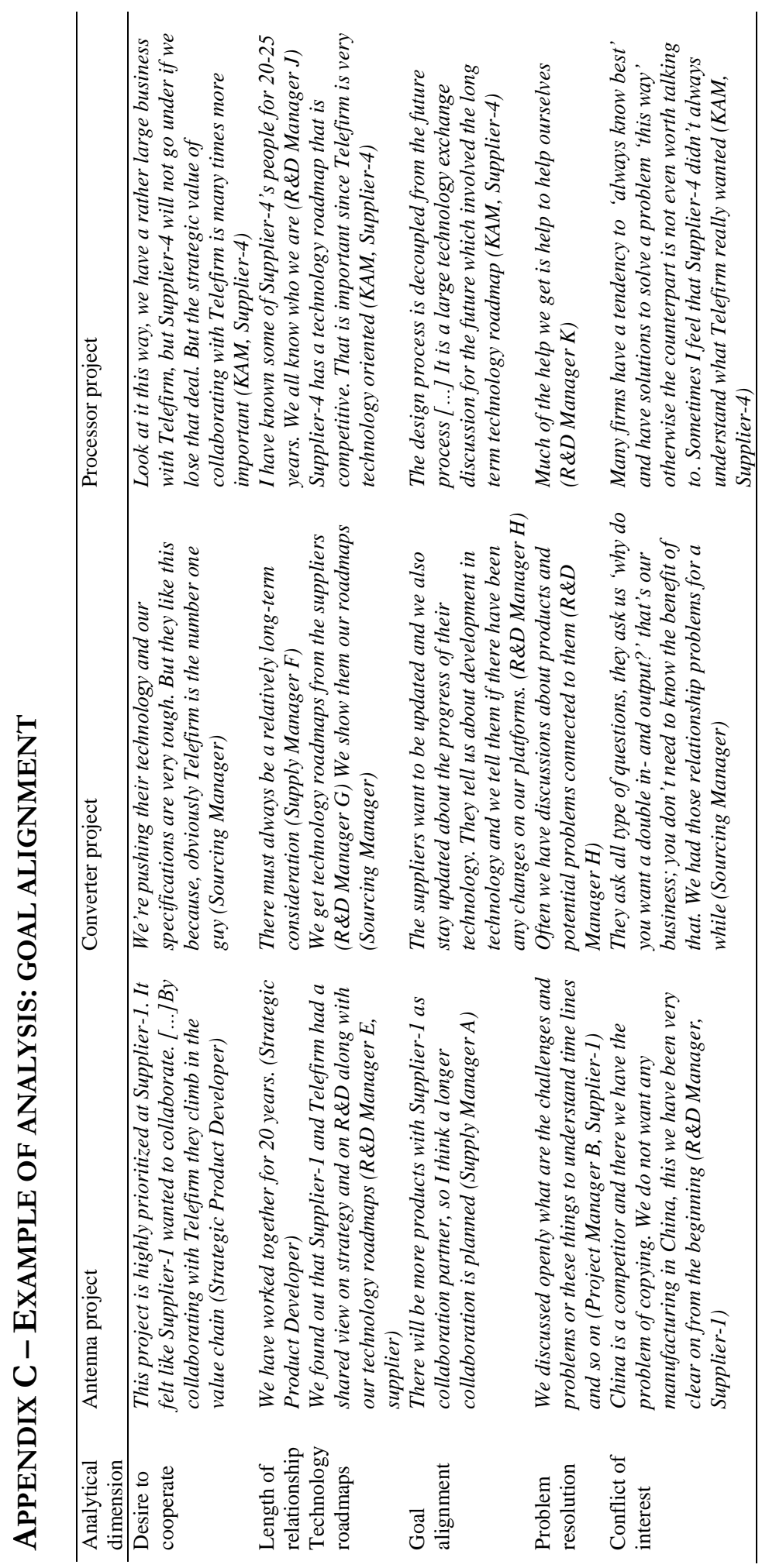




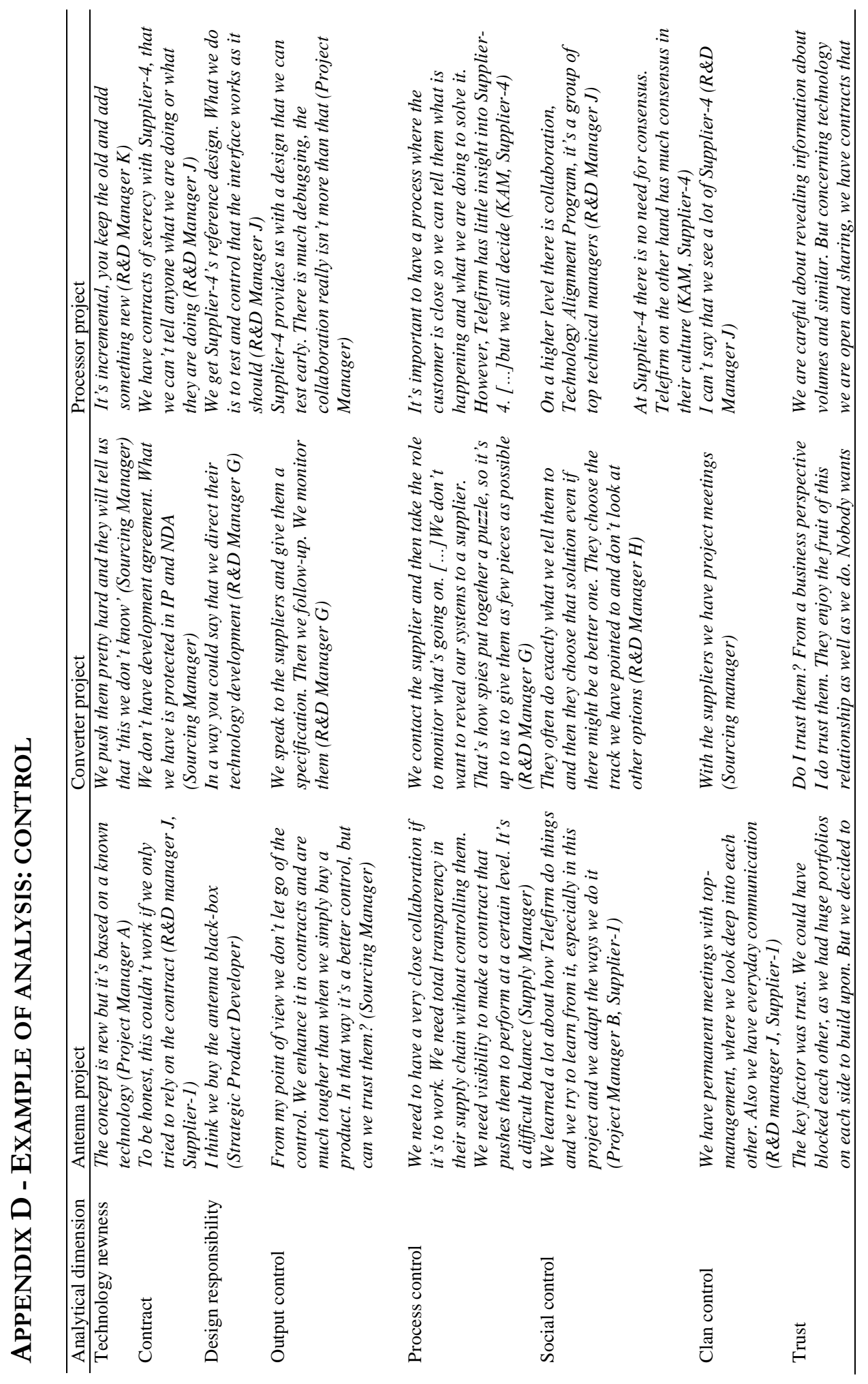




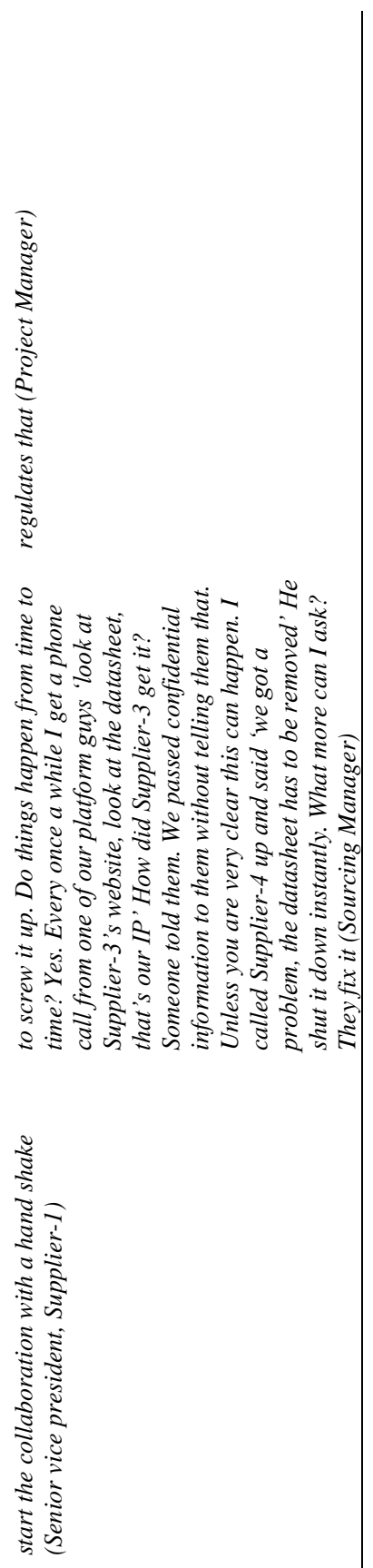




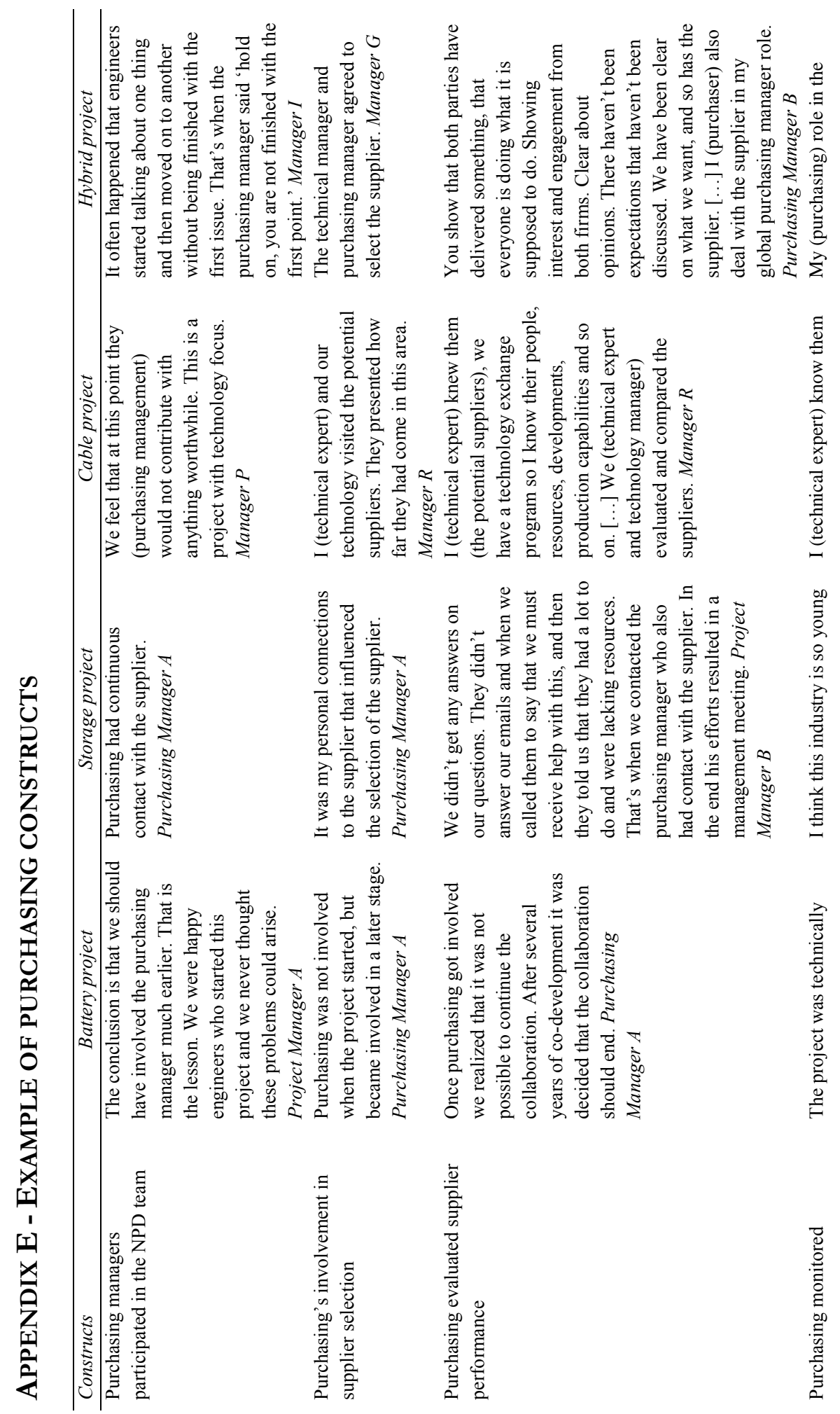




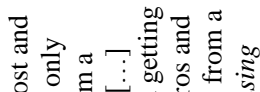

$\ddot{\circ} \cdot \Xi$

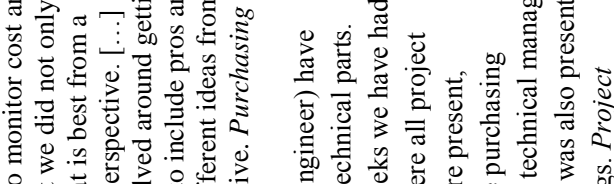

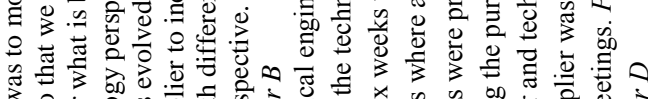

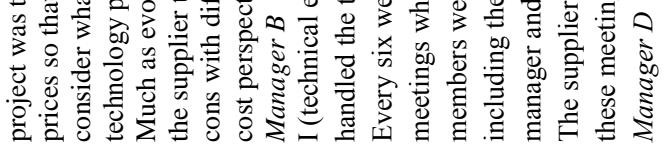

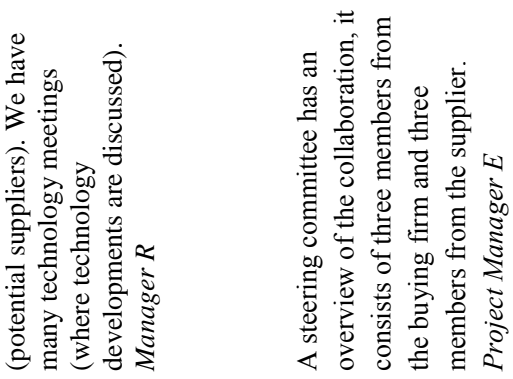

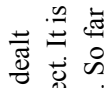

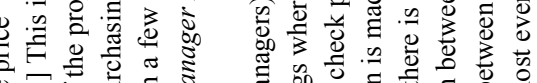

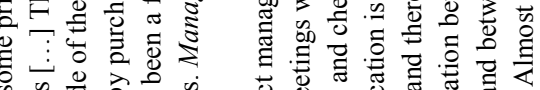

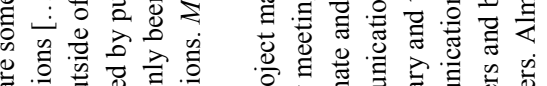

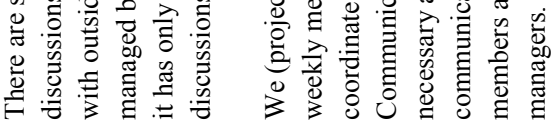

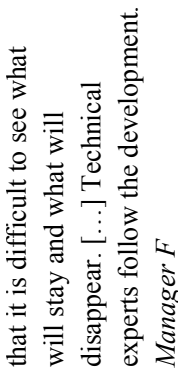

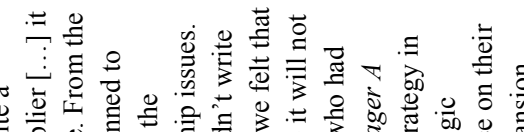

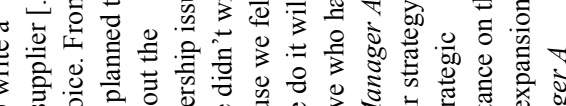
क के

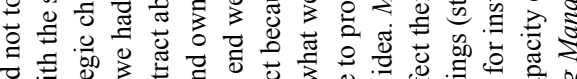

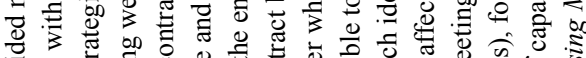

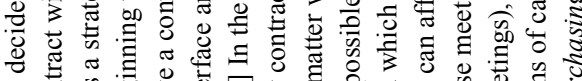

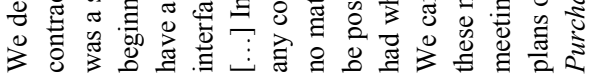

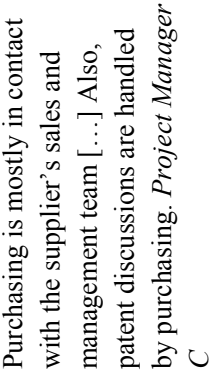

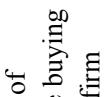
导<smiles>C1C[As]C1</smiles>

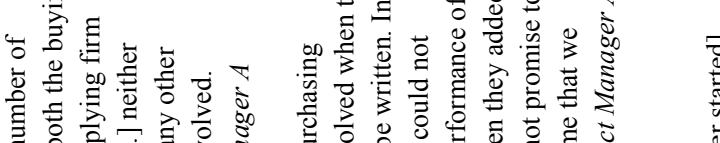

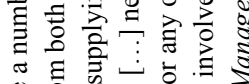
ह है

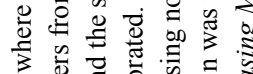

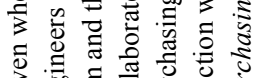

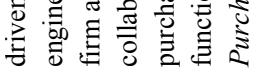

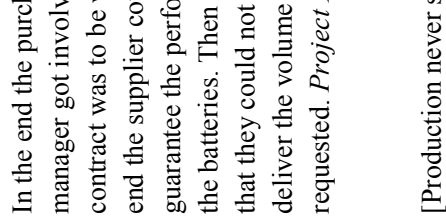
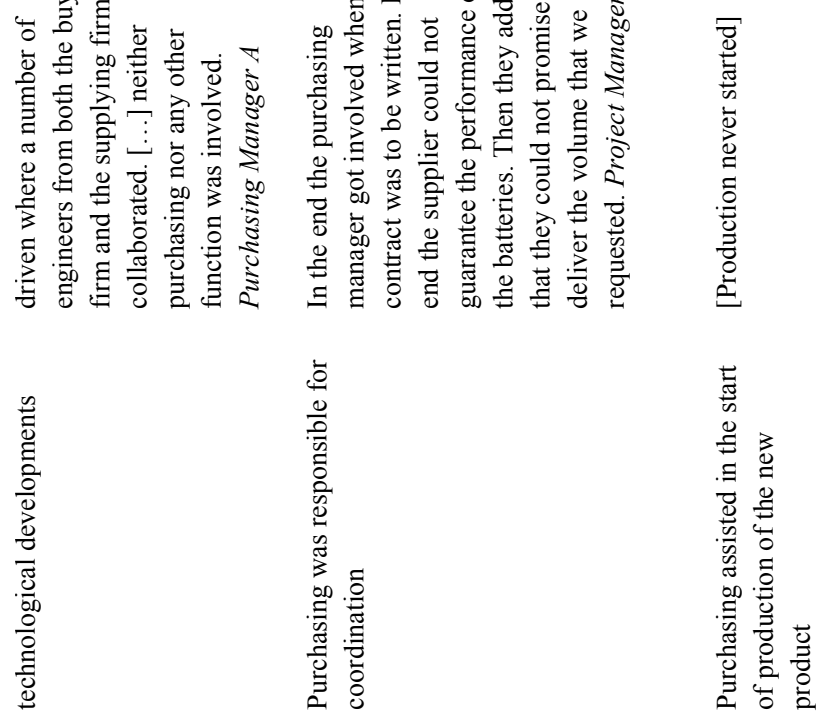


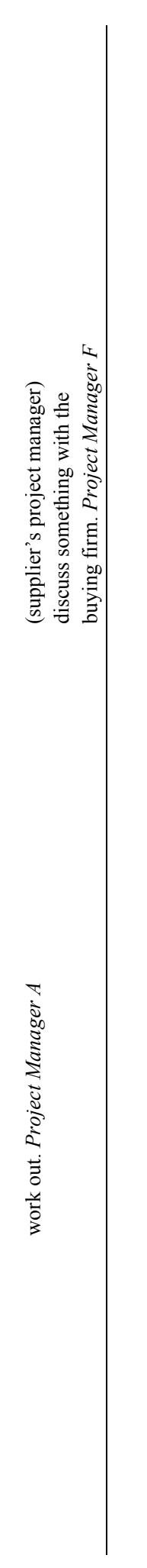




\section{APPENDIX F - KEY DEFINITIONS AND RESEARCH SCOPE}

Below, the reader will find definitions of the key constructs and terms that are used in the thesis, and thereby aid in specifying the scope of the research.

Adverse selection is the misrepresentation of the agent's abilities. "Adverse selection arises because the principal cannot completely verify these skills or abilities either at the time of hiring or while the agent is working." (Eisenhardt, 1989b p 61)

Agency theory "is concerned with resolving two problems that can occur in agency relationships. The first is the agency problem that arises when (a) the desires or goals of the principal and agent conflict and (b) it is difficult or expensive for the principal to verify what the agent is actually doing." (Eisenhardt, 1989b p 58)

An agent is an actor in the classical problem in agency theory, which deals with principalagent relationships within or between organisations where the principal delegates work to the agent. In this thesis, the agent is the supplier.

Asset specificity is defined by Williamson (1991 p 281) as having "reference to the degree to which an asset can be redeployed to alternative uses and by alternative users without sacrifice of productive value."

Black-box development represents a situation where the supplier has the responsibility to develop a subsystem or component, which is based on functional performance requirements rather than a detailed specification from the buyer (Clark \& Fujimoto, 1991).

A contract defines responsibilities, measures compliance. and establishes compensation (Baldwin, 2008).

Collaboration is described by Wagner \& Hoegl (2006 p 940) as "when a supplier is involved in the buying firm's NPD process, members from two different organizations have to collaborate for the achievement of common goals."

Control is applied by firms to govern inter-organisational exchange, minimize exposure to opportunism, and protect trans-action-specific investments (Jap \& Ganesan, 2000). Firms can strive to control their partner in a collaboration, which can be described as "as a regulatory process by which the partner's pursuit of mutually compatible interests is made more predictable" (Das \& Teng, 1998 p 494).

Coordination is shown in a review of the literature to have a variety of definitions, which share three commonalities (Okhuysen \& Bechky, 2009 p 469): "(1) people work collectively; (2) the work is interdependent; and (3) a goal, task, or piece of work is achieved."

Cross-functional coordination refers to interdependent departments that reduce uncertainty by transferring information between them (Song et al., 1997; Fliess \& Becker, 2006).

Division of labour and coordination specifies which responsibility the supplier should have (Clark \& Fujimoto, 1991), and depends on what type of problem is to be solved and how the problem is to be solved (Brusoni, 2005). 
Goal alignment means that firms share similar values, agree upon goals, and then work together to achieve these goals.

Goal conflict arises when parties who are collaborating together do not agree on a goal. Such conflicts are implicit when individuals with differing preferences engage in cooperative effort (Eisenhardt, 1989b).

Goal congruence is the degree to which the partner firms are jointly involved in the achievement of a goal (Samaddar, Nargundkar, \& Daley, 2006).

Information asymmetry is an situation is where the buyer has to deal with uncertainty since he has less information than the seller (Akerlof, 1970).

Inter-firm collaboration refers to buyer-supplier collaboration.

Intra-firm coordination refers to coordination between functions within the firm that is being examined. In this thesis, the internal functions that were studied are the R\&D function and the purchasing function.

Lock-in situation is a situation where one party is heavily dependent on the other party (Arthur, 1989).

An NPD project is a project where a new product (i.e., a completely new product or a new generation of an existing product) is being developed. The project is the unit of analysis in this study.

A principal is an actor in agency theory who delegates work to the agent. In this thesis, the principal refers to the buying firm.

Purchasing is a department at the buying firm that is responsible for managing the purchase of inputs (operational purchasing) and strategic collaborations with suppliers (strategic purchasing) (Gadde \& Håkansson, 1998).

The $\boldsymbol{R} \& \boldsymbol{D}$ function is the department at a firm that is responsible for product development.

Supplier collaboration in NPD refers to the situation where a supplier contributes with technology to an NPD project that is new to a buying firm.

Supplier involvement in NPD is defined as the buying firm sharing responsibility for a design of a new product (subsystem or component) with a supplier (Takeishi, 2001).

The supplier selection is limited to the selection of suppliers that are to be included in NPD projects.

TCE theory is 'transaction cost economics theory', which is based on the work by Williamson $(1973 ; 1991)$. 
Technological uncertainty, in this thesis, refers to a state of uncertainty with respect to a technology. (For example, it could evolve around uncertainties of the technology's capability to manage high voltage.)

A technological roadmap is a tool for communicating technology, and product and market perspectives. This provides a long-term vision to help the firm make strategic decisions (Phaal et al., 2004).

The technology selection is an important decision during the product development, where the product or component technology to be implemented is selected (Krishnan \& Bhattacharya, 2002).

A technology supplier is a supplier that contributes to an NPD project with technology that is new to the buying firm. In contrast, a regular supplier would be a supplier that contributes with off-the-shelf products or components to the buying firm. These products would incorporate technology that is generally known and accepted in the industry. Suppliers have been recognized as important sources of innovation (Cuervo-Cazurra \& Un, 2010). These suppliers provide new technology to a larger extent than normal, and are referred to as technology suppliers.

Trust is a concept that is interpreted in the literature in diverse ways. To limit it somewhat, this thesis applies Ring \& Van de Ven's (1994) two views on trust: (a) a business risk view, based on confidence in the predictability of expectations, and (b) a view that is based on confidence in another's goodwill. In the risk-based view, firms are exposed to adverse selection and moral hazard. They employ a variety of formal contracts and an organisational hierarchy to deal with uncertainty. The confidence view emphasizes faith in the moral integrity or goodwill of others, which is produced through interpersonal interactions, in dealing with uncertainty. 


\section{THE END}

It is a capital mistake to theorize before one has data. Insensibly one begins to twist facts to suit theories, instead of theories to suit facts.

(Sherlock Holmes in The Adventures of Sherlock Holmes: a Scandal in Bohemia) 